\title{
Nuclear Materials Focus Area Fiscal Year 2002 Mid Year Review
}

Elizabeth C. Thiel Paul W. Fuhrman

May 2002

Idaho National Engineering and Environmental Laboratory Bechtel BWXT Idaho, LLC 
INEEL/EXT-02-00755

\title{
Nuclear Materials Focus Area Fiscal Year 2002 Mid Year Review
}

\author{
Elizabeth C. Thiel \\ Paul W. Fuhrman
}

May 2002

\section{Idaho National Engineering and Environmental Laboratory Idaho Falls, Idaho 83415}

Prepared for the

U.S. Department of Energy

Assistant Secretary for Environmental Management Under DOE Idaho Operations Office

Contract DE-AC07-99ID13727 


\section{CONTENTS}

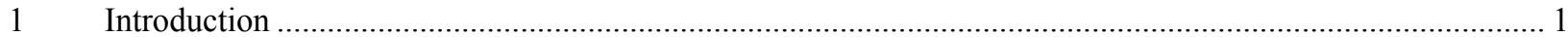

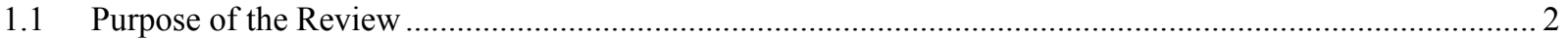

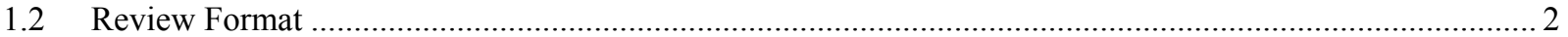

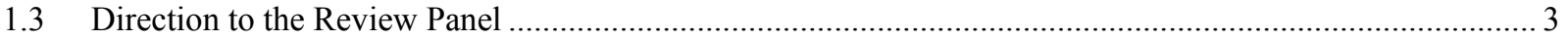

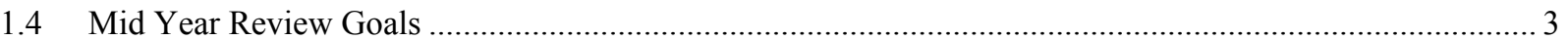

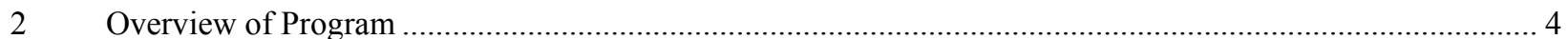

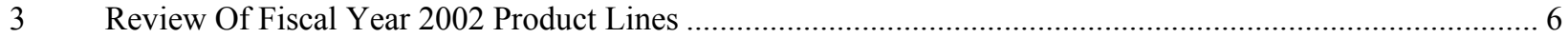

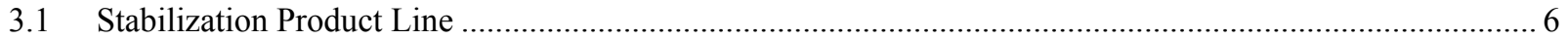

3.1.1 RL31NM12, Plutonium Thermal Treatment Furnace Load-Out System............................................. 6

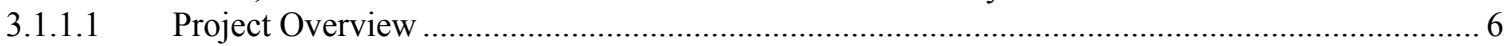

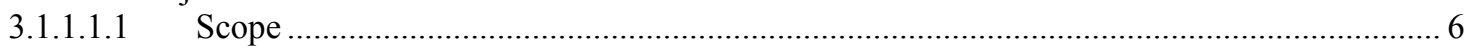

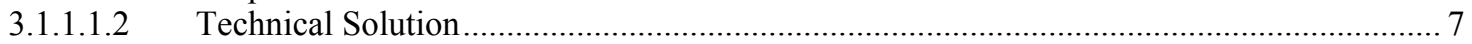

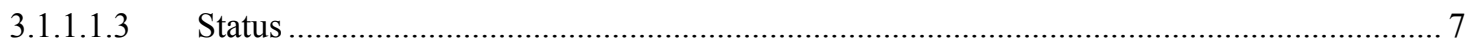

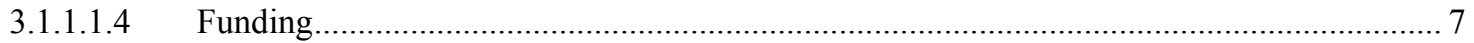

3.1.1.1.5 Alignment to Thrust Areas and Key Goals and Priorities .................................................. 8

3.1.1.2 Project Review Results Results ......................................................................................... 8

3.1.2 Moisture Measurement Projects (SR11NM13, Implementation of Moisture Measurement Technology

for Nuclear Materials Stabilization, and AL11NM13, Implementation of Moisture Measurement

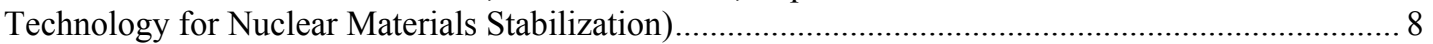

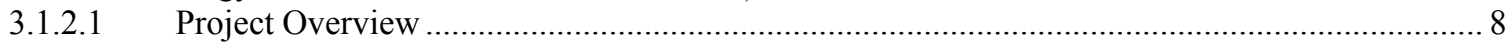

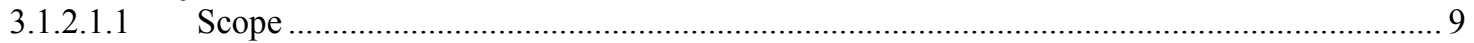

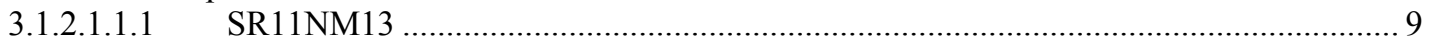

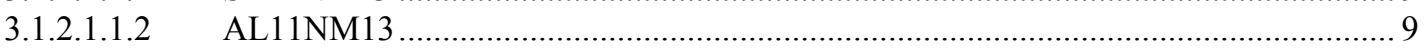

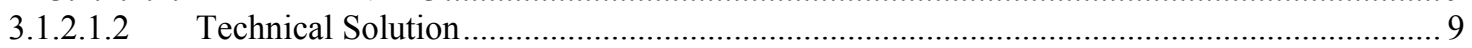

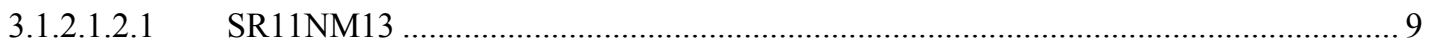

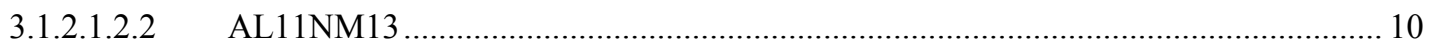

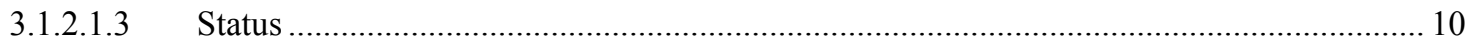

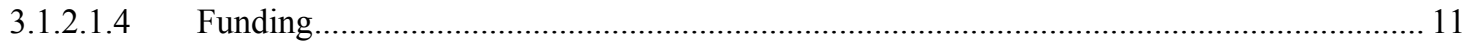

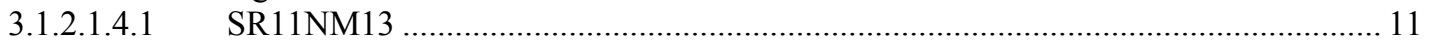

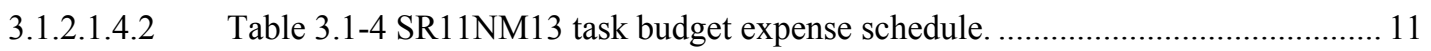

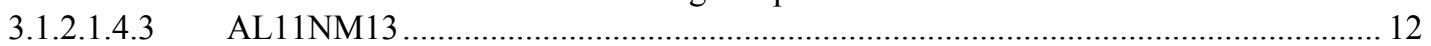

3.1.2.1.4.4 Table 3.1-6 AL11NM13 task budget expense schedule for SFE. ............................... 12

3.1.2.1.5 Alignment to Thrust Areas and Key Goals and Priorities ................................................ 13

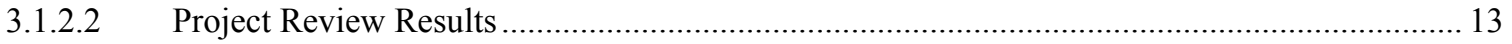

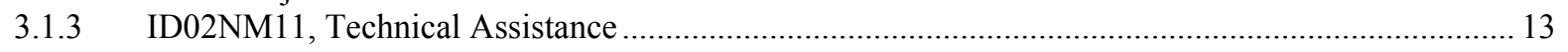

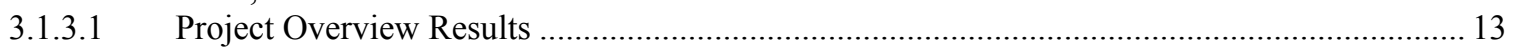

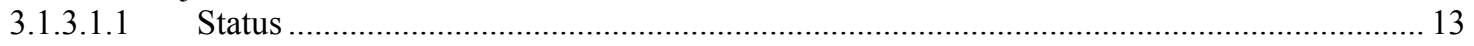

3.1.3.1.2 Alignment to Thrust Areas and Key Goals and Priorities .............................................. 14

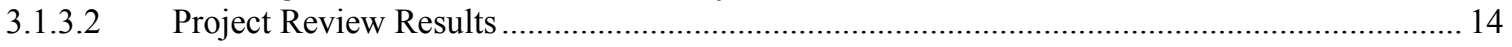

3.2 Packaging, Transportation and Storage Product Line.......................................................................... 14

3.2.1 Fernald Automation Projects (OH11NM21, Fernald Drum Handling System Project; AL11NM22,

Automated Packaging of Nuclear Materials LANL Engineering and Support-Robotics; AL21NM21,

Automated Packaging of Nuclear Material-Robotics) ...................................................................... 15

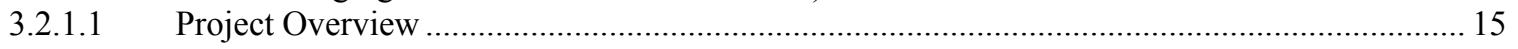

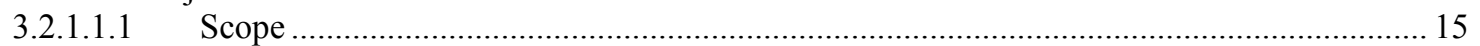

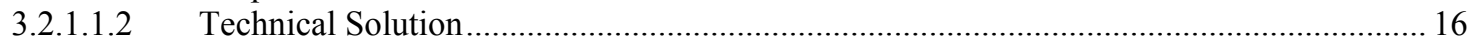

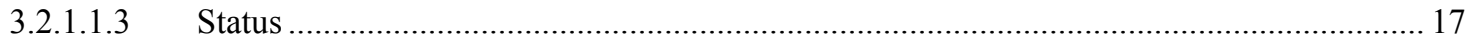

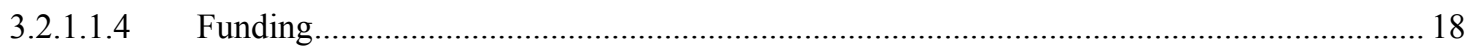

3.2.1.1.5 Alignment to Thrust Areas and Key Goals and Priorities ............................................. 19

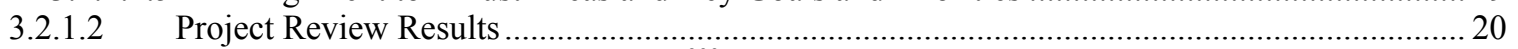

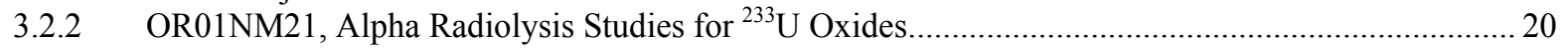

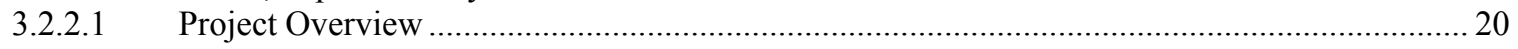

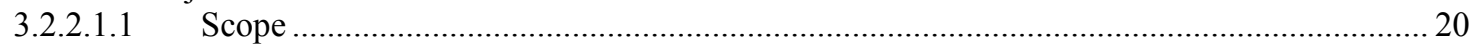




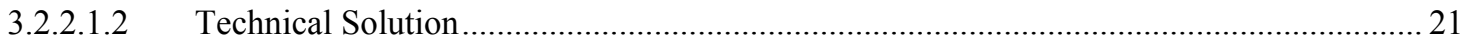

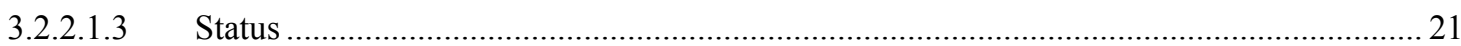

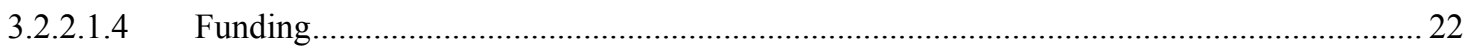

3.2.2.1.5 Alignment to Thrust Areas and Key Goals and Priorities ................................................. 23

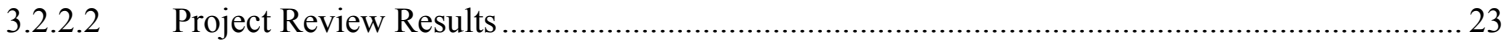

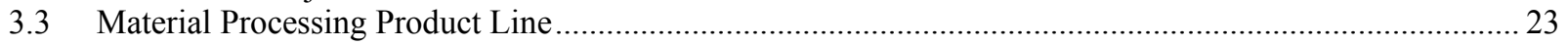

3.3.1 SR11NM12, Prevention of Precipitation of Unwanted Solids During Canyon Dissolution................. 24

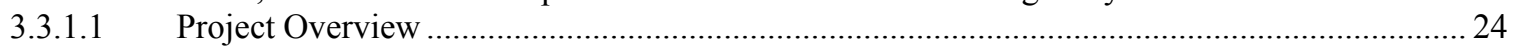

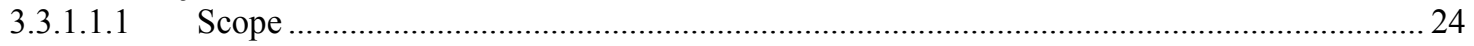

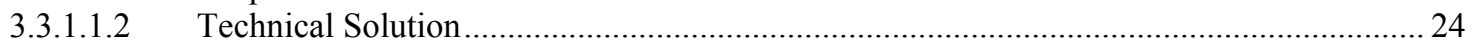

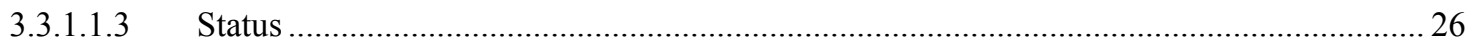

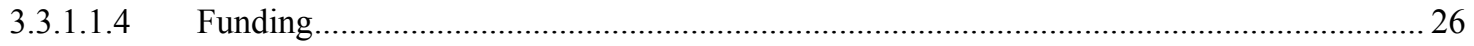

3.3.1.1.5 Alignment to Thrust Areas and Key Goals and Priorities ................................................ 26

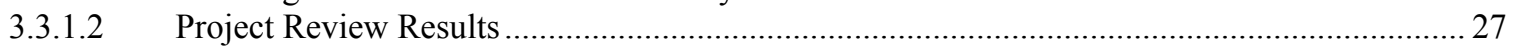

3.3.2 RL31NM13, Single Step Distillation Process for Plutonium Oxides Containing Chlorides ............... 27

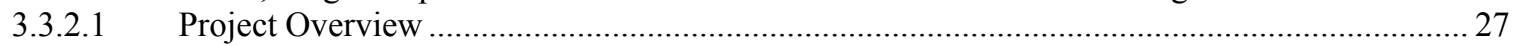

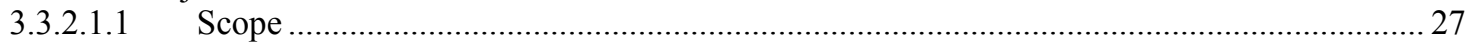

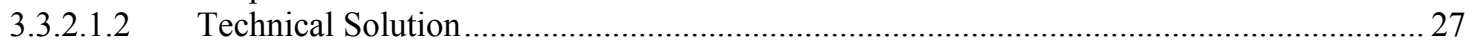

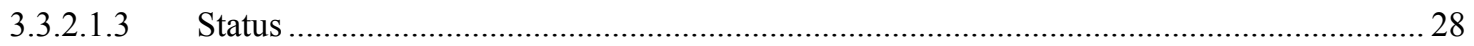

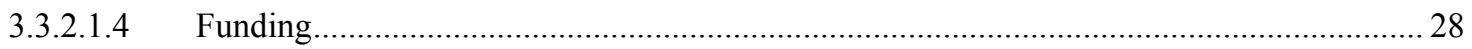

3.3.2.1.5 Alignment to Thrust Areas and Key Goals and Priorities ................................................. 28

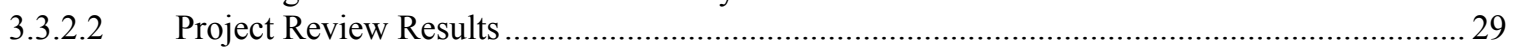

3.3.3 FT01AR01 and ID72NM31, Dry Blending for Isotopic Dilution......................................................2

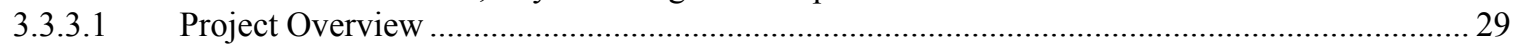

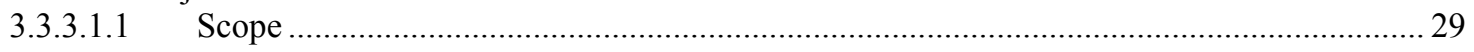

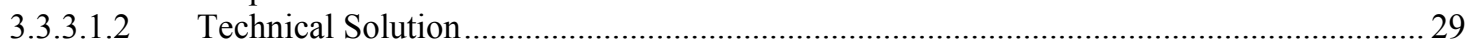

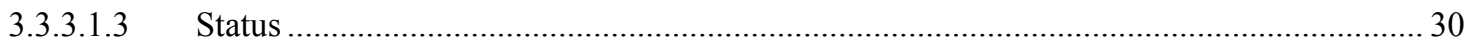

3.3.3.1.4 Alignment to Thrust Areas and Key Goals and Priorities .................................................... 30

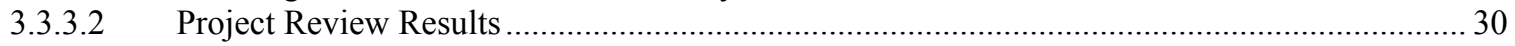

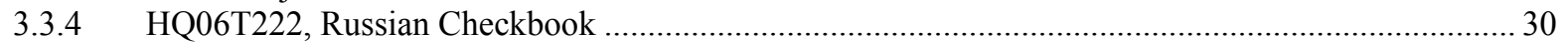

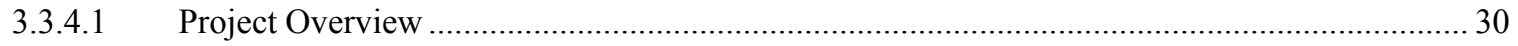

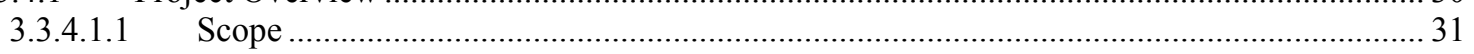

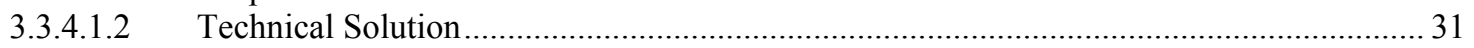

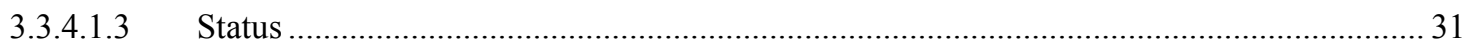

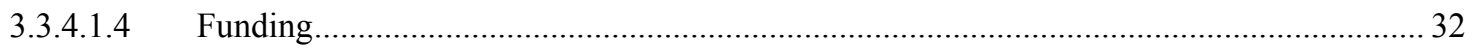

3.3.4.1.5 Alignment to Thrust Areas and Key Goals and Priorities .............................................. 32

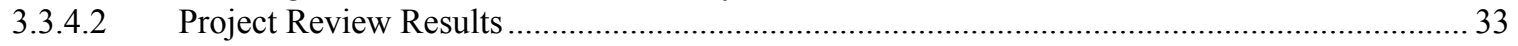

3.3.5 RL31NM11, Optimal Plutonium Precipitation for Stabilization Feed Preparation ............................... 33

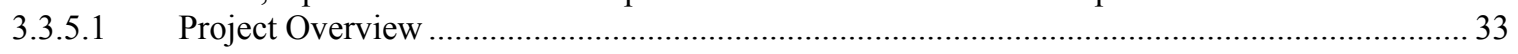

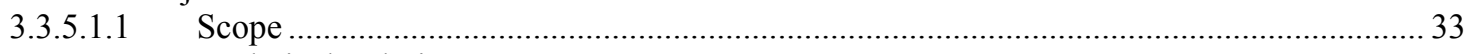

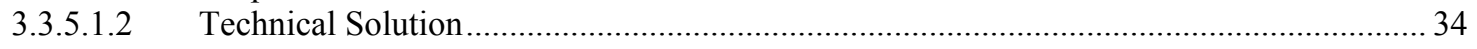

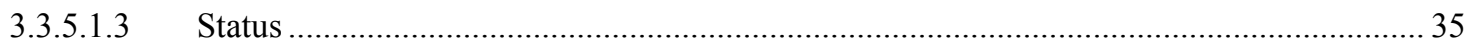

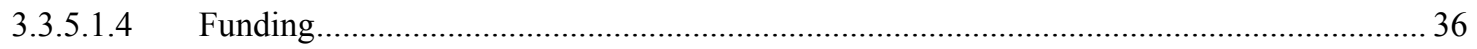

3.3.5.1.5 Alignment to Thrust Areas and Key Goals and Priorities ............................................... 37

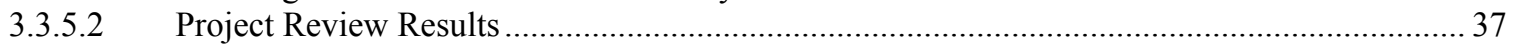

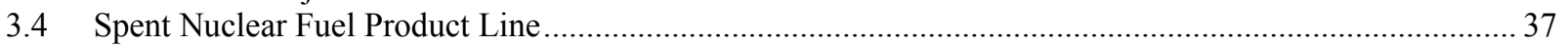

3.4.1 RL32NM41, Enhancement Reactivity Factor for Cold Vacuum Drying (CVD) Processing N-Reactor

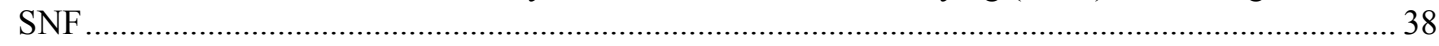

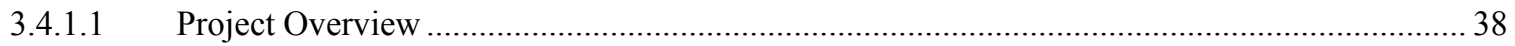

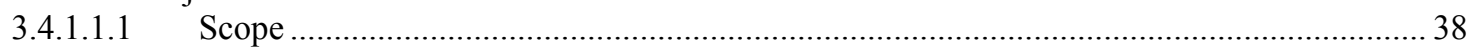

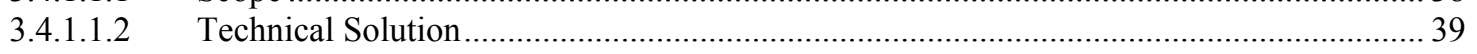

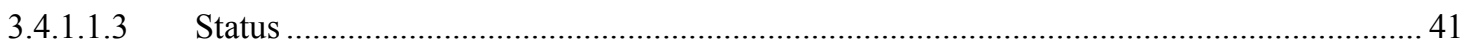

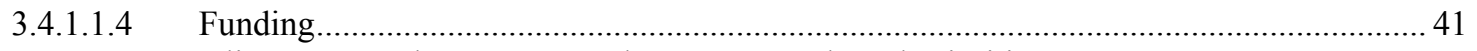

3.4.1.1.5 Alignment to Thrust Areas and Key EM Goals and Priorities .......................................... 42

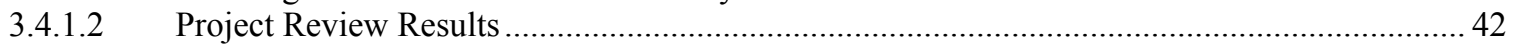


3.4.2 ID02NM41, Weld and NDE Technique and Equipment Development for DOE Standardized SNF Canister; and SR02NM41, Weld Optimization to Minimize Potential for Age-Related Degradation of

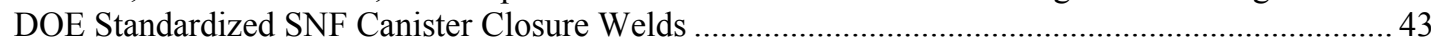

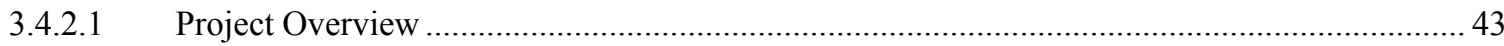

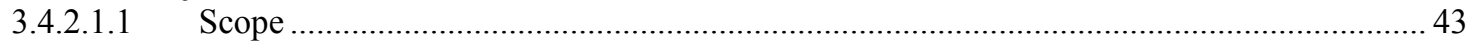

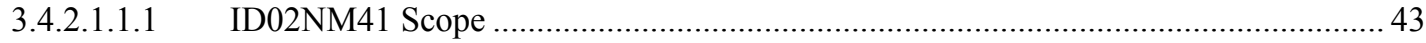

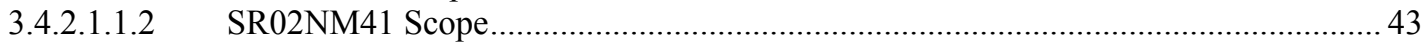

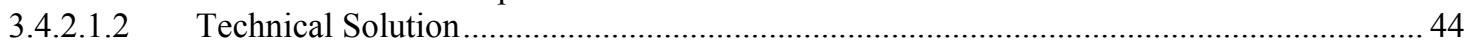

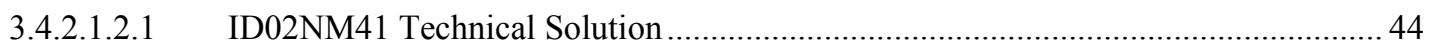

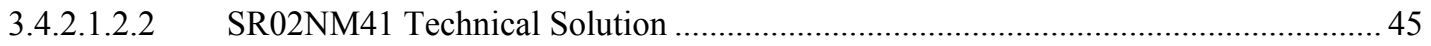

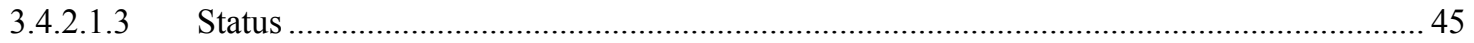

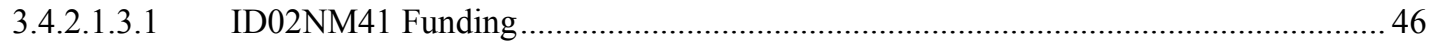

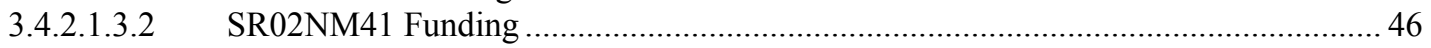

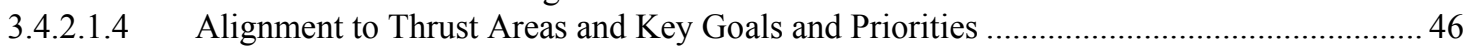

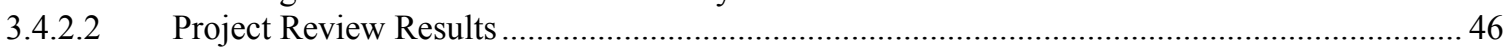

3.4.3 ID02NM44, INEEL HLW/SNF Canister Interaction Project Manager; CH22NM41, ANL HLW/SNF

Canister Interaction Studies; and SR02NM42, SRS HLW/SNF Canister Interaction Studies ............. 47

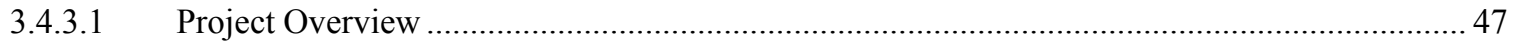

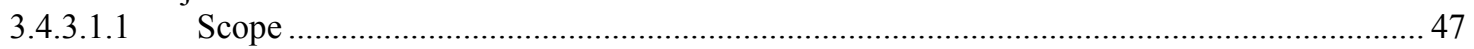

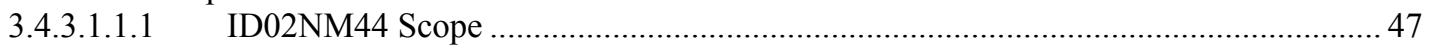

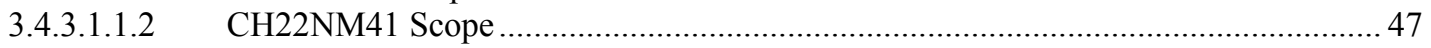

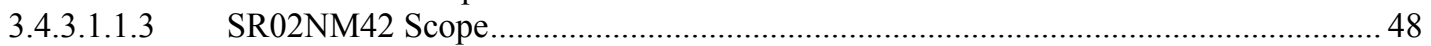

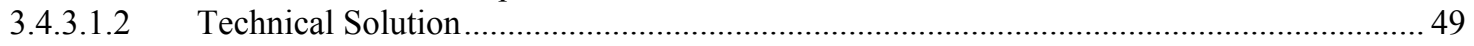

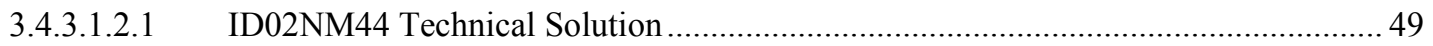

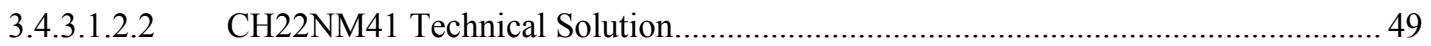

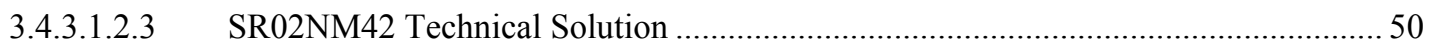

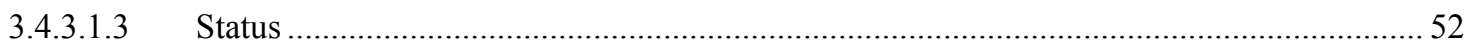

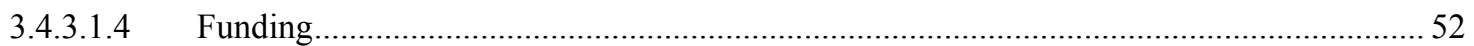

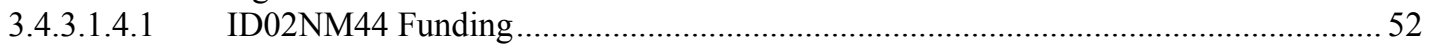

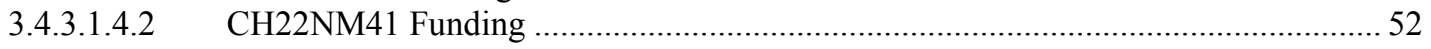

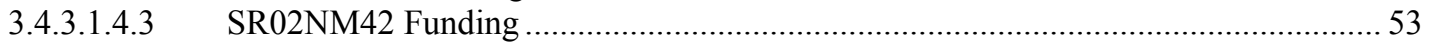

3.4.3.1.5 Alignment to Thrust Areas and Key Goals and Priorities ................................................ 53

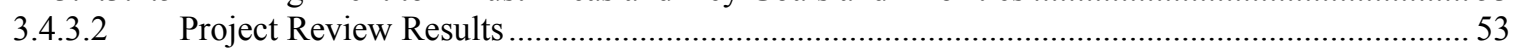

3.4.4 SR02NM51, Determination of Radiolysis Effects for Water on Spent Nuclear Fuel; and ID02NM45,

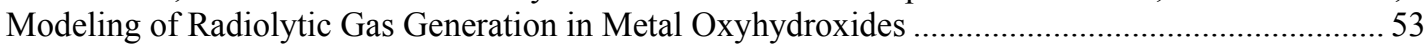

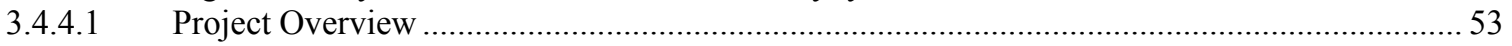

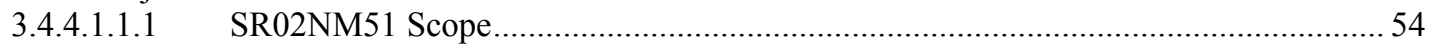

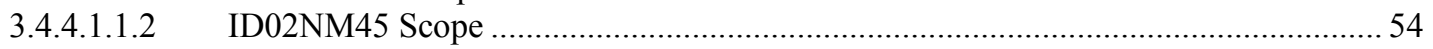

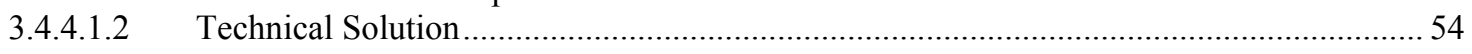

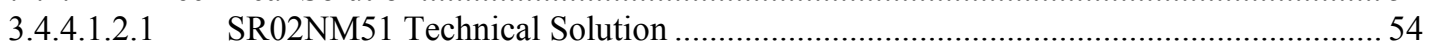

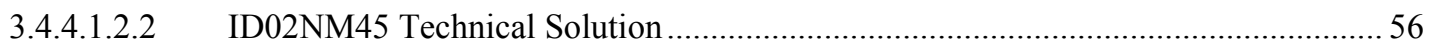

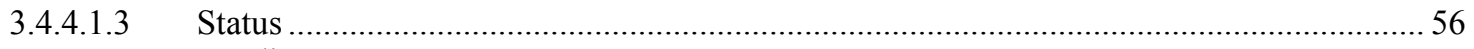

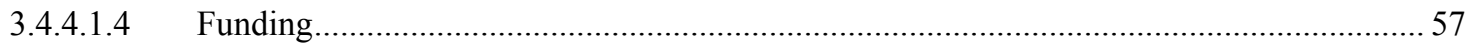

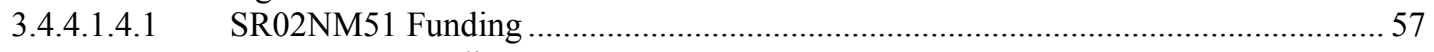

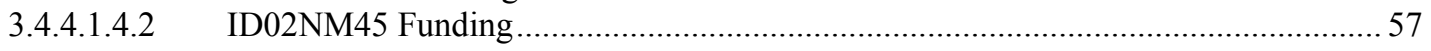

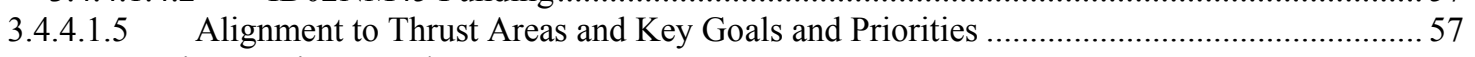

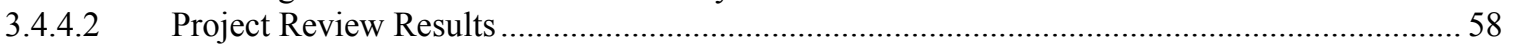

3.4.5 ID02NM42, Investigating the Corrosion Resistance of New Alloys; and AL22NM41,

Microstructure/Mechanical Properties Investigation for New Alloys to Control Nuclear Criticality.. 58

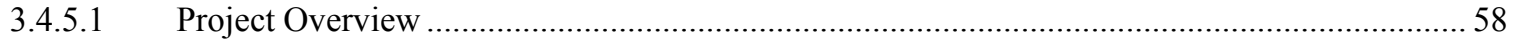

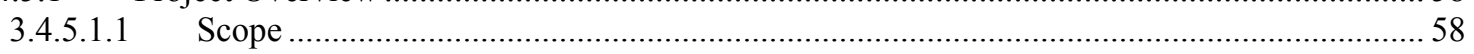

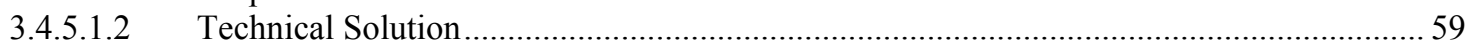

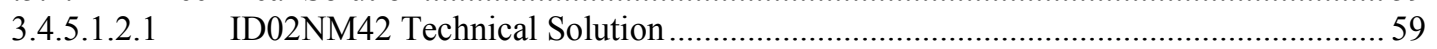

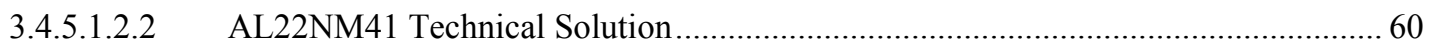

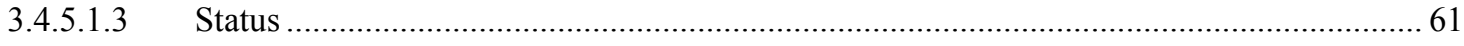

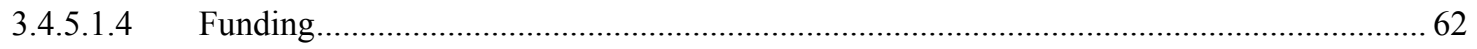




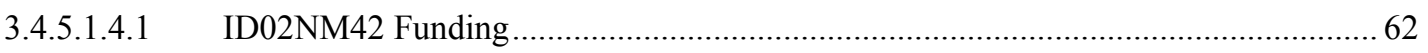

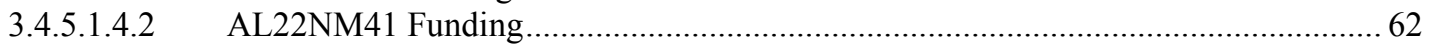

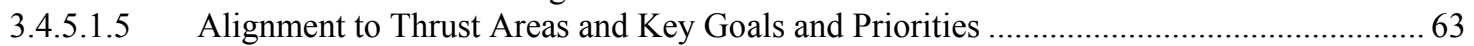

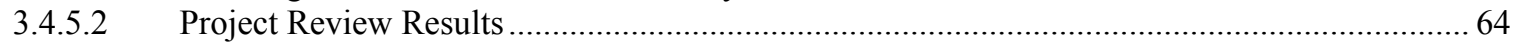

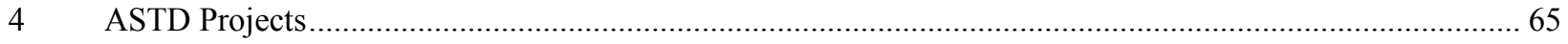

4.1 OH12NM31, Fernald ASTD Project, Waste Materials Processing System for the Fernald Site .................. 65

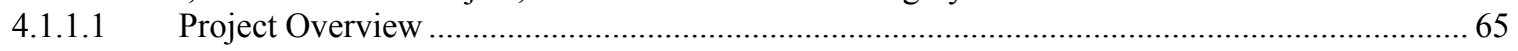

4.1.1.2 Alignment to Thrust Areas and Key Goals and Priorities............................................................. 65

4.2 RF02NM30, Rocky Flats ASTD Project, Disassembly and Disposition of Classified Shapes at Rocky

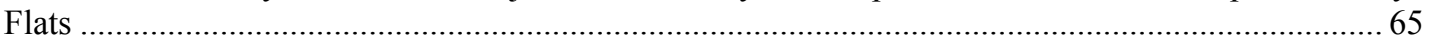

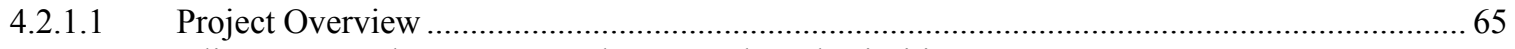

4.2.1.2 Alignment to Thrust Areas and Key Goals and Priorities......................................................... 66

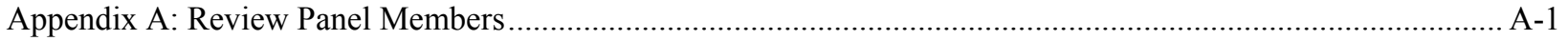

Appendix B: Review Panel Recommendations........................................................................................ B-1

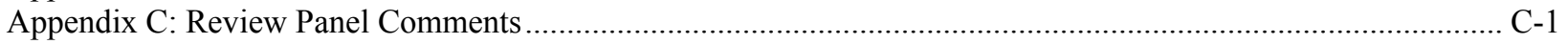

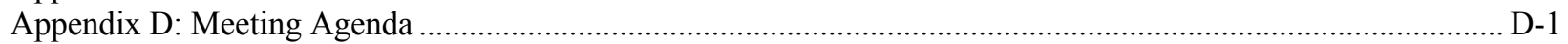

Appendix E: Meeting Attendees ....................................................................................................................

\section{FIGURES}

Figure 2.1-1 Nuclear Materials Focus Area FY 2002 Projects ............................................................................ 5

\section{TABLES}

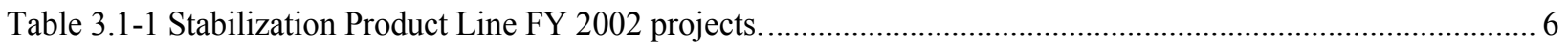

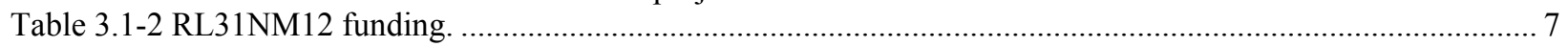

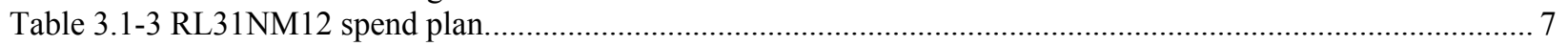

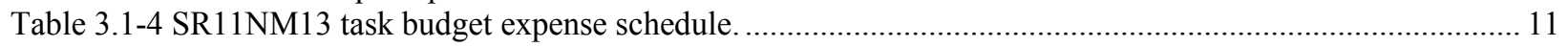

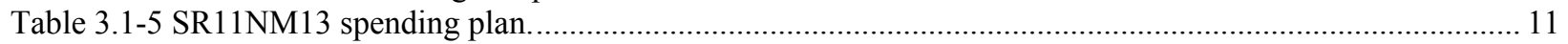

Table 3.1-6 AL11NM13 task budget expense schedule for SFE. .......................................................................... 12

Table 3.1-7 AL11NM13 task budget expense schedule for neutron moderation..................................................... 12

Table 3.1-8 AL11NM13 spend plan (\$K) FY-02 (neutron moderation).......................................................... 12

Table 3.1-9 AL11NM13 budget summary life cycle cost estimate (\$K) EM-50 funding B\&R code EW4010......... 13

Table 3.2-1 Packaging, Transportation and Storage FY 2002 projects............................................................... 15

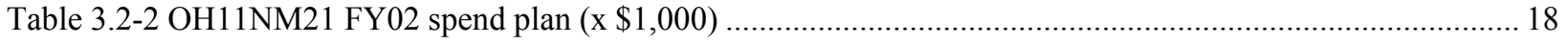

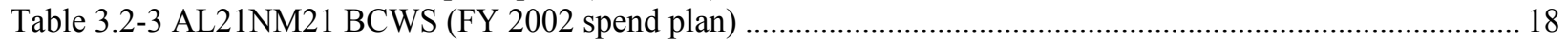

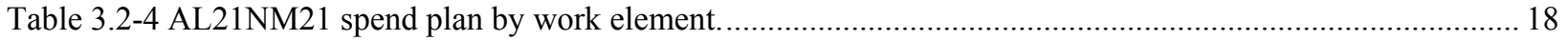

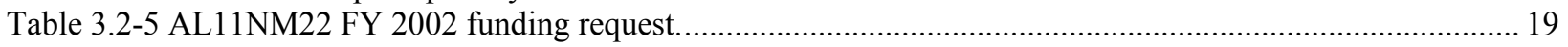

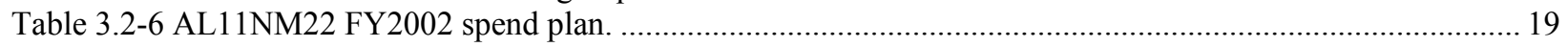

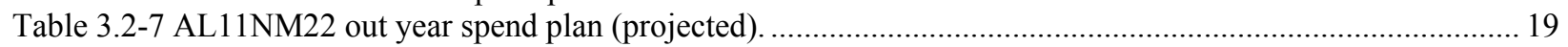

Table 3.2-8 OR01NM21 budget summary: (including \$61K carryover into FY 2002)............................................ 22

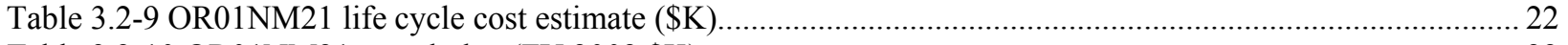

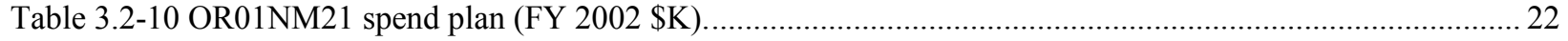

Table 3.3-1 Material Processing Product Line FY 2002 projects. ............................................................................... 23

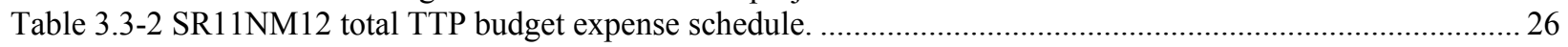

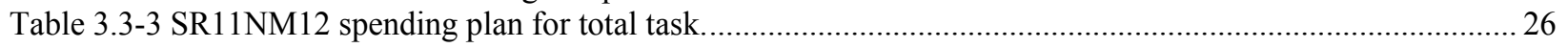

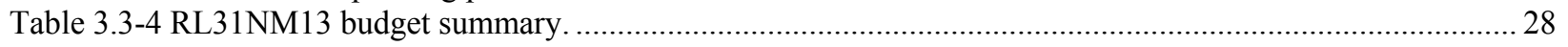

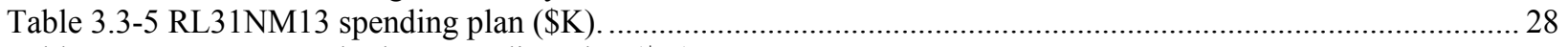

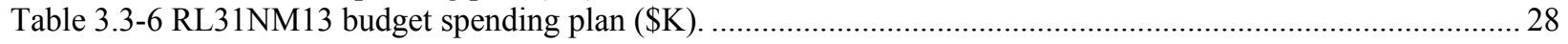

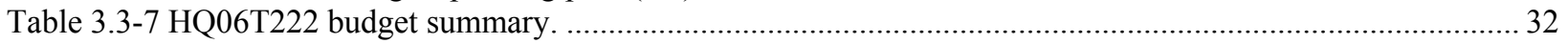

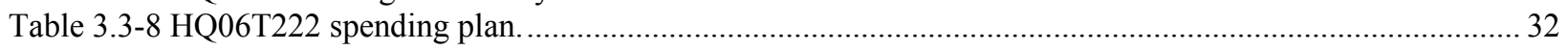

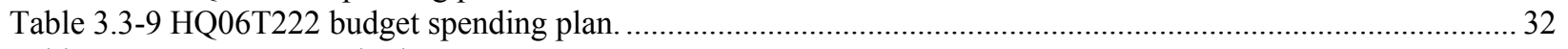

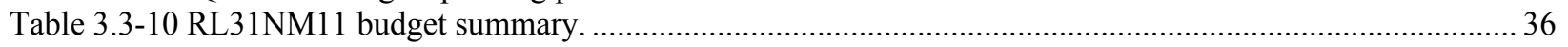

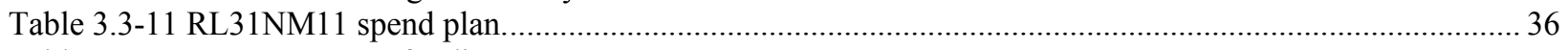

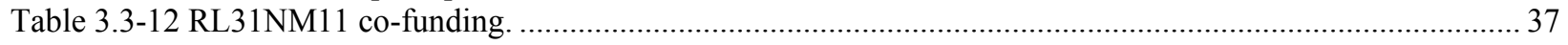


Table 3.4-1. Spent Nuclear Fuel Product Line FY 2002 projects. ........................................................................ 38

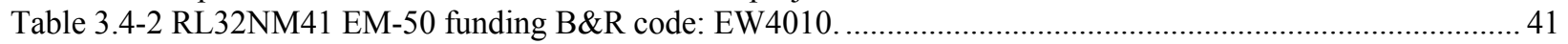

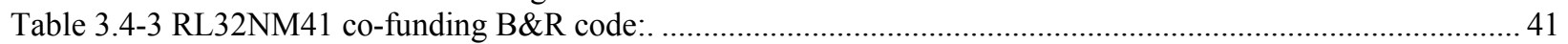

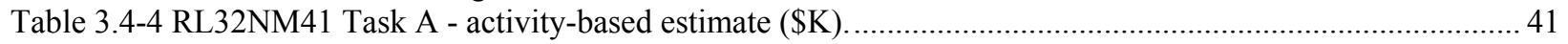

Table 3.4-5 RL32NM41 Task A - budget expense xchedule (\$K). .................................................................... 42

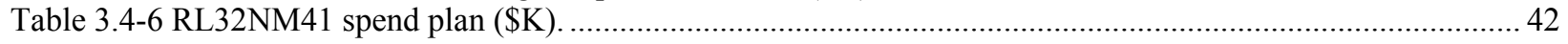

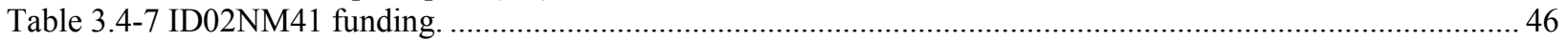

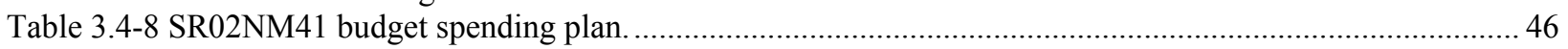

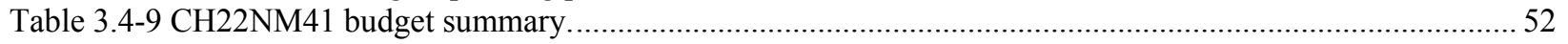

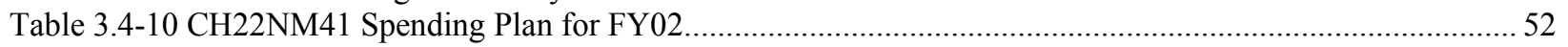

Table 3.4-11 SR02NM42 life cycle cost estimate (\$K) tasks A \& B....................................................................5 53

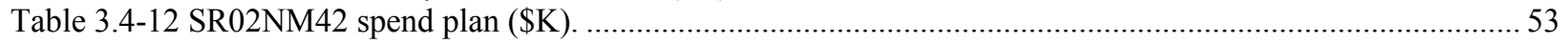

Table 3.4-13 SR02NM51 EM-50 funding B\&R code: EW4010 .......................................................................... 57

Table 3.4-14 SR02NM51 spend plan (\$K). ................................................................................................. 57

Table 3.4-15 ID02NM45 Task A - activity-based estimate (\$K)FY 2002 ………................................................. 57

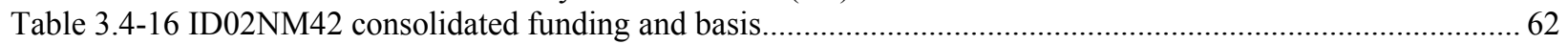

Table 3.4-17 AL22NM41 life cycle cost estimate (\$K) task A. ............................................................................ 62

Table 3.4-18 AL22NM41 Task A - activity-based estimate (\$K) FY 2002 ........................................................... 63

Table 3.4-19 AL22NM41 Task A - activity-based estimate (\$K) ....................................................................... 63

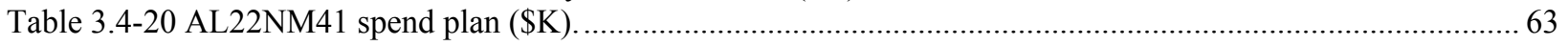




\section{INTRODUCTION}

The Nuclear Materials Focus Area (NMFA) held its annual mid-year review on February 13 and 14, 2002, in Santa Fe, New Mexico. The purpose of this review was to examine both the technical aspects and the programmatic aspects of its technology development program. The focus area activities were review by a panel consisting of personnel representing the end users of the technologies, and technical experts in nuclear materials. (See Appendix A for a list of the review panel membership and what Department of Energy (DOE) sites they are representing or their area of expertise.)

This year's review was somewhat different than in the past, as the stress was on how well the various projects being managed through the NMFA aligned with the two thrust areas and nine key goals and priories recently issued by the Deputy Assistant Secretary for DOE's Office of Environmental Management (EM). ${ }^{1}$

Thrust 1: Closure Site Support - Ensure that Closure Sites (Rocky Flats and Ohio) have necessary technology and technical support to meet closure schedules. Provide real-time response to site needs while ensuring high quality work. Thrust 2: Alternative Approaches to Current High Risk/High Cost Baselines - Address alternatives to current baselines for very high risk and/or high cost problems. Identify where technology areas where the greatest benefits could be realized by an aggressive investment strategy. Completely analyze the requirements for alternatives, the drivers for the requirements and the efficacy of the approach for the long term.

\section{The key EM goals and priorities are:}

1. Improve Safety Performance - Better apply resources to risk, driving down or eliminating risk by the work we do rather than avoiding or delaying this work.

2. Reduce Cost \& Time Required to Complete the EM Cleanup Mission - Reduce real cost of clean up by at least 100 billion dollars and time to complete by at least 30 years.

3. Close Rocky Flats, Fernald, and Mound by 2006 - Additionally, close at least six small sites by 2006 that were not scheduled to close.

4. Consolidate Nuclear Material Out of EM Sites by 2004 - Deinventory nuclear materials from Rocky Flats, Hanford, Ohio, and Idaho.

5. Eliminate the Need to Process High Level Liquid Wastes - Eliminate need to vitrify at least 75 percent of waste scheduled for vitrification today. Develop at least two proven, cost effective solutions to every high-level waste stream in the complex.

6. Make EM a Better Customer - Define what we want to accomplish far better and leave the how to the contractor.

7. Shrink the EM Footprint - Reduce the EM footprint (active landlord/utility area) by at least 40 percent over next four years.

8. Get Wastes to Disposal Facilities Quickly - Safely dispose 100,000 drums of transuranic waste at the Waste Isolation Pilot Plant. Decrease unit cost to dispose of tranuranic and low-level radioactive waste by at least 30 percent. Open the Nevada Test Site and Richland for out-of-state disposal of mixed hazardous and low-level radioactive waste.

\section{Reshape EM Systems and Infrastructure to Drive Accelerated Cleanup and Closure}

\footnotetext{
${ }^{1}$ Jessie H. Roberson, Assistant Secretary for Environmental Management, to Distribution, "Office of Environmental Management Science and Technology Program,” December 14, 2001.
} 


\subsection{Purpose of the Review}

Although the Nuclear Materials Focus Area (NMFA) may conduct programmatic reviews as needed, the most important programmatic reviews are those required at midyear because of their role in the annual budget cycle. Midyear reviews combine the attributes of independent end user technical evaluation, programmatic status reviews, and forward-looking vision. The principal focus of midyear reviews is user endorsement and progress toward meeting user requirements. Midyear reviews also expose ongoing work to other potential users, and guide current year adjustments.

The overall purpose of these reviews is to secure knowledgeable counsel on the attributes of an ongoing or proposed activity or program. While the exact goals, methods, and emphases of different review system components are somewhat different, certain attributes are consistently important in all reviews:

1. Endorsement by potential EM users;

2. Importance of the problem being addressed and the solution cost vs. benefit performance compared to baseline;

3. Solving problems for which no baseline exists or delivers a step improvement over baseline;

4. Solution has scientific and technical merit (it is good science);

5. Solution meets or exceeds current safety and health (S\&H) protection levels and/or reduces the risk to the public, workers, and the environment;

6. Readiness for a technology to advance to a later development stage;

7. Avoiding redundancy

8. Feasibility and likelihood of technical and economic success; and

9. Allow all interested and affected parties to track the progress of active projects at all stages of maturity.

\subsection{Review Format}

The mid-year review was conducted under the direction of the End User Steering Committee (EUSC) with input on technical issues from the Technical Advisory Group (TAG). Members of the EUSC and TAG were assembled into a review panel (see Appendix A for a listing of panel members). Oral presentations were made by the four FY 2002 Product Line Managers responsible for each of the funded projects.

In addition, NMFA members delivered presentations on two new Accelerated Site Technology Deployment (ASTD) projects, and on NMFA's vision for the future, given the changes anticipated from recent EM directives. The review panel did not comment on the ASTD projects, but did offer comments on NMFA's vision. 


\subsection{Direction to the Review Panel}

Prior to the mid-year review, panel members were provided a workbook with the programmatic and technical information for each of the FY 2002 funded projects. During the mid year review, the panel completed questionnaires on each project (Appendix $\mathrm{C}$ contains the combined comments and scores from the individual reviewers, captured on the questionnaire form that was provided to them), then met separately to confer on the projects. At the end of the mid year, the EUSC chair presented the panel's recommendations on the projects and offered commentary on the NMFA's vision (incorporated in Appendix B).

\subsection{Mid Year Review Goals}

The general message that NMFA provided to the review panel was that the advice provided by the review panel at the 2001 NMFA mid-year review had been taken into account, and that the NMFA was building a strong and technically sound program that was solving needs at the EM sites. NMFA was seeking feedback from the review panel on which active projects could align to the new OST thrust areas and goals and how the NMFA's vision also aligned to the new direction from EM. 


\section{OVERVIEW OF PROGRAM}

The NMFA consists of a management team and their support, a technical team consisting of lead laboratory personnel and product line managers, and the principal investigators who perform the actual technology development work. The NMFA interfaces with a technical advisory group, an end user steering committee, and site technical program officers. The work that the NMFA performs directly responds to technology needs identified by end users at the various EM sites. For each nuclear material need (this includes spent nuclear fuel needs as well) the NMFA product line managers (PLMs) develop a technical response that spells out how the NMFA would address the need, given adequate resources to do so. These technical responses are grouped into problem areas, and then the problem areas are grouped into product lines. The NMFA then requests proposals from site laboratories or other technology developers who could address the problem areas. The selected proposals are developed into active projects. The FY 2002 active projects are shown in Figure 2.1. 


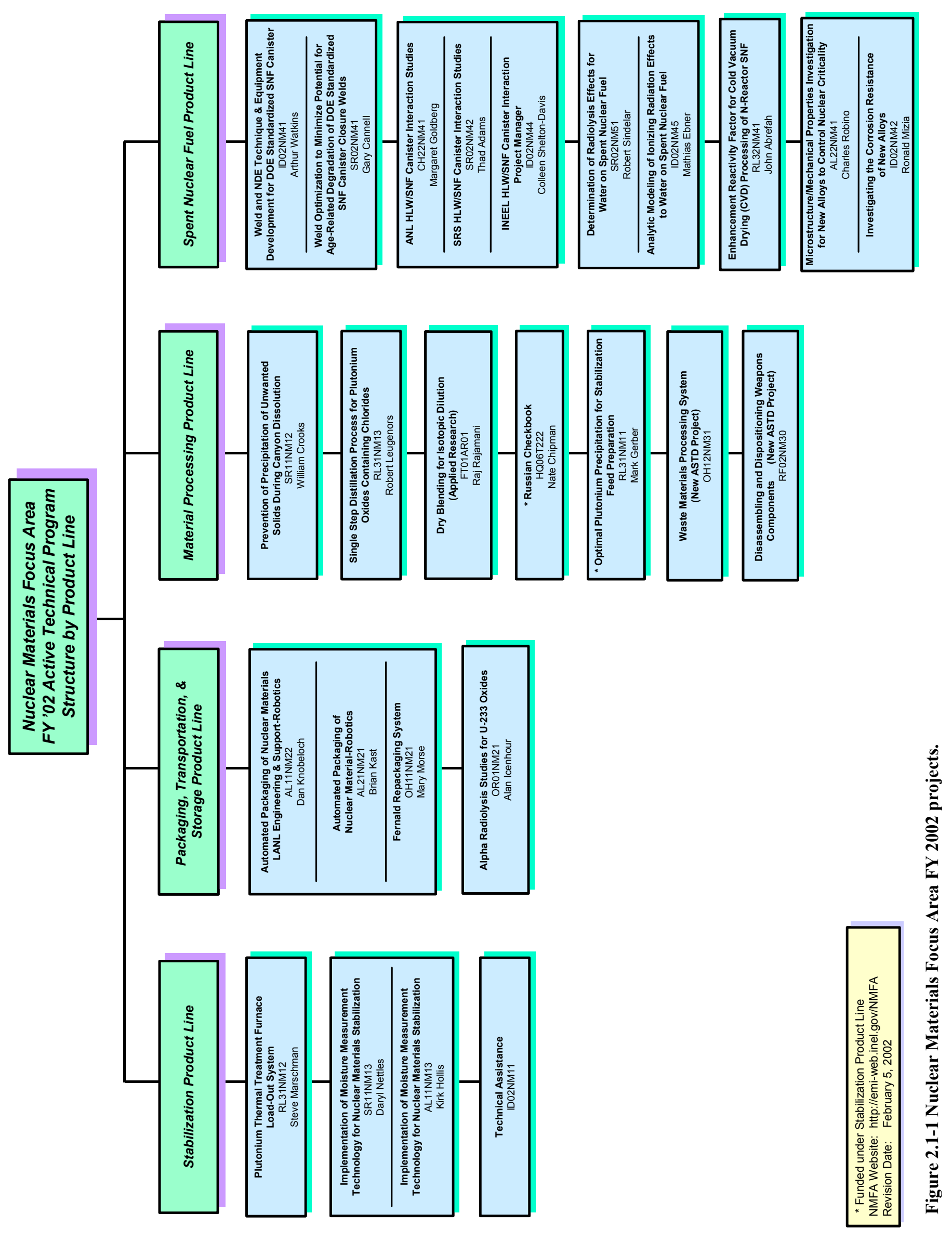




\section{REVIEW OF FISCAL YEAR 2002 PRODUCT LINES}

The review panel was asked to review each of the projects in the fiscal year (FY) 2002 product lines. As seen in Figure 2.1-1, NMFA has four active product lines in FY 2002. They are:

1. Packaging, Transportation and Storage,

2. Stabilization,

3. Material Processing, and

4. Spent Nuclear Fuel.

Two other product lines exist but do not have any projects funded this year. Those product lines are long-term storage and depleted uranium.

\subsection{Stabilization Product Line}

The Stabilization Product Line addresses technology needs for final stabilization processes intended to meet existing or future acceptance criteria for various nuclear materials.

The projects managed within the Stabilization Product Line are listed in table 3.1-1.

Table 3.1-1 Stabilization Product Line FY 2002 projects.

\begin{tabular}{||l|l|l||}
\hline \multicolumn{1}{|c|}{ TTP NUMBER(S) } & \multicolumn{1}{|c||}{ PROJECT TITLE(S) } & \multicolumn{1}{|c||}{$\begin{array}{c}\text { THRUST AREA - SITE } \\
\text { IMPACTED }\end{array}$} \\
\hline RL31NM12 & Pu Thermal Treatment Furnace Load-out System & $2-$ Hanford \\
\hline AL11NM13 & $\begin{array}{l}\text { Moisture Measurement Technology for Nuclear } \\
\text { Material Stabilization }\end{array}$ & $1-$ Rocky Flats \\
\hline SR11NM13 & $\begin{array}{l}\text { Implementation of Moisture Measurement } \\
\text { Technology for Nuclear Materials Stabilization }\end{array}$ & $2-$ SRS \\
\hline ID01NM11 & Technical Assistance & $1-$ Rocky Flats \\
\hline
\end{tabular}

\subsubsection{RL31NM12, Plutonium Thermal Treatment Furnace Load-Out System}

\subsubsection{Project Overview}

At the Hanford 234-5Z building, they are processing plutonium $(\mathrm{Pu})$-bearing materials using a thermal stabilization furnace. This operation has a potential rate-limiting step because the furnace cycle time is dominated by the heat up and cool down cycle segments. The task is to design and fabricate a system for furnace loading and unloading that eliminates cycle-time dependency, and will fit inside the HC-21C glovebox.

\subsubsection{Scope}

Thermal stabilization of Pu-bearing material in the PFP Room 230A furnaces is currently a slow process due to the lengthy heat up and cool down times associated with the two furnaces used to perform the treatment. The process can be accelerated if the furnaces can be kept at temperature, but this requires a method for loading and unloading the furnaces at temperature while maintaining safe operations. This 
project will solve the hot loading and unloading problem that will allow the thermal treatment process to be accomplished in a shorter period of time than can be accomplished at present.

\subsection{Technical Solution}

The Plutonium Thermal Treatment Furnace Load-Out System will allow operators to load and unload the heat-treated materials at near-room temperature. This will be accomplished by the system's two-chamber design.

The material loading/preheat chamber allows loading of the furnaces while isolating operators and the glovebox environment from excessive heat loads. Two charge boat shuttles located in the load chamber allow alternate charging of the two furnaces. The cool down chamber is used to rapidly cool the thermally treated materials and allows operators to unload the system while isolated from heat.

The proposed load-out system would be operated using simple push-pull mechanical devices to keep operations simple, robust, and easy to repair in a remote environment should any repair ever be necessary. The design concept protects the furnaces from the stresses of thermal cycling and repeated impacts and abrasion of linings from hand loading and unloading in difficult conditions. Heating element replacement, currently required on a frequent basis, should be reduced considerably.

The system that is proposed can accommodate most of the Pu-bearing materials that will need thermal treatment at the PFP. These include oxide materials, polycubes, chloride-bearing materials, and alloy materials. The only materials that cannot be directly processed using this system are those containing quantities of free water (e.g. magnesium hydroxide precipitates). However, even these materials can be processed if the free water is removed using simple preheating techniques (hot plate heating prior high temperature thermal stabilization).

\subsection{Status}

The plutonium furnace loadout system has been demonstrated in a mockup glovebox, and an operating manual is being prepared. This project is ready for deployment whenever the opportunity arises. Until then, the system is in storage at Hanford. The technical maturity is Stage 7.

\subsubsection{Funding}

Table 3.1-2 RL31NM12 funding.

\begin{tabular}{||l|l|l|l|l|l|l||}
\hline$\frac{\text { SOURCE }}{(\mathrm{B} \& \mathrm{R})}$ & $(\$ \mathrm{~K})$ & $\underline{\text { EST. 2001-CO }}$ & $\underline{2002}$ & $\underline{2003}$ & $\underline{2004}$ & $\underline{2005}$ \\
\hline EW4010 & Task A & 0 & 75 & 0 & 0 & 0 \\
\hline & Task B & 0 & 100 & TBD & TBD & TBD \\
\hline
\end{tabular}

Table 3.1-3 RL31NM12 spend plan.

\begin{tabular}{||l|l|l|l|l|l|l|l|l|l|l|l|l|l||}
\hline \hline$(\$ K)$ & $\underline{\text { OCT }}$ & $\underline{\text { NOV }}$ & $\underline{\text { DEC }}$ & $\underline{\text { JAN }}$ & $\underline{\text { FEB }}$ & $\underline{\text { MAR }}$ & $\underline{\text { APR }}$ & $\underline{\text { MAY }}$ & $\underline{\text { JUN }}$ & $\underline{\text { JUL }}$ & $\underline{\text { AUG }}$ & $\underline{\text { SEP }}$ & TOTAL \\
\hline Task A & 30 & 30 & 15 & 0 & 0 & 0 & 0 & 0 & 0 & 0 & 0 & 0 & 75 \\
\hline Task B & 8 & 8 & 9 & 8 & 8 & 9 & 8 & 8 & 9 & 8 & 8 & 9 & 100 \\
\hline
\end{tabular}




\subsubsection{Alignment to Thrust Areas and Key Goals and Priorities}

This technology supports Thrust 2, because deployment of this technology will provide an alternative to current high cost baseline for materials stabilization. The furnace loadout system also supports the following key EM goals and priorities:

1. Improves safety performance by reducing manpower intensity associated with the PFP line

2. Reduces cost and time required to close PFP by significantly increasing the rate of thermal stabilization for Pu-bearing materials

4. Deployment will support de-inventory of nuclear materials from Hanford by 2004

7. Helps shrink the EM Footprint by accelerating the processing rate and thereby allowing earlier closure of PFP.

\subsubsection{Project Review Results Results}

The review team said that the project technical scope appeared complete as it was presented. However, they recommended that NMFA conduct a "Lessons-Learned" critique regarding project execution relating to co-funding and deployment commitment. They did not recommend that this project continue in FY 2003.

\subsubsection{Moisture Measurement Projects (SR11NM13, Implementation of Moisture Measurement Technology for Nuclear Materials Stabilization, and AL11NM13, Implementation of Moisture Measurement Technology for Nuclear Materials Stabilization)}

\subsubsection{Project Overview}

The Defense Nuclear Facility Safety Board (DNFSB) recommendation 94-1 requires that the moisture content of plutonium-bearing material be measured to ensure that over pressurization or corrosion does not occur. Traditional moisture measurement methods, such as Loss-On-Ignition (LOI) are not accurate for impure plutonium bearing materials. This research task analyses the results of multiple analytical methods measuring the moisture content of pure and impure Pu-bearing materials. The methods are Supercritical Fluid Extraction (SFE) with FTIR, Thermogravimetric Analysis (TGA)/Mass Spectrometry (MS), and Neutron Moderation Analysis (NMA). Deployment provides technology solutions to problem of moisture measurement in impure Pu-bearing materials, and will allow DOE sites [Hanford, Rocky Flats, and Savannah River Site(SRS)] to meet DNFSB 94-1 milestone schedules. Rapid deployment is possible because the engineering and construction approaches use standard industry practice and equipment is available from commercial suppliers. Potentially, a cost avoidance of between 25 and 50 percent is possible, because of the reduction in false positives from using LOI.

Deployment of NMA will allow sites to determine moisture content of whole storage containers, and will provide enabling technology to support development of technical basis for process qualification as related to material stabilization and packaging at DOE sites (Hanford, Rocky Flats, and SRS). In addition, deployment will significantly reduce safety risks from corrosion and gas generation during transportation and storage. This work will meet end-user needs without invoking significant new regulatory, safety, or security requirements. 


\subsection{Scope}

\subsection{SR11NM13}

The potential for storage container over-pressurization and/or corrosion in storage containers is subject primarily to the function of the quantity of water in the stored material. To ensure that overpressurization or corrosion does not occur, the water content of the stabilized material must be measured and shown to be below specified limits. Moisture measurement by traditional methods such as Loss-OnIgnition (LOI) is not accurate for impure plutonium bearing materials.

Since the computer modeling and software development for the neutron moderation method requires experimental moisture data, it is recommended that the SFE method be deployed. The SFE method will act in conjunction with LOI measurements, allowing packaging operations to proceed. In terms of analytical capability, SFE and IGA are comparable. However, since all of the components for SFE can be purchased commercially as an essentially turnkey system while analyzing larger samples, and since documentation, including hazard analysis, analytical procedure, and training requirements can be provided immediately, this method would be preferred. The primary drawback to the SFE method is the requirement for sub-sampling (thermal stabilization at $950^{\circ} \mathrm{C}$ prior to any additional moisture analysis), but this also applies to LOI and IGA.

The technical scope will consist of two items: First, the procurement of a SFE system by SRS to be delivered to LANL for qualification/checkout, then to SRS. The instrument will be assembled at SRS in non-radiological lab module, and LANL personnel will travel to SRS to assist in set up and training. Physical modifications to a glove box and radiological lab module will be completed to deploy the SFE system for analysis of plutonium bearing samples in FY02.

\subsection{AL11NM13}

Proposed work will include the deployment of a SFE moisture measurement system to SRS. In addition to the deployment of the SRS system, support for the systems deployed at Hanford and RFETS will also be included.

Proposed work will include the deployment of a Neutron Moderation (NM) moisture measurement system to RFETS and SRS sites. After the initial deployment an additional NM system will be reviewed for a second deployment.

\subsection{Technical Solution}

\subsection{SR11NM13}

The implementation of SFE moisture analysis at the Savannah River Site (SRS) Aiken, South Carolina, is the primary objective of this activity. The supercritical fluid extraction (SFE) equipment will be procured by the site, and all initial training, hardware setup and acceptance testing will be completed at SRS. In this way, the analysts can familiarize themselves with the equipment set up in a non-radiological facility, initially. While gaining operating experience, the SRS personnel will test the SFE instrument and be trained on the equipment set up in the non-radiological module of the facility. Subsequently, the equipment will be ready for deployment in a radiological area in FY02. Concurrently the assembly of the non-radiological instrument and a number of other activities will be initiated at SRS. These activities include, but are not limited, to the appropriate facility modifications, safety reviews, and work authorizations. 
In FY2002, this work will involve the use of supercritical fluid extraction (SFE) to validate the moisture content of materials being evaluated under the 94-1R\&D MIS program.

Specific milestones will include:

- Complete the procurement of the instrumentation at SRS.

- Install SFE system in clean laboratory at SRS and demonstrate operability.

- Complete modifications to all necessary laboratory modules and glove boxes

- Deploy SFE system in radiological glove box and demonstrate operability.

- Also, SRS will optimize the SFE operational procedure.

\subsection{AL11NM13}

\section{$\underline{\text { SFE }}$}

Since the computer modeling and software development for the neutron moderation method requires experimental moisture data, it is recommended that a second method be concurrently deployed. This second method will, at the same time, act as a back up to LOI measurements, allowing packaging operations to proceed. In terms of analytical capability, SFE and IGA are comparable. However, since all of the components for SFE can be purchased commercially as an essentially turnkey system while analyzing larger samples, and since documentation, including hazard analysis, analytical procedure, and training requirements can be provided immediately, this method would be preferred. The primary drawback to the SFE method is the requirement for sub-sampling, but this also applies to LOI and IGA.

\section{$\underline{\text { Neutron Moderation }}$}

The validation of the neutron moderation technique, using experimental data from other analytical methods, is promising but is still in the developmental stage. The three remaining comparative studies will provide valuable additional data on the effects of specific impurities (chloride and magnesium). However, it is strongly recommended that data collection be accelerated by implementing the method at DOE sites as soon as possible. This is especially important since it is anticipated that the first materials to be packaged will be of relatively high purity, and least problematic for neutron moderation analyses. Such data will be invaluable in developing the method by allowing baseline effects to be incorporated into the computer model and operating software. Once these relatively pure materials are packaged, it will probably not be possible to re-acquire the supporting, independent moisture data using the other, intrusive methods. Also, this data will extend the use of the method to more impure materials.

\subsection{Status}

The conceptual design, installation plan, and project schedule is complete. The NMA equipment was assembled at LANL and is ready for transfer to Hanford. The outlook is that work to deploy TGA/MS at SRS will begin, and NMFA deployment at Hanford will occur within a few months. These technologies could be deployed at other sites, such as Rocky Flats, if the opportunity arises. The project maturity is Stage 7 (deployment) for NMFA. 


\subsection{Funding}

\subsection{SR11NM13}

Table 3.1-4 SR11NM13 task budget expense schedule.

\begin{tabular}{||l|l|l|l|l||}
\hline \hline COST ELEMENT & PRIOR YEARS (\$K) & FY 2002 (\$K) & FY 2003 (\$K) & FY 2004 (\$K) \\
\hline Labor & $\$ 0.0$ & $\$ 186$ & $\$ 0.0$ & $\$ 0.0$ \\
\hline Travel & $\$ 0.0$ & $\$ 11$ & $\$ 0.0$ & $\$ 0.0$ \\
\hline Equipment & $\$ 0.0$ & $\$ 57$ & $\$ 0.0$ & $\$ 0.0$ \\
\hline Supplies/ Materials & $\$ 0.0$ & $\$ 0.0$ & $\$ 0.0$ & $\$ 0.0$ \\
\hline Total & $\$ 0.0$ & $\$ 254$ & $\$ 0.0$ & $\$ 0.0$ \\
\hline
\end{tabular}

Table 3.1-5 SR11NM13 spending plan.

\begin{tabular}{||l|c|c|c||}
\hline & EM-50 FUNDING & EM-40 FUNDING & TOTAL \\
\hline PY-CO & 0 & & 0 \\
\hline October & 0 & 0 & 0 \\
\hline November & 0 & 0 & 0 \\
\hline December & 57 & 0 & 0 \\
\hline January & 36 & 0 & 0 \\
\hline February & 47 & 0 & 0 \\
\hline March & 31 & 0 & 0 \\
\hline April & 32 & 0 & 0 \\
\hline May & 31 & 0 & 0 \\
\hline June & 7 & 0 & 0 \\
\hline July & 5 & 0 & 0 \\
\hline August & 4 & 0 & 0 \\
\hline September & 4 & 0 & 0 \\
\hline FY-CO & 0 & 0 & 0 \\
\hline TOTAL & 254 & & \\
\hline \hline
\end{tabular}




\subsection{AL11NM13}

Table 3.1-6 AL11NM13 task budget expense schedule for SFE.

\begin{tabular}{||l|l|l|l|l||}
\hline \hline COST ELEMENT & PRIOR YEARS (\$K) & FY 2001 (\$K) & FY 2002 (\$K) & FY 2003 (\$K) \\
\hline Labor & $\$ 0.0$ & $\$ 136.0$ & $\$ 220.0$ & $\$ 40.0$ \\
\hline Travel & $\$ 0.0$ & $\$ 14.0$ & $\$ 14.0$ & $\$ 10.0$ \\
\hline Subcontracts & $\$ 0.0$ & $\$ 0.0$ & $\$ 0.0$ & $\$ 0.0$ \\
\hline Supplies/ Materials & $\$ 0.0$ & $\$ 80.0$ & $\$ 36.0$ & $\$ 0.0$ \\
\hline Total & $\$ 0.0$ & $\$ 230.0$ & $\$ 250.0$ & $\$ 50.0$ \\
\hline
\end{tabular}

Table 3.1-7 AL11NM13 task budget expense schedule for neutron moderation.

\begin{tabular}{||l|l|l|l|l||}
\hline \hline COST ELEMENT & PRIOR YEARS (\$K) & FY 2001 (\$K) & FY 2002 (\$K) & FY 2003 (\$K) \\
\hline Labor & $\$ 0.0$ & $\$ 0.0$ & $\$ 106 \mathrm{~K}$ & $\$ 40.0$ \\
\hline Travel & $\$ 0.0$ & $\$ 0.0$ & $\$ 14.0$ & $\$ 10.0$ \\
\hline Subcontracts & $\$ 0.0$ & $\$ 0.0$ & $\$ 0.0$ & $\$ 0.0$ \\
\hline Supplies/ Materials & $\$ 0.0$ & $\$ 0.0$ & $\$ 80.0$ & $\$ 0.0$ \\
\hline Total & $\$ 0.0$ & $\$ 0.0$ & $\$ 200.0$ carryover from FY01 & $\$ 50.0$ \\
\hline
\end{tabular}

Table 3.1-8 AL11NM13 spend plan (\$K) FY-02 (neutron moderation)

\begin{tabular}{|c|c|c|c||}
\hline PY-CO & EM-50 FUNDING & EM-40 FUNDING & Total \\
\hline October & 50 & 00 & 50 \\
\hline November & 50 & 00 & 50 \\
\hline December & 100 & 00 & 100 \\
\hline January & 20 & 00 & 20 \\
\hline February & 20 & 00 & 20 \\
\hline March & 50 & 00 & 50 \\
\hline April & 50 & 00 & 50 \\
\hline May & 20 & 00 & 20 \\
\hline June & 20 & 00 & 20 \\
\hline July & 20 & 00 & 20 \\
\hline August & 20 & 00 & 20 \\
\hline September & 30 & 00 & 30 \\
\hline FY-CO & 0 & 0 & 0 \\
\hline Total & 450 & 0 & \\
\hline
\end{tabular}


Table 3.1-9 AL11NM13 budget summary life cycle cost estimate (\$K) EM-50 funding B\&R code EW4010.

\begin{tabular}{||l|l|l|l|l|l|l|l||}
\hline \hline TOTAL ACT & TO DATE & 2002 & 2003 & 2004 & 2005 & TOTAL & RANGE OF CERTAINTY \\
\hline Task A\&B & 213 & 450 & 100 & 100 & 100 & 963 & $20[+/-\%]$ \\
\hline
\end{tabular}

\subsection{Alignment to Thrust Areas and Key Goals and Priorities}

The technologies being developed as part of these two projects support Thrust 1. This is because the direct interface of the moisture analysis to the stabilization and shipment of material off-site, deployment provides support for closure sites (Rocky Flats) and closure of facilities at Hanford (Plutonium Finishing Plant) and Savannah River. These projects also support the following key EM goals and priorities:

1. Improve safety performance for packaging and storage operations at multiple DOE sites

2. Reduce cost and time required to complete the EM cleanup mission at Rocky Flats, Hanford, and the Savannah River Site (SRS)

3. Deployment will support closure of Rocky Flats by 2006

4. Deployment will support de-inventory of nuclear materials from Rocky Flats, Hanford, SRS, and LANL and consolidate nuclear material out of EM sites by 2004

7. Deployment will reduce EM footprint at Rocky Flats, Hanford, and SRS over the next four years.

\subsubsection{Project Review Results}

The review team recommended that the projects be allowed to complete in FY 2002 as proposed, but that the SRS project switch from SFE to TGA/MS deployment at Savannah River.

\subsubsection{ID02NM11, Technical Assistance}

\subsubsection{Project Overview Results}

DOE Standard DOE-STD-3013 requires moisture measurement to confirm stabilization; however, there are shortcomings with all available methods. Sites needed technical assistance to rapidly review fast-moving development work. They also required technical assistance to analyze technical problems regarding moisture measurement methods. NMFA had an independent review team work with site customers, principal investigators and EM management to determine their issues. High impact technical issues were identified for assessment and efficient analytical teams were formed.

\subsection{Status}

The uranium LOI bias paper that the technical assistance team developed avoided several months of Rocky Flats closure schedule slippage (at the cost of. \$1 million/day). The team provided timely reviews of method development, which allowed TGA-based methods development to meet Rocky Flats site and Hanford Plutonium Finishing Plant closure schedules. The team developed a draft paper on "Process Qualification" technical basis, which defines Rocky Flats site and Hanford Plutonium Finishing Plant process parameters that will eliminate the need to perform moisture measurement on every calcination batch. 
The team wrote the following papers:

Gary Eller (LANL), Jerry Stakebake (RFETS) and Thurman Cooper (Fluor-Hanford), Redox Bias in Loss on Ignition Moisture Measurement for Relatively Pure Plutonium Oxides, LA-UR-01-5315 (5315)

Gary Eller (LANL), Randall Erickson (LANL), Richard Mason (LANL), Technical Basis for Process Qualification of Stabilization of Plutonium-Bearing Oxide Materials, LA-UR-01-6288 (Draft, Rev. 1, January 2002)

Gary Eller (LANL), Technical Basis Bibliography Update for DOE-STD-3013, LA-UR-01-6276

\subsection{Alignment to Thrust Areas and Key Goals and Priorities}

The technical assistance for moisture measurement supports Thrust 1 by providing technical support to meet closure schedules of sites (Rocky Flats) and facilities (Plutonium Finishing Plant at Hanford). Technical assistance also supports the following key EM goals and priorities:

- Stabilizing and consolidating Rocky Flats and Hanford (PFP) materials drives down risk

- Technical assistance work avoids costly Rocky Flats and Hanford (PFP) closure delays

- Provides technical support to meet closure schedules of Rocky Flats and Hanford facility (PFP)

- Enables consolidation of Rocky Flats and Hanford (PFP) nuclear materials to SRS

- Technical assistance provides Rocky Flats and Hanford (PFP) with technical solutions to reduce EM footprint

\subsubsection{Project Review Results}

The review team commended the technical assistance team on their moisture measurement efforts in FY 2002. They recommended that moisture measurement technical assistance continue in FY 2003 as needed if User Site pull exists.

\subsection{Packaging, Transportation and Storage Product Line}

The Packaging, Transportation, and Storage Product Line addresses technology needs for nuclear material packages, packaging, storage and transportation processes, and technical assessments of potential failure scenarios during packaging, storage or transport.

The projects within the Packaging, Transportation, and Storage Product Line are listed in table 3.2-1. Three of these projects, OH11NM21, AL11NM22 and AL21NM21 are closely related, in that they are all dealing with different aspects of the automation work for Fernald. 
Table 3.2-1 Packaging, Transportation and Storage FY 2002 projects.

\begin{tabular}{||l|l|l||}
\hline $\begin{array}{l}\text { TECHNICAL TASK PLAN } \\
\text { (TTP) }\end{array}$ & PROJECT TITLE & $\begin{array}{l}\text { THRUST AREAS - } \\
\text { SITE IMPACTED }\end{array}$ \\
\hline OH11NM21 & Fernald Drum Handling System Project & $\begin{array}{l}1 \text { (Fernald) } \\
2\end{array}$ \\
\hline AL11NM22 & $\begin{array}{l}\text { Automated Packaging of Nuclear Materials LANL } \\
\text { Engineering \& Support-Robotics }\end{array}$ & $\begin{array}{l}1 \text { (Fernald) } \\
2\end{array}$ \\
\hline AL21NM21 & Automated Packaging of Nuclear Material-Robotics & $\begin{array}{l}1 \text { (Fernald) } \\
2\end{array}$ \\
\hline OR01NM21 & Alpha Radiolysis Studies for U-233 Oxides & $\begin{array}{l}1 \text { (Rocky Flats) } \\
2\end{array}$ \\
\hline
\end{tabular}

\subsubsection{Fernald Automation Projects (OH11NM21, Fernald Drum Handling System Project; AL11NM22, Automated Packaging of Nuclear Materials LANL Engineering and Support-Robotics; AL21NM21, Automated Packaging of Nuclear Material- Robotics)}

\subsubsection{Project Overview}

The overall, automated packaging of nuclear materials program, predominantly focusing on the needs of the Fernald site, consists of three related projects: AL11NM22, Automated Packaging of Nuclear Materials - LANL Engineering Design; AL21NM21, Fernald Drum Handling Project Enhancement (Sandia National Laboratories); and, OH11NM21, Fernald Repackaging System / Drum Handling System (at Fernald). The overall program is divided into three segments to allow for separate funding of work at the three sites, Sandia National Laboratories, Los Alamos National Laboratory, and Fernald Environmental Management Project (FEMP), respectively.

These are joint efforts between the FEMP, Uranium Management Division Oak Ridge Operations (UMD-ORO) and the NMFA to cooperatively accelerate closure of the FEMP site by developing and deploying improved technology for the processing of FEMP nuclear materials. The overall goal cooperative effort is to disposition the entire inventory of nuclear materials from Fernald. The disposition of approximately 586 containers (137 metric tons) of low-enriched uranium (LEU) metal is critical to the FEMP plan for accelerated site closure.

Project OH11NM21 will contribute to the design, construction, and operation of a LEU Dry Powder Blending Pilot Plant (Module 3) at Nuclear Fuel Services (NFS). Project AL11NM22 provides funding for Los Alamos National Laboratory, to provide conceptual design support and non-destructive assay (NDA) expertise to NFS and FEMP. After the work is completed at FEMP, this technology or a scale-up of this technology could support deinventorying uranium materials at other DOE sites (Hanford, Paducah, SRS, OR). Project AL21NM21 will integrate drum handling enhancement technologies into baseline operations, as appropriate, to support FEMP operations and closure schedules.

\subsubsection{Scope}

The primary focus of these projects is to design, construct, and operate a pilot plant with improved material processing capabilities (frequently referred to as module 3 ). The technology and experience gained from developing and deploying the material processing pilot plan is expected to have direct benefit when transferred to other sites across the DOE complex by resulting in the beneficial reuse of uranium. 


\subsection{Technical Solution}

\section{Automated Dry Powder Blending Technology for Nuclear Materials}

Nuclear Fuel Services (NFS) is tasked to define the engineering criteria for a pilot-scale materials processing (thermal oxidation) and dry powder-blending capability for LEU materials from FEMP, to be implemented at their site in Erwin, Tennessee. In support of the powder blending engineering design process, Los Alamos National Laboratory will contribute expertise in uranium processing and powder handling along with recommendations for nondestructive assay (NDA) measurements and technology. The overall goal is to assess the design basis of the dry powder blending operation to ensure successful operation from a process engineering perspective along with providing state-of-the-art expertise in NDA instrumentation and methods for at-line and/or on-line nuclear material assays. Previously developed technologies will be adapted and matured to address these needs.

\section{Fernald Drum Handling Project Enhancement - Engineering Design}

Successful implementation of the dry powder blending technology as a key disposition path for Fernald is linked to the need to provide automation enhancements to existing, manual nuclear material drum inspection, processing, and repackaging lines at Fernald, as addressed in TTP AL21NM21, Fernald Drum Handling Project Enhancement, as conducted by Sandia National Laboratories. Los Alamos National Laboratory will contribute process engineering expertise and support for the automation enhancements described in TTP AL21NM21. Specifically, LANL will support the Sandia National Laboratories' design, integration, and deployment tasks in the areas of uranium handling, Authorization Basis as it relates to the overall system design, and other specific tasks as defined during the testing and support of the system at Fernald.

This project also addresses automation enhancement functions related to uranium waste drum handling at the Fernald site. The equipment and processes developed will provide assistance and enhancement to the existing, manual operations being performed at the site. The work will be performed in conjunction with Los Alamos National Laboratory and the FEMP to best address the needs of the drum handling personnel and site management. Attention is focused on mitigating mechanical and radiological hazards and on workload reduction (throughput).

Fiscal Year 2002 activities are directed toward drum venting, opening, and draining activities. A control system will be integrated with the site-wide material information database in order to improve process control and records keeping functions.

Development Platform - A subset of the equipment intended for use at the Fernald site will be accumulated at Sandia National Laboratories. This equipment will be used to validate and integrate system components for deployment at Fernald. A full set of hardware will not be procured, only those items required to test and integrate the systems developed at Sandia.

Control System - This activity develops an integrated control package for the existing, manual Drum Handling System inspection, processing and repackaging lines at Fernald. A supervisory computer and associated software will be developed to integrate process control, operator interface, data package accumulation, and communication with the site's electronic data handling facilities (the Fernald SiteWide Waste Information Forecasting and Tracking System, SWIFTS). This integrated process and data control system will be deployed at the Fernald site.

Control System Upgrade - The control system will be deployed as early as practical in order to maximize benefit at the site. Some capabilities and refinements will not be available in the first version. 
This task encompasses follow-on additions and improvements that will occur throughout the remainder of the project.

Additive Feed System - Dry additives will be required to stabilize some of the materials for shipment. A feed system for dry additives will be developed to support addition of metered quantities of dry materials to the drums. The specific materials to be handled will be defined by the site. Sandia will provide a conceptual design to Fernald.

Drum Venting, Purging, and Opening- A variable number of overpack drums must be vented, possibly purged, and then opened in order to access the material contents. Opening the drums manually is a difficult and time-consuming operation. This activity will focus on providing automated assistance to the opening procedure. Full automation of this function for all drum cases is not likely. The intent is to provide the operator with significant assistance at a minimum investment. The drum venting, purging, and opening system will be demonstrated at Sandia and transferred to the Fernald site.

Drum Draining - Some of the drums on site contain liquids, primarily water. In many cases the liquids can be removed by suction from the top opening of the drum. Certain material groups are expected to preclude direct physical access from the top of the drum. This task will pursue techniques to remove the liquids from these drums. . The drum draining techniques will be demonstrated at Sandia and transferred to the Fernald site.

Thermal Monitoring - The storage drums at Fernald must be monitored thermally during activity and for 24 hours afterwards. Automated thermal monitoring will be investigated and, if practical, integrated into the process control system.

Deployment Support - Facilitate transfer of technology and integration into the site environment. This tasks covers transportation and labor costs associated with deployment, testing, and support of the system at the Fernald site.

\subsection{Status}

The project accomplishments are listed below:

\section{Dry Powder Blending}

- FEMP Baseline Project modified, with major focus on Module 3 Pilot Plant, 7/01

- Drafted Pilot Plant Design Basis Document, 7/01

- Successful completion of Material Blending Proof of Concept, at NFS, 10/01

- LANL and NFS signed Non-disclosure Agreement, 12/01 (proprietary info)

\section{Drum Handling}

- Demonstration of Intelligent Drum-Puncturing System at SNL, 9/25/01. Technology Summary Sheet and Technology Safety Data Sheet prepared

- Report "Needs Assessment at FEMP, With Respect to MERLIN," 11/01, (documents multiple FEMP baseline changes in project scope, 2001) 


\subsubsection{Funding}

\section{Drum Handling}

TTP OH11NM21

FY02 Funding: $\$ 1,000,000$

Table 3.2-2 OH11NM21 FY02 spend plan (x \$1,000)

\begin{tabular}{||l|l|l|l|l|l|l|l|l|l|l|l||}
\hline OCT & NOV & DEC & JAN & FEB & MAR & APR & MAY & JUN & JUL & AUG & SEPT \\
\hline 50 & 50 & 100 & 100 & 100 & 100 & 100 & 100 & 100 & 80 & 80 & 40 \\
\hline
\end{tabular}

FY03 Funding: $\$ 1,100,000$

FY04 Funding: $\$ 580,000$

\section{TTP AL21NM21}

Financial Planning Information:

Table 3.2-3 AL21NM21 BCWS (FY 2002 spend plan)

\begin{tabular}{||l|l|l|l|l|l|l|l|l|l|l|l|l||}
\hline OCT & NOV & DEC & JAN & FEB & MAR & APR & MAY & JUN & JUL & AUG & SEPT & TOTAL \\
\hline 35 & 40 & 40 & 50 & 60 & 50 & 40 & 30 & 20 & 15 & 10 & 10 & 400 \\
\hline
\end{tabular}

Table 3.2-4 AL21NM21 spend plan by work element.

\begin{tabular}{||l|l|l||}
\hline WORK ELEMENT A.1 & SNL DEVELOPMENT PLATFORM & $\$ 40 \mathrm{~K}$ \\
\hline Work Element A.2 & Control System & $\$ 150 \mathrm{~K}$ \\
\hline Work Element A.3 & Additive Feed System & $\$ 40 \mathrm{~K}$ \\
\hline Work Element A.4 & Drum Venting/Purging/Opening & $\$ 75 \mathrm{~K}$ \\
\hline Work Element A.5 & Drum Draining & $\$ 30 \mathrm{~K}$ \\
\hline Work Element A.6 & Thermal Monitoring & $\$ 25 \mathrm{~K}$ \\
\hline Work Element A.7 & Deployment support & $\$ 40 \mathrm{~K}$ \\
\hline TOTAL & & $\$ 400 \mathrm{~K}$ \\
\hline
\end{tabular}




\section{Dry Powder Blending (TTP AL11NM22)}

Budget Summary:

FY02 Funding: \$200K Total for TTP AL11NM22

Table 3.2-5 AL11NM22 FY 2002 funding request.

\begin{tabular}{||l|l|l|l|l||}
\hline $\begin{array}{l}\text { Site } \\
\text { Code }\end{array}$ & B/R Code & Prior Yr & $\begin{array}{l}\text { Current } \\
\text { Year }\end{array}$ & $\begin{array}{l}\text { Total } \\
\text { Funding }\end{array}$ \\
\hline LANL & EW4010 & 75 & 200 & 200 \\
\hline
\end{tabular}

FY02 Spend Plan: \$200K Total

Table 3.2-6 AL11NM22 FY2002 spend plan.

\begin{tabular}{|l|l|l|l|l|l|l|l|l|l|l|l||}
\hline OCT & NOV & DEC & JAN & FEB & MAR & APR & MAY & JUN & JUL & AUG & SEPT \\
\hline 15 & 15 & 15 & 16 & 19 & 19 & 15 & 16 & 16 & 18 & 18 & 18 \\
\hline
\end{tabular}

Table 3.2-7 AL11NM22 out year spend plan (projected).

\begin{tabular}{||l|l|l|l|l||}
\hline \hline FISCAL YEAR & 2003 & 2004 & 2005 & ALL SUBSEQUENT \\
\hline TTP Amount & 200 & 200 & 0 & 0 \\
\hline
\end{tabular}

\subsubsection{Alignment to Thrust Areas and Key Goals and Priorities}

The dry powder blending and the drum handling projects support Thrust 1 by directly providing FEMP Closure Site with technical support. They also support Thrust 2 because they are developing alternative approaches to high risk baseline (materials processing and disposition, and automation enhancements).

The projects also support the following key EM goals and priorities:

1. Improves FEMP safety performance

2. Reduces time required to complete EM cleanup mission

3. Helps close Fernald by 2006

4. Helps consolidate nuclear material out of FEMP way before 2006

7. Shrink the EM (Fernald) footprint

9. Reshapes EM systems and infrastructure to drive accelerated cleanup and closure 


\subsubsection{Project Review Results}

The review team recommended that the Fernald Repackaging System (OH11NM21) continue in FY 2002, and continue into FY 2003, if User Site pull exists and appropriate co-funding is provided.

The review team recommended that Automated Packaging-Robotics (AL21NM21) and Automated Packaging - LANL Engineering \& Support (AL11NM22) continue in FY 2002 and continue into FY 2003 if User Site pull exists.

\subsubsection{OR01NM21, Alpha Radiolysis Studies for ${ }^{233} \mathrm{U}$ Oxides}

\subsubsection{Project Overview}

Radiolytically generated gas data is needed to show that containment design integrity is safe, not compromised, for safe storage of ${ }^{233} \mathrm{U}$ oxides. Alpha radiolysis studies are providing gas laboratory data (such pressure increases, and composition, as a function of the amount of water or impurities). The data will support multi-site needs on long-term storage and transportation packaging for ${ }^{233} \mathrm{U}$ oxides. The data will be used to establish technical basis for the ${ }^{233} \mathrm{U}$ storage standard (DNFSB 97-1). Using this data as a basis will enable sites to reduce the unnecessary handling operations, costs, and risks to worker safety, and will facilitate certification efforts for uranium and plutonium transportation packages.

\subsubsection{Scope}

Alpha radiolysis studies of ${ }^{233} \mathrm{U}$ oxides will provide needed data [i.e., pressure changes and gas composition, as a function of the water content and of other impurities (e.g., fluorides)] to understand the long-term radiolytic behavior of these materials and to support on-going modeling efforts. The data will support multi-site needs on long-term storage, transportation, and packaging of actinide oxides, and it will be used in establishing the technical basis for a ${ }^{233} \mathrm{U}$ storage standard. Alpha radiolysis experiments initiated in FY01 will be continued. Tasks will include monitoring of sample pressures, periodic gas sampling and analysis, and initiation of additional samples as results direct. This may include adjustment in moisture levels to further the investigation on the effect of the amount and types of water (i.e., hydrate, hydroxide, and absorbed) present on the oxide surface.

Planning for the safe storage of ${ }^{233} \mathrm{U}$ oxides must include an experimental basis for demonstrating that radiolytically generated gases do not exceed container design pressures or produce conditions (either corrosive or explosive) that might compromise the integrity of the containment. This radioactivity comes both as gamma (mainly from the decay of ${ }^{232} \mathrm{U}$ daughters often present in small amounts with the ${ }^{233} \mathrm{U}$ isotope) and as alpha (from the decay of the ${ }^{233} \mathrm{U}$ itself). Gamma radiolysis experiments have been performed on uranium oxides to demonstrate the effects on residual fluoride impurities in the oxides and on sorbed water. Similar studies are needed to demonstrate the effect of alpha radiation in these systems, and such studies were initiated during FY01. Sample containers of uranium oxides and uranium oxyfluorides, each spiked with ${ }^{244} \mathrm{Cm}$ as the alpha source, were loaded and pressure monitoring was initiated. The results of this proposed work could be used to address DOE complex-wide needs to understand and model radiolysis for both storage and transportation of radioactive materials - in particular, for uranium and plutonium oxides.

The data provided by the proposed work will be used in the technical basis for the ${ }^{233} \mathrm{U}$ storage standard and such data are also important in understanding the behavior of other actinide oxides. The DNFSB expects to see such data to clearly establish requirements for ${ }^{233} \mathrm{U}$ storage. If such data are not available, overly conservative criteria will be applied and, as a result, materials may be unnecessarily opened, treated, and repackaged. Such operations increase risk to personnel and result in higher cost. 
Additionally, data obtained by this work will broaden the understanding of radiolysis in these types of systems, which is important not only to storage but also to transportation. Consequently, these experiments will impact ongoing efforts across the complex (e.g., at Los Alamos and Savannah River) to establish storage and transportation requirements with respect to radiolysis. An effort is underway at LANL to develop models of radiolysis for both storage and transportation. Data from the proposed experiments will provide valuable input into such model development, by providing a means to benchmark and validate the models.

\subsection{Technical Solution}

Alpha radiolysis studies of ${ }^{233} \mathrm{U}$ oxides will be preformed by spiking uranium oxides and uranium oxyfluorides with ${ }^{244} \mathrm{Cm}$ and monitoring the sample pressure as a function of time. The samples will contain different amounts of water to provide insight on the effect of water content on radiolytic gas generation. Results from these tests will be used to further the understanding of the radiolytic behaviour of impurities (e.g., water and fluorides) in uranium oxides that are placed into long-term storage. This work will directly support a defined NMFA technology need at ORNL, ORNM-01 Alpha Radiolysis Studies, with PBS OR-331. The data generated by this work will be used as part of the ongoing effort to update storage standards for radioactive materials and to improve models on radiolytic gas generation. Additionally, during FYO1 a concern was raised about moisture measurement techniques for mixed $\mathrm{Pu}-\mathrm{U}$ oxides that had been stabilized for storage. The data from these alpha radiolysis experiments will address concerns about residual moisture on these types of materials, as well.

Activities during FY 2002 will include the continued monitoring of sample pressures and periodic sampling of gases. The continuation of these experiments into FY 2002 may result in the establishment of a pressure plateau, as has been done in the gamma radiolysis experiments. Short-term, relatively low dose experiments provide information on initial G-values. However, longer-term, higher dose experiments, such as those proposed, are required to establish the radiolytic behavior that may ultimately be achieved in storage conditions. Based on results from the experiments initiated in FY 2001, experiments for selected samples may be repeated or water-loading levels may be varied-allowing for the study of the effects of the amount and type (i.e., hydrate, hydroxide, adsorbed) water. Additionally, the accumulation of experimental evidence indicates that back-reaction mechanisms play a dominant role in limiting net radiolytic yields. Such mechanisms will be a focus during this FY. The experiments currently underway will be a key factor in the elucidation of the back-reaction mechanism.

The experiments will be concluded during FY 2002. Solid samples may be analyzed (e.g., valence and structure changes), as appropriate. Experimental equipment will be disassembled and disposed. Expected outcomes of this effort include a measurement of the rate (i.e., G-value) and amount of gas generation, and also identification of the composition of the gases produced. Additionally, a pressure plateau may be demonstrated, thereby establishing a damage limit for the material being studied. Measurement of these types of parameters can be directly used in establishing requirements for the safe storage of ${ }^{233} \mathrm{U}$. Such parameters also serve as important input to the ongoing modeling effort currently under way at other DOE sites. Periodic reports on project status will be prepared and presented to include monthly reports and a final project report.

\subsection{Status}

In FY 2002, the project is monitoring the gases from uranium samples. 


\subsection{Funding}

Table 3.2-8 OR01NM21 budget summary: (including \$61K carryover into FY 2002)

\begin{tabular}{||l|l|l|l||}
\hline COST ELEMENT & PRIOR YEARS & FY 2002 & FY 2003 \\
\hline Labor & 178 & 200 & 40 \\
\hline Travel & 5 & 6 & 5 \\
\hline Subcontracts & 11 & 30 & \\
\hline Supplies/Materials & 18 & 25 & \\
\hline TOTAL & 212 & 261 & 45 \\
\hline
\end{tabular}

Table 3.2-9 OR01NM21 life cycle cost estimate (\$K)

\begin{tabular}{||l|l|l|l|l|l|l|l||}
\hline & 2001 & 2002 & 2003 & 2004 & 2005 & TOTAL & $\begin{array}{l}\text { RANGE OF } \\
\text { CERTAINTY }\end{array}$ \\
\hline EM-50 Funding B\&R Code: EW4010 & 212 & 261 & & & & & \\
\hline TOTAL & 212 & 261 & 45 & & & 518 & {$[+/-20 \%]$} \\
\hline Co-Funding B\&R Code: None & & & & & & & \\
\hline TOTAL & & & & & & 0 & \\
\hline
\end{tabular}

Table 3.2-10 OR01NM21 spend plan (FY 2002 \$K).

\begin{tabular}{||l|l|l||}
\hline & NMFA FUNDING & JOINT FUNDING \\
\hline PY-Carry Over & 61 & 0 \\
\hline October & 10 & 0 \\
\hline November & 15 & 0 \\
\hline December & 15 & 0 \\
\hline January & 22 & 0 \\
\hline February & 22 & 0 \\
\hline March & 23 & 0 \\
\hline April & 25 & 0 \\
\hline May & 25 & 0 \\
\hline June & 25 & 0 \\
\hline July & 25 & 0 \\
\hline August & 25 & 0 \\
\hline September & 29 & 0 \\
\hline FY-CO & 0 & 0 \\
\hline TOTAL & 261 & 0 \\
\hline
\end{tabular}

Co-Funding: 0 
Basis of Estimate: The estimate is based on the amount of funding required for scientific and technical staff to perform laboratory tests and subsequent analyses. The estimate includes the cost of materials, samples preparation, support services, and chemical analysis. Funds are included for the project administration (which is estimated cost about $\$ 20 \mathrm{~K}$ ).

\subsection{Alignment to Thrust Areas and Key Goals and Priorities}

The project supports Thrust 1, Closure Site Support, by addressing a gas generation need identified by the Rocky Flats closure site. The project also supports the following key EM goals and priorities:

1. Improve safety performance by providing the gas data needed to establish technical basis for the ${ }^{233} \mathrm{U}$ storage standard, reducing unnecessary handling operations, costs, and risks to worker safety

3. Help accelerate the closure of Rocky Flats by 2006

4. Help consolidate nuclear materials out of Rocky Flats by 2006

\subsubsection{Project Review Results}

The review team recommended that the project continue and be funded to complete in FY 2003 as planned. Any future funding beyond the current planned scope should be pursued under Basic Science.

\subsection{Material Processing Product Line}

The Material Processing Product Line addresses the technology needs of sites holding or processing these materials so that they can be stabilized. In addition, the Product Line addresses a variety of orphan materials that require processing so that they can meet acceptance requirements of other facilities, such as K-area at the Savannah River Site (SRS) or the Waste Isolation Pilot Plant, for interim or final disposition.

The projects within the Material Processing Product Line are listed in table 3.3-1.

Table 3.3-1 Material Processing Product Line FY 2002 projects.

\begin{tabular}{|c|c|c|}
\hline $\begin{array}{l}\text { TTP } \\
\text { NUMBER }\end{array}$ & PROJECT TITLE(S) & $\begin{array}{l}\text { THRUST AREA -SITES } \\
\text { IMPACTED }\end{array}$ \\
\hline RL-31-NM-11 & $\begin{array}{l}\text { Optimal Plutonium Precipitation For } \\
\text { Stabilization }\end{array}$ & 2 - Hanford \\
\hline RL-31-NM-13 & High-Chloride Content in Plutonium Oxides & 2 - Hanford \\
\hline HQ-06-T2-22 & $\begin{array}{l}\text { Porous Crystalline Matrix (Gubka) for } \\
\text { Stabilizing Problematic Laboratory Solutions }\end{array}$ & $\begin{array}{l}1 \text { - Fernald, RFETS } \\
2 \text { - INEEL }\end{array}$ \\
\hline FT-01-AR-01 & $\begin{array}{l}\text { Nuclear Isotopic Dilution of Highly Enriched } \\
\text { Uranium by Dry Blending via the RM-2 Mill } \\
\text { Technology }\end{array}$ & 2 - INEEL \\
\hline SR-11-NM-12 & $\begin{array}{l}\text { Prevention of the Precipitation of } \\
\text { Unwanted Solids }\end{array}$ & SRS \\
\hline
\end{tabular}




\subsubsection{SR11NM12, Prevention of Precipitation of Unwanted Solids During Canyon Dissolution}

\subsubsection{Project Overview}

As the processing of typical materials is being completed in the canyons at Savannah River, some unusual nuclear materials are being targeted for stabilization. Many of these materials are difficult to dissolve or require more aggressive conditions in order to dissolve them (e.g., some fluoride salts are insoluble). Precipitation of unwanted solids results in operational and criticality safety issues and costly delays.

This project's approach to the problem of unwanted solids is to collect fundamental data for plant species (e.g., $\mathrm{KBF}_{4}, \mathrm{HgF}_{2}, \mathrm{PuF}_{4}$, and $\mathrm{H}_{\mathrm{F}}$ ). Then this data is incorporated into an established computer model in order to predict chemical speciation and conditions that avoid precipitation. These will improve process efficiency by avoiding solid analysis and increase safety by improved understanding of solution stability.

\subsubsection{Scope}

The precipitation of unwanted solids during the aqueous processing of EM nuclear materials at the Savannah River Site (SRS) results in costly schedule delays to identify and eliminate solids. The build-up of solids in process equipment is undesirable from a process efficiency and safety standpoint. The SRS Canyon facilities were designed to dissolve and process spent nuclear fuel and targets. As the processing of typical materials is completed, unusual and exotic nuclear materials (e.g., materials that are unirradiated, heterogeneous, or contain atypical materials) from various sites are being targeted for stabilization. These unusual materials are often difficult to dissolve using historical flow sheet conditions, and require more aggressive dissolver solutions (e.g., high fluoride concentrations).

The purpose of this work ultimately is to prevent precipitation of undesirable solids in aqueous process solutions. To improve the accuracy of established computer models that predict the formation of unwanted precipitates, fundamental data for solid salts are needed. The needed data includes solubility, activity coefficients, and solubility products that were determined at ionic strengths expected in process solutions.

\subsection{Technical Solution}

The objective of the project is to incorporate activity coefficients into the speciation program that has been developed to calculate individual component concentrations in acidic aqueous fluoride systems. This will enable accurate predictions of solubilities of potentially precipitating species in plant solutions and provide the ability to calculate solution adjustments to assure stability. In order to do this, solubility and activity coefficient data must be fitted to a suitable activity coefficient model and its parameters determined. Then, the fitted model can be used to calculate the activity coefficients for process solution compositions.

Determine solubilities of the redox stable thorium (IV) fluoride as functions of ionic strength.

Plutonium (IV) fluoride is a potential precipitate in plant process solutions that contain high fluoride concentrations. Review of the plutonium literature indicates that it will be impractical to determine the activity coefficients for plutonium (IV) fluoride because the +4 oxidation state will be 
difficult to control in the simplified system (neutral $\mathrm{pH}$, no stabilizing ligands). The plutonium (IV) will certainly disproportionate to other oxidation states. Our practical resolution to this issue is to use oxidation state analogs, and thorium (IV) appears to be the best analog for plutonium (IV). Thorium (IV) fluoride will be used to simulate plutonium (IV) fluoride solubility as a function of ionic strength. Activity coefficients determined from thorium (IV) fluoride solubility data will be corrected using the Born equation to estimate plutonium (IV) activity coefficients. The solubility measurement will be performed according to the procedure developed for $\mathrm{KBF}_{4}$ in $\mathrm{FY} 01$.

Design experimental approach and setups to measure activity coefficients of $\mathrm{HF}$ in $\mathrm{HNO}_{3}$ solutions

Hydrofluoric acid (HF) is an important reactant in plant solutions that participates in fluoride complexation reactions and metal fluoride precipitating reactions. Literature data indicate that the activity coefficients of $0.1 \mathrm{M} \mathrm{HF}$ increases dramatically in nitric acid solutions greater than 1.8 molar. For the characterization of Canyon solutions containing HF. The HF activity coefficient effects will be vital to development of our model for the prevention of the precipitation of unwanted solids in the Canyons.

To determine activity coefficients of HF as s function of ionic strength, we propose a careful quantitative study in which the partial vapor pressure of HF is measured over solutions of varying HF and $\mathrm{HNO}_{3}$ concentrations. At the pressures observed in literature reports, polymer vapor species of $\mathrm{HF}$ are negligible and only the monomer needs to be considered in the vapor pressure measurements. The partial vapor pressure measurement of HF will be made either by infrared spectroscopy or by a transpiration method, and the activity of HF in the solutions will be calculated.

In conjunction with determination of the activity coefficients of HF, the amperometric response of the HF-selective electrode would be measured to obtain a correlation with HF activity. This will advance the technology for use of the electrodes for studying aqueous fluoride systems and in characterizing HF concentrations in plant solutions. For example, they have proven useful in determining metal fluoride complexation constants for sequential complexation reactions, using the N-bar method. In addition, the HF-selective electrode has been used to monitor and control nuclear fuel dissolution process solutions at the INTEC and are currently being similarly used at the BWX Technologies plant in Lynchburg, Virginia. By incorporating HF activity coefficient effects, the versatility and usefulness will be enhanced. Once the effects are known, the electrodes could, for example, be used to measure HF activities and activity coefficients in acidic solutions.

$\underline{\text { Calculate activity coefficients of plutonium (IV) fluoride as functions of ionic strength }}$

Calculation will be performed in order to determine the activity coefficients of plutonium (IV) fluoride. The experimentally determined solubilities of thorium (IV) fluoride will be used to calculate activity coefficients. The thorium fluoride activity coefficients will be corrected using the Born equation to give plutonium (IV) fluoride activity coefficients. These activity coefficient data will be incorporated into activity coefficient models for mixed electrolyte systems

Derive thermodynamic parameters that can be incorporated into a free energy minimization program to enable calculation of the equilibrium condition for a specified plant solution

The calculational program will designed, developed, and updated with the activity coefficients of $\mathrm{HF}$, plutonium (IV) fluoride, and $\mathrm{KBF}_{4}$. This program will calculate the equilibrium position for a given starting dissolver solution composition. The activity coefficients calculated from the model fitted to the experimental solubility data will be inputted for the applicable species at the ionic strength of the system being evaluated. Then, the solution stability can be evaluated. Solution compositions can be varied to determine the concentration limit at which precipitation will begin in a dissolver solution. 


\subsection{Status}

$\underline{\mathrm{KBF} 4}$

For the $\mathrm{KBF}_{4}$ system, experimental conditions were selected for developing Pitzer activity coefficient ion interaction parameters for multielectrolyte systems. The needed solubility data have been collected for $\mathrm{KBF}_{4}$ solutions, and activity coefficients have been derived for $\mathrm{KBF}_{4}$ in $\mathrm{NaNO}_{3}$ ionic strength adjuster solutions from provisional solubility data. They identified some anomalous behavior of crystalline $\mathrm{KBF}_{4}$, in that it may be slow to equilibrate or may change into its amorphous form. They also discovered unknown issues for boron analyses, and experiments are underway to resolve biases and matrix effects, and to identify any implications. A manuscript will be presented at the Waste Management '02 conference, to be held in Tucson February 24-28, 2002.

$\underline{\mathrm{HF}}$

For the HF system, effect of HNO3 on activity coefficients of HF under SRS plant conditions was identified. Incorporation of HF activity coefficients into the model will lead to a more generally useful model. Also, an experimental approach/design to measure HF activity coefficients was developed

The technical maturity of these systems are exploratory - advanced development.

\subsection{Funding}

Budget Summary for Total Task:

Table 3.3-2 SR11NM12 total TTP budget expense schedule.

\begin{tabular}{||l|l|l||}
\hline COST ELEMENT & PRIOR YEARS (\$K) & FY 2002 (\$K) \\
\hline Labor & $\$ 89.5$ & $\$ 148$ \\
\hline Travel & $\$ 4$ & $\$ 3$ \\
\hline Subcontracts & $\$ 65.5$ & $\$ 109$ \\
\hline Supplies/ Materials & $\$ 9$ & $\$ 15$ \\
\hline Total & $\$ 168$ & $\$ 275$ \\
\hline
\end{tabular}

Table 3.3-3 SR11NM12 spending plan for total task.

\begin{tabular}{||c|c|c|c|c|c|c|c|c|c|c|c|c||}
\hline \hline MONTH & OCT & NOV & DEC & JAN & FEB & MAR & APR & MAY & JUN & JUL & AUG & SEPT \\
\hline$(\$ K)$ & 3 & 21 & 15 & 33 & 15 & 33 & 16 & 35 & 16 & 35 & 16 & 37 \\
\hline
\end{tabular}

\subsubsection{Alignment to Thrust Areas and Key Goals and Priorities}

This project aligns to the following key EM goals and priorities: 
1. Improved safety performance. This project will eliminate concerns about unwanted precipitates that may affect criticality safety basis

2. Reduce cost and time required to complete the EM cleanup mission by providing boundary parameters for potential flowsheets, and by making flowsheet development more efficient

\subsubsection{Project Review Results}

The review team recommended that this project be allowed to complete in FY 2002, and recommended that any future funding should be pursued under Basic Science.

\subsubsection{RL31NM13, Single Step Distillation Process for Plutonium Oxides Containing Chlorides}

\subsubsection{Project Overview}

There are approximately 1000 items of high-chloride plutonium oxide materials that require stabilization at the Plutonium Finishing Plant in order to meet DOE-STD-3013 storage criteria. The chlorides volatilize at the stabilization temperatures and the resulting off gas can cause extensive corrosion damage to the furnace components. The baseline technology is to wash the chlorides away from the oxide matrix, and is labor intensive resulting in high radiation dose to workers.

This project is to design and build a furnace system that can control and capture volatile chloride salts during stabilization, and to demonstrate the furnace system in a non-radioactive environment.

\subsection{Scope}

An inventory of approximately 1000 high chloride salt bearing plutonium oxide items at PFP must undergo thermal stabilization processing to meet DOE 3013 Standards. The existing technology to process these items involves washing to remove the salts, drying the washed solids on a hot plate, followed by thermal stabilization in the muffle furnace. This would require the installation of a chloride wash system to treat the high chloride plutonium. Although the existing technology provides high confidence for achieving DOE Standard 3013 requirements, it requires multiple handling, transfers, and processes that are operator intensive. This is significant because qualified operators are a limiting resource and consequently this represents the schedule limiting aspect for PFP plutonium stabilization. More importantly, the reduced operator effort will translate directly into reduced dose (ALARA). This testing may demonstrate a potential resolution for the Hanford STCG Need Number RL-01-014-NM, "Chloride Wash Process to Pretreat Feed to Thermal Stabilization."

\subsection{Technical Solution}

PNNL has proposed an engineered approach using distillation of volatile salts because it would allow a single-step process. The key design feature is that the off-gas salts must be contained and removed with a simple and robust process. The proposed system will contain and remove the volatile chloride salts to prevent deleterious effects to the muffle furnace, process ventilation off gas, and vacuum systems. A molten salt resistant metal (Haynes HR-160) has been identified and test coupons have been obtained for other potential materials.

For this test system, vapor will be drawn from a boat with a loose fitting lid. The boat will be made from a ceramic material and will include a cover and an opening for the off-gas tube. The boat and lid 
will slide on to the fixed off gas pipe located in the muffle furnace. Vacuum will be drawn on the boat from the suction side of a blower. The lid and vent connections to the boat will be loose to allow gas flow from the furnace chamber to the boat interior. The off-gas pipe will be routed to the back of the muffle furnace and then routed to the quench chamber. In the quench chamber the off-gas containing salt vapors will be quenched to a gas temperature below $300^{\circ} \mathrm{F}$. This will condense and precipitate the salt vapors. The vapor will then be filtered and bubbled through water to capture any $\mathrm{HCl}$ or salts.

\subsection{Status}

The design, fabrication and installation of the test system has been completed. Two proof-ofconcept tests have shown that corrosion does not appear to be a problem. Chemical analysis is in progress. So far, the non-radioactive system has been demonstrated. The project maturity is in the advanced engineering stage.

\subsection{Funding}

Table 3.3-4 RL31NM13 budget summary.

\begin{tabular}{||l|l|l|l|l|l||}
\hline $\begin{array}{l}\text { B\&R } \\
(\$ K)\end{array}$ & FY01 CO & FY02 & FY03 & FY04 & ALL FOLLOWING YRS \\
\hline EW4010 & 25 & 50 & 0 & 0 & 0 \\
\hline
\end{tabular}

Table 3.3-5 RL31NM13 spending plan (\$K).

\begin{tabular}{||c|c|c|c|c|c|c|c|c|c|c|c|c||}
\hline OCT & NOV & DEC & JAN & FEB & MAR & APR & MAY & JUN & JUL & AUG & SEP & TOTAL \\
\hline 10 & 10 & 7 & 10 & 10 & 3 & 0 & 0 & 0 & 0 & 0 & 0 & 50 \\
\hline
\end{tabular}

\section{CO-FUNDING}

No cofunding.

Table 3.3-6 RL31NM13 budget spending plan (\$K).

\begin{tabular}{||l|l|l|l|l|l|l|l|l|l|l|l|l|l|l|l||}
\hline \hline OCT & NOV & DEC & JAN & FEB & MAR & APR & MAY & JUN & JUL & AUG & SEP & $\begin{array}{l}\text { FY02 } \\
\text { TOTAL }\end{array}$ & FY03 & FY04 & TOTAL \\
\hline 10 & 10 & 5 & 10 & 8 & 7 & 0 & 0 & 0 & 0 & 0 & 0 & 50 & 0 & 0 & 50 \\
\hline
\end{tabular}

\subsection{Alignment to Thrust Areas and Key Goals and Priorities}

This project supports Thrust 2, Baseline Alternatives, because it eliminates the baseline unit operation (aqueous wash) for high-chloride plutonium oxide materials by an improved stabilization furnace design. It supports the following key EM goals and priorities:

1. Improves safety performance, because it is less labor intensive than aqueous wash, and reduces radiation dose 
2. Reduces cost and time required to close PFP, by significantly increasing the process throughput for high-chloride plutonium oxide materials. Helps shrink the EM Footprint, by accelerating the processing rate, thereby allowing earlier closure of PFP

\subsubsection{Project Review Results}

The review teams recommended that the project be allowed to complete in FY 2002.

\subsubsection{FT01AR01 and ID72NM31, Dry Blending for Isotopic Dilution}

\subsubsection{Project Overview}

There are about 1700 kilograms of excess high-enriched uranium (HEU) stored at the Idaho National Engineering and Environmental Laboratory (INEEL) that do not meet Tennessee Valley Authority (TVA) specifications for ${ }^{232} \mathrm{U}$ and ${ }^{236} \mathrm{U}$ content. Aqueous processing of the material would require restart of facilities, so another processing technology is needed to prepare material for recycle or disposal. NMFA is researching the feasibility of isotopic dilution (lowering the ${ }^{235} \mathrm{U}$ concentration) by dry blending the material with other uranium isotopes. Although volume of material increases, significant savings in Safeguards and Security costs could be possible because attractiveness level of the material is reduced. The dry process can be sized to meet site-specific throughput rates, and should require only minimal hot-cell space. Along with the University of Utah and INEEL, they are assembling a system for non-radioactive testing of the dry blending process.

TTP ID72NM31 funds the INEEL subject matter expert portion of this work. FT01AR01 is the Applied Research [National Energy Technology Laboratory (NETL)] TTP that funds the University funded part of this project.

\subsection{Scope}

The INEEL has about 1,700 kilograms of off-specification HEU currently stored in CPP-651. This is "excess" HEU material that does not meet the Oak Ridge acceptance criteria and has transportation issues related to shipping containers and external radiation fields. In its current state this material cannot be removed from its current configuration for disposition. The disposition paths for this material include: a) isotopic dilution to about $5 \%{ }^{235} \mathrm{U}$ enrichment for the off-spec TVA fuel fabrication program, or b) isotopic dilution to $0.9 \%{ }^{235} \mathrm{U}$ enrichment for disposal. These proposed disposition paths require the HEU to be processed at the INEEL or be transferred to another site. This project may demonstrate a resolution to the INEEL STCG need ID-8.1.01,"Non- Aqueous Disposition of HEU at INTEC (Dry Blending)", and is directly related to the INEEL STCG need ID-8.1.03 "Remote Milling System for Isotopic Dilution of Off-Spec HEU and Size Reduction of ${ }^{233}$ U Materials."

\subsection{Technical Solution}

Previous studies completed at the University of Utah include a laboratory-scale project to test a concept for dry milling and blending of oxides using a patented milling technology. The technology (a patented technology called the RM-2 mill, U. S. patent \#6086242 July, 2000) is based on the principle of a planetary ball mill operation and uses novel but simple mechanical principles to effect and vary the centrifugal field and mill rotation.

Feasibility testing with simulant materials (titanium monoxide blended with titanium dioxide) has produced excellent milling and blending results. Size reduction to sub-micron particles has been accomplished in a matter of an hour. 
The National Energy Technology Laboratory under the auspices of the Nuclear Materials Focus Area has recently funded new follow-on studies. Under contract DE-AC26-01NT41312, the University of Utah will further demonstrate this technology with DU and NU oxide materials, to better define operating parameters and identify related safety issues. A subject matter expert from the INEEL is also funded to support this effort. The effect of mill operating and design variables on the blending of NU/DU oxides will be evaluated with the intent to optimize the process. Spatial sampling of the mixture and analyzing for uniform ${ }^{235} \mathrm{U}$ concentration in each of the samples will characterize the blend achieved in a single grinding test.

\subsection{Status}

This project was just recently funded, however, the structure to house the RM-2 mill is assembled and the HEPA filtered ventilation system and RM-2 mill are being installed. Also, uranium test materials are being obtained, various grinding media is being purchased, and the test plan, and supporting plans (analytical, QA, and health and safety) are being drafted. The project maturity is at the applied research stage.

\subsection{Alignment to Thrust Areas and Key Goals and Priorities}

This project supports Thrust 2, Baseline Alternatives. The Dry Blending project provides a nonaqueous alternative that is quicker and cheaper than processing these INEEL materials (disposal or recycle) via aqueous operations. There are two disposition options: (1) Dry blend all materials to $0.9 \%$ enrichment in ${ }^{235} \mathrm{U}$ for disposal, or (2) dry blend all materials to $5 \%$ enrichment in ${ }^{235} \mathrm{U}$ for recycle to commercial reactor fuel (i.e., the TVA program).

This project supports the following key EM goals and priorities:

3. Reduce the Cost and Time Required to Complete the EM Cleanup Mission, by replacing aqueous recycle operations by the faster dry blending system. Dry blending for disposal provides significant savings over aqueous processing.

4. Consolidate Nuclear Materials Out of INEEL by 2004. Dry blending will move material sooner to recycle or disposal.

7. Shrink the EM Footprint. Dry blending requires less facility space than aqueous processing.

8. Get Wastes to Disposal Facilities Quickly. Dry blending provides a non-aqueous conditioning system that does not exist today.

\subsubsection{Project Review Results}

The review team recommended that the project continue as required if user site pull exists. The team anticipates alignment to ongoing EM priorities.

\subsubsection{HQ06T222, Russian Checkbook}

\subsubsection{Project Overview}

There are radioactively contaminated laboratory waste solutions that need a stabilization or disposition path. Historical disposition strategies may not be an option because of reduction of capability 
at DOE sites as they prepare for closure. So, they are seeking an alternate technology to stabilize and to dispose of these materials. NMFA is utilizing Russian expertise to develop new applications of a porous crystalline material called Gubka. Demonstration tests will be done at Russian facilities using simulated and actual wastes, and ASTD funding will be requested for demonstrations and deployments at DOE sites.

This process is a simple stabilization process that produces low-level waste. It will be useful at DOE facilities where other capabilities have been dismantled.

\subsection{Scope}

This project supports the development of new innovative Russian technologies, including the application of the Gubka technology to DOE needs. These needs include: a) stabilization of hazardous and radioactive contaminated solutions present at DOE and Russian facilities (including liquid technical standards, Purex solvent wastes, and organic liquids and sludges), b) selectively cleaning up radioactive and hazardous components from contaminated solutions using modified Gubka matrices, c) clean up of contaminants from vitrification offgas, and d) trapping of hydrogen and trace organics generated during radioactive material and waste storage.

A collaborative agreement has been signed between the DOE and the Ministry of Atomic Energy of the Russian Federation to conduct work under the authorized scope of work for FY02 and FY03. This joint program was started in FY99 to investigate the stabilization of actinide bearing solutions, and has continued to the present date. This project has demonstrated a resolution to the Ohio STCG need OHF177 "Improved Method to Safely Store, Treat, Dispose of Liquid Radiological Laboratory Standards", and is directly related to the INEEL STCG need ID-3.1.53 "Stabilization and Disposal of INEEL Laboratory Solutions as an Alternative to Existing Practices, Including Disposal in Waste Tanks".

\subsection{Technical Solution}

A statement of work has been developed to test the application of Gubka to waste solutions containing hazardous metals and organics, which heretofore have not been tested. Minimal testing will also be conducted to support further development of Gubka to stabilize other acidic radioactive liquids. Other activities include the development of design and cost estimates for manufacturing industrial scale amounts of Gubka. Methods for modifying Gubka and subsequent testing of the material as a selective ion trapping and gas gettering agent will be conducted.

\subsection{Status}

In FY 1999, the feasibility of stabilizing americium and curium solutions were determined. In FY 2000, NMFA tested stabilization of Hanford and INEEL solution matrices, and was able to increase the porosity from $50 \%$ to $90 \%$, thereby increasing capacity. In FY 2001, a batch of Gubka was prepared in Russia and shipped to the United States for tests, and Gubka was demonstrated at INEEL (mixed waste solution) and at Fernald. Currently NMFA is working with a private firm in Kansas regarding potential applicability of Gubka to stabilize industrial acid waste.

The Gubka matrix was demonstrated on Fernald and INEEL solutions, and it was deployed at Fernald, using Fernald funding. The technology is mature enough for deployment for small-scale use at Fernald for acidic solutions. Engineering development needed to produce Gubka materials in 10-100 kilogram batches. Other applications, such as selective ion trapping, gas gettering, and organic solvents, are at the exploratory development stage. 


\subsection{Funding}

Table 3.3-7 HQ06T222 budget summary.

\begin{tabular}{||l|l|l|l|l|l||}
\hline $\begin{array}{l}\text { B\&R } \\
(\$ K)\end{array}$ & FY01 CO & FY02 & FY03 & FY04 & ALL FOLLOWING YRS \\
\hline & & 150 & 150 & 0 & 0 \\
\hline
\end{tabular}

Table 3.3-8 HQ06T222 spending plan.

\begin{tabular}{|c|c|c|c|c|c|c|c|c|c|c|c|c|c||}
\hline \hline .MONTH & OCT & NOV & DEC & JAN & FEB & MAR & APR & MAY & JUN & JUL & AUG & SEP & TOTAL \\
\hline SK & & & 30 & & 30 & & 30 & & 30 & & 30 & & 150 \\
\hline
\end{tabular}

Co-Funding: No Co-funding.

Table 3.3-9 HQ06T222 budget spending plan.

\begin{tabular}{||l|l|l|l|l|l|l|l|l|l|l|l|l|l|l|l|l||}
\hline & Oct & Nov & Dec & Jan & Feb & Mar & Apr & May & Jun & Jul & Aug & Sep & $\begin{array}{l}\text { FY02 } \\
\text { Tot }\end{array}$ & FY03 & FY04 & Total \\
\hline (\$K) & & & 30 & & 30 & & 30 & & 30 & & 30 & & 150 & 150 & 0 & 300 \\
\hline
\end{tabular}

\subsection{Alignment to Thrust Areas and Key Goals and Priorities}

The project supports Thrust 1 - Closure site support. It has been deployed at Fernald to stabilize technical standards for shipment and off site disposal as a low-level waste, and there are similar materials at RFETS that could be stabilized using this technology.

The project also supports Thrust 2 - Alternatives to Baseline. It provides a simple means to stabilize small volumes of miscellaneous materials identified as sites prepare for closure and may not have previous capabilities. Without a technology to stabilize miscellaneous materials, site closure plans could be delayed.

This project supports the following key EM goals and priorities:

1. Improves safety performance, because it reduces risk by converting solutions to a solid matrix

2. Reduces cost and time required to close Fernald, because it provides a simple treatment for material that does not involve facility modifications or capital equipment expenditures

3. Close Fernald and RFETS by 2006. It provides simple treatment for material that does not involve facility modifications or capital equipment expenditures

7. Helps shrink the EM Footprint because it eliminates need for liquid storage facility

8. Get Wastes to Disposal Facilities Quickly, because the stabilized material can be disposed of as low-level waste. 


\subsubsection{Project Review Results}

The review team recommended that NMFA document current applicability and other potential uses and consider any existing international agreements associated with this project. They did not recommend that the project be funded in FY 2003.

\subsubsection{RL31NM11, Optimal Plutonium Precipitation for Stabilization Feed Preparation}

\subsubsection{Project Overview}

4,200 liters of plutonium/nitric acid solutions at PFP must be stabilized by July 31, 2002. These solutions include pure product solutions, single pass and double pass filtrate solutions that have high impurity content, Critical Mass Laboratory solutions with high uranium content, and other miscellaneous solutions. To meet the schedule, thermal stabilization of product from solutions must be done in RMC line, which has limited humidity control. Because of the humidity, the thermally stabilized product oxides from many solutions have exhibited high weight gains, i.e., above DOE-STD-3013 criteria. What is needed is the approval and validation of moisture measurement techniques for each solution family.

To address these problems a team of Pacific Northwest National Laboratory (PNNL), Plutonium Finishing Plant (PFP), NMFA, DOE Richland, and Fluor Hanford Technology Management personnel was assembled to maintain focus on critical needs. The approach was to perform laboratory and benchscale testing on surrogates, surrogates with plutonium and uranium, and actual solutions. This was to be followed by full-scale process testing. In this approach, all unit operations were examined.

\subsection{Scope}

\section{Task A}

To satisfy DNFSB 94-1/2000-1 requirements, the magnesium hydroxide $\left[\mathrm{Mg}(\mathrm{OH})_{2}\right]$ precipitation process for stabilizing plutonium and nitric acid solutions was started at the Plutonium Finishing Plant (PFP) in September 2000. In accordance with the DNSFB requirements, the $4200 \mathrm{~L}$ of Pu solutions at PFP must be stabilized by December 31, 2001. As of July 27, 2001, 660 liters of solution have been stabilized. To account for processing throughput challenges, on June 30, 2001, a baseline change request was approved by the project to extend the completion date for solutions stabilization to July 31, 2002.

The technologies being addressed/evaluated/optimized in the task are:

- Magnesium Hydroxide Precipitation - a non-specific, but very robust precipitation process that precipitates multivalent cations along with plutonium. The process is selfbuffering. All excess $\mathrm{Mg}(\mathrm{OH})_{2}$ reports to the filtercake.

- Calcium Hydroxide Precipitation - a non-specific, but very robust precipitation process that precipitates multivalent cations along with plutonium. The process is not selfbuffering, and higher end point pHs are achievable (where Pu solubility is lower). Excess $\mathrm{Ca}(\mathrm{OH})_{2}$ remains in the solution. 
- Oxalate Precipitation - a selective precipitation process that precipitates plutonium (and some uranium) while leaving most cations and excess oxalate in solution. Theoretically, a higher concentration of plutonium remains in solution than in the hydroxide precipitation processes.

In addition to the precipitation step, the following steps follow both of these precipitation technologies: filtration, hot plate drying, and muffle furnace calcinations. This task addresses various aspects of each of these steps.

- Chloride Leaching - the selective removal of soluble chloride salts (by contact with an aqueous solution) from high chloride containing plutonium oxide solids.

\section{Task B}

Participate in the Moisture Measurement Technical Advisory Panel (MMTAP) to provide guidance and review to the DOE technical community regarding means to attain, and verify the attainment, of the 3013 moisture content criterion.

The MMTAP will address the issues related to understanding and resolving the difficulties associated with moisture measurement and process qualification for plutonium-bearing materials stabilized and packaged according to DOE-STD-3013.

\section{Task C: CML Moisture Up-take Testing}

Solutions Stabilization Support is needed to conduct testing to evaluate the drying, calcination, and calcine moisture uptake behaviors of plutonium-bearing products prepared by oxalate precipitation of mixed plutonium/uranium nitrate solutions from the Hanford Critical Mass Laboratory (CML). Technical questions must be answered so that the feasibility of stabilizing the CML solutions to meet the DOESTD-3013 standards in the humid gloveboxes of the Plutonium Finishing Plant RMC line can be evaluated. Adequate conditions for the precipitation of CML solutions will be established in the PNNL testing under subtask A of this TTP, then subsequent tests will be performed under subtask C to study the oxalate product following filtercake drying and calcination. The influence of humidity on moisture uptake by the calcined solids will be examined. Also, the need for a filtercake rinsing step will be determined. For this new scope, the extent and character of the moisture uptake as a function of relative humidity and time under controlled conditions will be investigated and analyzed via thermogravimetric analysis / mass spectrometry (TGA/MS). Some characterization of the solid phases by X-ray diffractometry (XRD) also is planned. This testing must be executed in an accelerated manner, since PFP needs preliminary results early to develop operating plans for the processing of the CML solutions.

\subsection{Technical Solution}

For FY 2002, the Pacific Northwest National Laboratory (PNNL) will continue to support the processing of the solutions at PFP. The work will be a collaborative effort between PNNL and PFP, and will be an extension of work performed in FY 2000 and FY 2001. The tests to be conducted will provide additional information for tailoring the process to specific PFP conditions, and will cover areas where further evaluation is needed. The overall goals of this work will be to improve process throughput, reduce worker exposure, and enhance the quality of the final calcined product. Specific activities to be conducted are:

- Support the implementation of the oxalic acid precipitation process for the single and double pass filtrate and pure product solutions. 
- Support other precipitation alternatives (e.g., calcium hydroxide) in lieu of oxalic acid and magnesium hydroxide precipitation schemes, as determined necessary.

- Conduct a limited number scoping laboratory tests to extend the oxalic acid precipitation process to other plutonium solution families, including uranium-containing solutions.

- Conduct a limited set of scoping tests to extend the oxalic acid precipitation process to other orphan and miscellaneous plutonium-containing solutions being generated at PFP and not currently part of the current solutions stabilization effort.

- Support resolution of moisture issues using a limited number of scoping tests of both simulants and PFP derived precipitates (as available) to quantify moisture measurement adequacy and to identify precipitate post treatment strategies to reduce moisture in canned product.

- Provide support to PFP as needed on alternative materials for direct stabilization/solidification of PFP solutions containing low concentrations of plutonium.

- Conduct a limited number of laboratory-scale tests to provide a baseline of data on the use of the solution stabilization process for treating chloride-bearing plutonium oxide solids.

- Conduct two technical exchanges between PNNL, PFP, and RL in FY 2002 to expeditiously communicate test results and recommendations and to appropriately establish testing priorities and schedules.

As was practiced in FY2001, this task will also provide rapid response to address unforeseen processing problems that may emerge during the processing campaigns in FY 2002.

\subsection{Status}

The investigators identified a better precipitation magnesium hydroxide reagent for pure plutonium nitrate solutions. This reagent allowed reduced worker radiation exposure, and the foaming issues were mitigated. It also resulted in a fifty percent reduction in filter cake volume during processing of pure solutions, resulting in a higher throughput with less volume of solids to handle.

The magnesium preciptation process had problems with impure plutonium solutions, so the investigators switched from the magnesium hydroxide process development to the oxalate process development. Because of this efficient switch in paths, they were able to reduce processing costs at the PFP by about $\$ 9$ million, and recovered 12 months of schedule. To support implementing a new oxalate precipitation process, the investigators resolved key hazardous operation issues including flammable gas and plutonium (VI). They also deployed a hand-held fiber optic spectrophotometer. The investigators identified, procured and deployed an improved filter media for the oxalate process. This new media allowed for reduced worker exposure through improved removal of filter cake from filter, and increased process throughput while minimizing plutonium losses to filtrate.

To address the CML uranium solutions, a method to precipitate plutonium selectively from uranium was developed and validated. They demonstrated that the CML solutions can be processed in the high humidity of the PFP RMC Line, and validated loss-on-ignition (LOI) analysis for moisture measurement. This new method for precipitating plutonium allowed for a two month schedule gain in FY2002 (\$1.5 million savings over baseline), and over a three times reduction in the volume of CML product going into 3013 storage cans. The life cycle savings to DOE are significant, but not estimated. 
A strategy for the miscellaneous solutions was developed. To minimize the moisture uptake in the product, silica or kaolin were used, resulting in a reduction in schedule over the baseline.

To summarize:

- Demonstrated oxalate precipitation on DPF solutions

- Deployed filter media

○ Improved high flux and cake recovery

○ Minimized plutonium losses

- Deployed hand-held fiber optic spectrophotometer

- Addressed plutonium (VI) safety issues deployed suitable magnesium hydroxide reagent

- Implemented selective plutonium precipitation process for CML solutions

The technology maturity includes elements from applied research through deployment.

\subsection{Funding}

Table 3.3-10 RL31NM11 budget summary.

\begin{tabular}{|l|l|l|l|l||}
\hline $\begin{array}{l}\text { SOURCE } \\
(\mathrm{B} \& \mathrm{R})(\$ \mathrm{~K})\end{array}$ & EST. 2001-CO & 2002 & 2003 & 2004 \\
\hline EW4010 & & & & \\
\hline Task A & 25 & 360 & TBD & TBD \\
\hline Task B & 0 & 80 & 0 & 0 \\
\hline Task C & & 75 & & \\
\hline TOTAL & 25 & 515 & TBD & TBD \\
\hline
\end{tabular}

Table 3.3-11 RL31NM11 spend plan.

\begin{tabular}{||l|l|l|l|l|l|l|l|l|l|l|l|l|l||}
\hline \hline$(\$ K)$ & OCT & NOV & DEC & JAN & FEB & MAR & APR & MAY & JUN & JUL & AUG & SEP & TOTAL \\
\hline Task A & 47 & 48 & 31 & 41 & 35 & 21 & 22 & 23 & 20 & 23 & 25 & 24 & 360 \\
\hline Task B & 11 & 11 & 9 & 11 & 9 & 9 & 10 & 10 & 0 & 0 & 0 & 0 & 80 \\
\hline Task C & & & & 75 & & & & & & & & & 75 \\
\hline TOTAL & 58 & 59 & 40 & 127 & 44 & 30 & 32 & 33 & 20 & 23 & 25 & 24 & 515 \\
\hline
\end{tabular}

\footnotetext{
${ }^{2}$ Per TCR02-NM-002, \$75K was added to this project to support task C in December 2001

${ }^{3}$ Per TCR02-NM-002, \$75K was added to this project to support task C in December 2001. This amount has not been distributed by month.
} 
Table 3.3-12 RL31NM11 co-funding.

\begin{tabular}{||l|l|l|l|l|l||}
\hline SOURCE (B\&R) (\$K) & EST. 2001-CO & 2002 & 2003 & 2004 & $\begin{array}{l}\text { ALL } \\
\text { FOLLOWING } \\
\text { YEARS }\end{array}$ \\
\hline Task A. & & & & & \\
\hline WBS 1.4.5.13, Stabilize Pu bearing Solutions & 25 & TBD & TBD & TBD & 0 \\
\hline $\begin{array}{l}\text { Fluor Technology, Management Direct } \\
\text { Funding }\end{array}$ & 0 & 120 & TBD & TBD & 0 \\
\hline Task B. & 0 & 0 & 0 & 0 & 0 \\
\hline Task C. & 0 & 0 & 0 & 0 & 0 \\
\hline
\end{tabular}

\subsection{Alignment to Thrust Areas and Key Goals and Priorities}

This project supports Thrust 2, Baseline Alternatives. This project has been integral to the resolution of issues encountered as PFP began processing plutonium solutions. Without this support, the baseline technology (precipitation of plutonium) would not have been successful for the variety of plutonium solutions that needed to be stabilized.

This project addresses the following key EM goals and priorities:

1. Improved Safety Performance - Reductions in Worker Exposure, by increasing process throughput resulting in less operational time, selectively precipitating plutonium which reduces the americium-241 in the product, and by eliminating filter cake rinsing which was an operator-intensive step.Reduce Cost and Time Required to Complete the EM Cleanup Mission, by reducing the quantity of oxide product generated, providing both near-term and long-term savings and cost avoidance, and through schedule improvements

5. Consolidate Nuclear Materials out of Hanford by 2004, by increasing the process throughput resulting in less operational time, and through selective plutonium precipitation resulting in fewer items to process for storage.

\subsubsection{Project Review Results}

The review team recommended that the project be allowed to complete in FY 2002.

\subsection{Spent Nuclear Fuel Product Line}

The Spent Nuclear Fuel Product Line addresses technology needs in measurement of properties of DOE spent fuel and container materials, in modeling long-term storage of SNF, and in handling and monitoring of SNF containers during storage. 
Table 3.4-1 lists the projects in this product line for FY 2002.

Table 3.4-1. Spent Nuclear Fuel Product Line FY 2002 projects.

\begin{tabular}{||c|l|l||}
\hline \hline PROJECT TTP(S) & \multicolumn{1}{|c||}{ SUBJECT } & THRUST AREAS -D SITES IMPACTED \\
\hline RL32NM41 & $\begin{array}{l}\text { Enhancement Reactivity Factor for } \\
\text { Cold Vacuum Drying (CVD) } \\
\text { Processing of N-Reactor SNF }\end{array}$ & $\begin{array}{l}\text { Area 2 } \\
\text { Hanford, INEEL }\end{array}$ \\
\hline $\begin{array}{l}\text { ID02NM41 } \\
\text { SR02NM41 }\end{array}$ & Welding Development & $\begin{array}{l}\text { Area 2 } \\
\text { INEEL, SRS }\end{array}$ \\
\hline ID02NM44 & High Level Waste/Spent Nuclear & Area 2 \\
CH22NM41 & Fuel Canister Interaction Studies & Hanford, INEEL, SRS \\
SR02NM42 & & Area 2 \\
\hline SR02NM51 & SNF Drying Standard & INEEL, SRS \\
ID02NM45 & & Area 2 \\
\hline ID02NM42 & Advanced Neutron Absorber & Hanford, INEEL, SRS \\
AL22NM41 & Development & \multicolumn{2}{|l}{} \\
\hline
\end{tabular}

\subsubsection{RL32NM41, Enhancement Reactivity Factor for Cold Vacuum Drying (CVD) Processing N-Reactor SNF}

\subsubsection{Project Overview}

Damaged uranium metal spent nuclear fuel (SNF) reacts with water to form $\mathrm{UH}_{3}$ during interim storage. To eliminate formation of more $\mathrm{UH}_{3}$ during interim storage, residual water must be removed from this source. Hanford developed a cold vacuum process to dry SNF, but processing is slower than expected. Their concern is that the $\mathrm{UH}_{3}$ reaction has slowed processing. They would like to be able to reduce conservatism on the CVD process by demonstrating that reaction does not proceed at postulated rates.

This project takes another look at the data that was used to construct existing safety authorization basis, and the processing data from processing 40 multi-canister overpacks (MCO) through the CVD operations. This information will be used to evaluate possibly decreasing the reactivity enhancement factor, which may be used to increase the operating temperature of the CVD process, and increase process throughput. If this is successful, it will reduce the processing costs for CVD through reduced schedule to complete activity. Another side benefit is the potential verification of uranium metal fuel characteristics used in repository modeling for consequence analysis in facilities.

\subsubsection{Scope}

Spent nuclear fuel from the Hanford N-Reactor has been stored under water in the 100-Area KBasins for approximately 30 years. Over 2000 metric tons of spent fuel are stored in the two basins at the K-Reactor site. The basins are aging and a portion of the fuel inventory is degraded. In 1994, the Department of Energy began the task of cleaning up these basins. A strategy for decommissioning the basins was developed, as was a disposition plan for the 2000 metric tons of spent fuel. The plan for spent fuel includes recovering the fuel from the basins, repackaging it in large "multi-canister overpack" canisters (MCOs), subjecting the contents of those canisters to a low-temperature drying process, sealing the canisters and moving them to an interim storage facility away from the Columbia River. 
The project was developed at a fast pace, and conservatism was built in to the spent fuel drying strategy to protect the health of workers, the public, and the environment. The fast pace of the project meant that research data could not be gathered in time to reduce the conservatisms inherent in the process. The resulting fuel drying process has been demonstrated to work (nine canisters have been dried at the time of this submittal), but the process is relatively slow. The long fuel drying time jeopardizes the project schedule and critical Tri-Party Agreement Milestones for the Hanford Site. Delays in completion of the project increase the project lifecycle cost. There is also an increased risk to the environment in the form of radioactive material release due to potential leaks in the basins.

The long fuel drying time has prompted the SNF project management to explore ways to streamline or speed the drying process. One option is to increase the temperature of the drying process. However, the temperature that can be used to dry the spent fuel is influenced by the potential reactivity of the spent fuel with oxygen and water vapor. Besides temperature, the reactivity is influenced by several factors such as the amount of hydride contained in the fuel and the exposed fuel surface area available for reaction. To manage and simplify the combined effect of these other factors, the project has developed a dimensionless term call the "enhancement factor" that relates the potential reactivity of the water-stored N-Reactor spent fuel to that of literature-reported oxidation rates for unirradiated uranium metal. The exposed spent fuel surface area that was anticipated to be loaded into an average MCO was theoretically estimated using visual examination data obtained during characterization campaigns in the 1990s of fuel elements in the $\mathrm{K}$-East basin. The estimates included surface areas that would be attributed to scrap and small pieces of broken spent fuel that would also be added to the MCOs.

The empirically derived spent fuel reactivity factor of 22 has been used in the development of the fuel drying process to insure the operations are sufficiently conservative (to preclude any chance for a runaway fuel reaction during drying). This conservatism was then built into the safety basis for the spent fuel drying process. Before an increase in the drying process temperature can be made, the impacts on the process safety basis must be evaluated and approved before implementation. It must be demonstrated that the enhancement factor for the fuel is too high in order to justify a higher drying temperature while maintaining an adequate safety basis.

\subsection{Technical Solution}

The first step of the work is to reanalyse existing data from the seven whole fuel elements that were used in the laboratory scale drying studies and TGA studies on small-spent fuel samples. The laboratoryscale drying studies evaluated the drying behavior of fuel elements that ranged from completely intact to severely degraded and represent a cross-section of the best to worst case fuel elements that are found in the K-Basins. The TGA tests evaluated the oxidation kinetics of smaller fuel samples (from intact and damaged fuel) under a variety of atmosphere conditions (dry to moist inert). The off-gas analysis conducted for the laboratory-scale drying studies will be re-examined and compared with the TGA data to determine a more realistic reactive surface area for each type of fuel element (intact to damaged). It is with the expectation that this evaluation will yield lower reactive surface areas for the various types of fuel than is currently used in the basis for the enhancement factor. Next, the videotape data of the 2000+ fuel elements (may be as high as 4000 elements by the end of FY 2001) that have been loaded into the MCOs and processed will be compared with the results of the laboratory scale tests. It is also expected this comparison will result in a reduction in the enhancement factor, and this reduction will be justified by the actual data from the fuel.

A preliminary study will be performed to determine the level of safety margin built into the current treatment of the K-West (KW) spent fuel by the CVD process. In this exercise the two factors (i.e., reactivity enhancement factor and exposed fuel surface area) that influence the thermal margin will be reviewed using the visual examination data from processing 7 MCOs and the testing on N-Reactor spent 
fuel material. Any additional factors that were viewed as influencing properties of the damaged $\mathrm{N}$ Reactor spent fuel behavior will be considered.

In the model for calculating the surface area, all the damaged spent fuel elements were distributed among damage categories as follows:

- Incipient: The corroding areas are generally barely discernible and the estimated fraction of the corroded cross section is $1 \%$.

- Rupture: The corroding areas are generally smaller than the geometrical cross sectional area of an element. The assigned area is $25 \%$ of the unit area.

- Loose End Cap: The corroded area is described by loss of the end cap and the assigned surface area is unit cross sectional area.

- Split Cladding: It is assumed that for this kind of damage, about three inches of the metal fuel element are exposed and the corresponding areas for a split cladding are (a) 17Auo for outer element and (b) 15Aui for the inner element, where Auo and Aui are the unit areas for the outer and inner fuel elements, respectively.

The failed spent fuel elements that were examined during the K-East Basin visual inspection campaign were distributed among these four categories to arrive at the estimated surface areas for a loaded MCO.

The visual campaign during the Phase 4 of loading K-West Basin spent fuel elements into the first 7 MCOs has generated a similar database. This data will be analyzed using a similar method to determine the surface area of the KW spent fuel elements that has been loaded into each MCO. As a complimentary effort, the RGA hydrogen generation rate will be used to estimate the actual exposed uranium surface area with an assumed reaction rate constant. The two sets of information will be used to determine a revised surface area estimate for loaded MCO inventory of N-Reactor spent fuel.

The current value of a reactivity multiplier for N-Reactor spent fuel was based on the observations of higher oxidation rate for the damaged metallic uranium matrix in dry air at lower temperatures. The authors of this report speculated that the higher oxidation rates may be due to the products of the spent fuel corrosion in the K-Basins. These products were uranium hydride and cracking of the uranium matrix. To account for this unexpected observation the spent nuclear fuel project made the decision to bound the higher reactivity with a multiplication factor of 12 . And a factor of 10 was chosen to represent the overall spread of literature data on metallic uranium reaction in dry air. Two experimental studies have been performed on $\mathrm{N}$-Reactor spent fuel in oxygen free moisture atmosphere that showed encouraging results. The reactivity of the corroded N-Reactor metallic uranium falls within the spread of the literature data on unirradiated metallic uranium. This additional information suggests that the conservative multiplier of 22 assumed by the project may be too high and the additional data will be used to re-evaluate the reaction rate safety factor that is applicable to processing the damaged N-Reactor spent fuel during CVD.

These two new determined fuel behavior factors would be used to rerun the major codes such as HANSF and/or GOTH for the CVD process to assess the safety margins without changing any other parameters. The outputs from these codes will provide input to a project decision to move forward and make changes in the technical baseline for treating $\mathrm{KW}$ basin spent fuel.

A technically defensible argument will be put together and presented to the spent nuclear fuel project to support a decision for increasing the CVD process temperature. All the technical reports that are the basis for the safety analysis report for the CVD process will be revised to support the changes needed for formal approval by the Department of Energy. 


\subsection{Status}

At the time of the mid-year, the project had reevaluated the laboratory data on SNF fuel reactivity, resetimated the surface area of damages whole SNF elements, and drafted a report on SNF reactivity limits. They are in the process of assembling CVD process data and analyzing the residual gas analyzer data for the CVD process.

The project maturity is at Level 5 - Engineering Development. They are working to refine the current operating envelope and are studying SNF canister reaction. There is little laboratory work, but rather the re-analysis of existing laboratory and operating data. They expect to be able to be ready to evaluate possible changes to the operations of the CVD process at Hanford by the end of June, 2002, depending on analysis results

\subsection{Funding}

Life Cycle Cost Estimate (\$K)

Table 3.4-2 RL32NM41 EM-50 funding B\&R code: EW4010.

\begin{tabular}{|l|l|l|l|l|l|l||}
\hline $\begin{array}{l}\text { TOTAL ACT } \\
\text { TO DATE }\end{array}$ & 2002 & 2003 & 2004 & 2005 & TOTAL & $\begin{array}{l}\text { RANGE OF } \\
\text { CERTAINTY } \\
{[+/-\%]}\end{array}$ \\
\hline Task A & & 365 & 65 & N/A & N/A & 430 \\
\hline
\end{tabular}

Table 3.4-3 RL32NM41 co-funding B\&R code:.

\begin{tabular}{||l|l|l|l|l|l|l||}
\hline $\begin{array}{l}\text { TOTAL ACT } \\
\text { TO DATE }\end{array}$ & 2002 & 2003 & 2004 & 2005 & TOTAL & $\begin{array}{l}\text { RANGE OF } \\
\text { CERTAINTY } \\
{[+/-\%]}\end{array}$ \\
\hline Task A & & 300 & 200 & N/A & 500 & \\
\hline
\end{tabular}

Table 3.4-4 RL32NM41 Task A - activity-based estimate (\$K).

\begin{tabular}{||l|l||}
\hline & FY 2002 \\
\hline Work Element A.0 & 60 \\
\hline Work Element A.1 & 90 \\
\hline Work Element A.2 & 60 \\
\hline Work Element A.3 & 90 \\
\hline Work Element A.4 & 65 \\
\hline TOTAL & 365 \\
\hline
\end{tabular}


Table 3.4-5 RL32NM41 Task A - budget expense xchedule (\$K).

\begin{tabular}{||l|l|l|l||}
\hline COST ELEMENT & PRIOR YEARS & FY 2002 & FY 2003 \\
\hline Labor & & 225 & 65 \\
\hline Travel & & 15 & 0 \\
\hline Subcontracts & & 110 & 0 \\
\hline Supplies/Materials & & 15 & 0 \\
\hline TOTAL & & 365 & 65 \\
\hline
\end{tabular}

Table 3.4-6 RL32NM41 spend plan (\$K).

\begin{tabular}{|l|r|r|r|r|r|r|r|r|r|r|r|r|r|r|r||}
\hline \hline $\begin{array}{l}\text { NMFA } \\
\text { FUNDING }\end{array}$ & 0 & 70 & 60 & 60 & 60 & 40 & 25 & 15 & 10 & 10 & 5 & 5 & 5 & 0 & 365 \\
\hline $\begin{array}{l}\text { JOINT } \\
\text { FUNDING }\end{array}$ & 0 & 40 & 50 & 40 & 60 & 40 & 20 & 20 & 10 & 10 & 10 & 0 & 0 & 0 & 300 \\
\hline
\end{tabular}

Basis of Estimate:

The subcontract would be Fauske \& Associates, Inc. who has performed similar calculations for the CVD process. The past experience for the CVD process technical baseline calculations and the SNF Characterization program was used to determine the cost.

Additional Costs:

In addition to the activities described in this TTP, arrangements for the following items will be made as requested by NMFA. These activities are not expected to have a significant impact on project costs.

- Independent Peer Reviews

- User Reviews

- Cost Savings/Return on Investment Analyses (Innovative Technology Summary Report)

- Midyear Technical Review

- Development of Follow-on Long-Form Technical Task Plans (LTTPs) Basis of Estimate

\subsection{Alignment to Thrust Areas and Key EM Goals and Priorities}

Alignment to the Thrust Areas and goals and priorities was not evaluated. This project will be completed at the end of FY 2002.

\subsubsection{Project Review Results}

The review team recommended that the project continue and complete in FY 2002. 


\subsubsection{ID02NM41, Weld and NDE Technique and Equipment Development for DOE Standardized SNF Canister; and SR02NM41, Weld Optimization to Minimize Potential for Age-Related Degradation of DOE Standardized SNF Canister Closure Welds}

\subsubsection{Project Overview}

The SNF canisters bound for the Monitored Geologic Repository (MGR) must be seal-welded and inspected to meet acceptance criteria and ASME requirements. However, there is not an approved system currently designed to accomplish these welds. One of the attributes that a system must have, is to be able to reduce the risk of residual weld degradation. This project will establish the weld requirements and develop weld process parameters. Also, it will select proposed welding equipment and develop remote inspection and grinding equipment.

The proposed system will reduce radiation exposure during disposition of SNF, and provide realtime nondestructive examination (NDE) and rework, resulting in reduced cycle time and weld heats to package SNF, resulting in potential cost savings to program.

\subsection{Scope}

\subsection{ID02NM41 Scope}

Successful weld closure of nuclear materials packages, whether for use in an operating system, for interim storage or for disposal in a repository, requires the development, demonstration and qualification of the welding process. Additionally, confirmation of the weld quality on individual packages may also be required. Historically, package requirements have been met by developing an operational or process window that assures the production of high quality welds, monitoring the process variables to assure operation within the established process window and inspecting the closure weld to confirm quality requirements. The quality of the closure weld on a nuclear materials package is thus assured through the combination of process development, in-process monitoring and post closure inspection. However, even when the quality of a closure weld is firmly established, the integrity of the container may be compromised during storage by stress corrosion cracking, pitting, crevice corrosion and/or other agerelated degradation processes. The planned work outlined herein will mitigate or minimize the adverse effects of welding.

The joint design and weld process for the DOE Standardized Spent Nuclear Fuel (SNF) Canister closure weld must be selected to minimize weld induced residual stresses, crevices and other material variables generally associated with stress corrosion cracking, crevice corrosion and other age-related degradation processes. The welding technology must be suitable for remote application, adaptable to various size canisters and compatible with relatively fixed canister designs. Weld quality must be demonstrated through process control and weld inspection technologies. This TTP outlines the experimental program necessary to demonstrate and qualify weld and NDE technologies that maximize initial weld quality and minimize the potential for post weld degradation.

\subsection{SR02NM41 Scope}

Successful weld closure of nuclear materials packages, whether for use in an operating system, for interim storage or for disposal in a repository, requires the development, demonstration and qualification of the welding process. Additionally, confirmation of the weld quality on individual packages may also be required. Historically, package requirements have been met by developing an operational or process window that assures the production of high quality welds, monitoring the process variables to assure 
operation within the established process window and inspecting the closure weld to confirm quality requirements. The quality of the closure weld on a nuclear materials package is thus assured through the combination of process development, in-process monitoring and post closure inspection. However, even when the quality of a closure weld is firmly established, the integrity of the container may be compromised during storage by stress corrosion cracking, pitting, crevice corrosion and/or other agerelated degradation processes. The planned work outlined herein will mitigate or minimize the adverse effects of welding.

The joint design and weld process for the DOE Standardized SNF Canister closure weld must be selected to minimize weld induced residual stresses, crevices and other material variables generally associated with stress corrosion cracking, crevice corrosion and other age-related degradation processes. The welding technology must be suitable for remote application, adaptable to various size canisters and compatible with relatively fixed canister designs. Weld quality must be demonstrated through process control and weld inspection technologies. This TTP outlines the experimental program necessary to demonstrate and qualify weld technologies that maximize initial weld quality and minimize the potential for post weld degradation.

The work will be integrated with and complimentary to work being performed under TTP Number: ID02NM41, Title: Weld and NDE Technique and Equipment Development for DOE Standardized SNF Canister Closure Seal Welds. This work will develop and demonstrate weld repair and inspection technologies for closure of the DOE Standardized SNF Canister, which will further help to minimize the potential for post-weld degradation

\subsection{Technical Solution}

\subsection{ID02NM41 Technical Solution}

Remote welding and nondestructive examination equipment will perform the required function that will produce, repair (if required), and inspect closure welds on the NSNFP canister. The technologies will consist of head (welding, NDE, and repair) manipulation hardware, in-process ultrasonic inspection equipment, surface examination equipment (eddy current techniques), and repair equipment. User interfaces between the operator and equipment will also be developed, which allows in-process adjustments during equipment operation. Remote camera will be included that aid the equipment operator during initial equipment setup and operation. Parameter development and optimization are included to add robustness to the standardized closure remote welding and inspection. Development of the remote welding and NDE equipment can be divided into five major tasks: development and demonstration of welding processes and equipment (including weld repair), development and demonstration of NDE process and equipment, optimization of welding techniques and parameters, optimization of NDE techniques and parameters, and technology transfer, development of in-process and post-weld volumetric inspection equipment.

The tasks under this project include:

- A1 - Develop Remote Repair Welding Equipment Platforms

- A2 - Develop Remote NDE Equipment

- A3 - Optimization of Welding Techniques and Parameters

- A4 - Develop and Optimize NDE Techniques and Parameters

- A5 - Technology Transfer 
- A6 - Reporting

\subsection{SR02NM41 Technical Solution}

Several techniques for reducing weld heat input, and hence minimizing associated effects responsible for age-related degradation processes, have been demonstrated over the recent years. One in particular, that will be the focus of this effort, is the use of a narrow-groove weld joint. The narrowgroove technique along with the use of a state-of-the-art, articulating weld-head, coupled with the selection of carefully designed welding parameters, including pulsed current, will be utilized for this effort. In conjunction with this, a rigorous process development and qualification effort will be conducted. This effort will include evaluation of critical welding parameters by statistical means and the demonstration of the optimized technologies through appropriate and thorough testing.

The overall effort will develop, demonstrate and qualify the process for remote closure welding of DOE Standardized SNF Canisters. The completed weld will meet applicable codes and standards dictated by the WASRD requirements. The weld technologies will minimize overall heat input and thus reduce the risk for age-related degradation processes. The FY2002 work scope will build upon the FY2001 effort to organize and establish the foundation for a coordinated effort with INEEL for this work. Technical objectives for the FY2002 work scope include: Identification of weld requirements and criteria, selection and setup of laboratory welding equipment, and design of the experimental development test plan. In addition, welding trials will be conducted to evaluate various narrow-groove weld joint details. In conjunction with weld joint evaluation, evaluation of various welding parameters designed for narrow groove applications will be performed. Major outyear activities include optimization and qualification of the DOE Standardized SNF Canister closure weld and equipment demonstration and technology transfer. This effort will be integrated with work being performed at INEEL, work that will compliment the objectives stated herein. INEEL is developing inspection and repair welding technologies that will further reduce overall weld heat input. The INEEL work elements and milestones are not shown here, but regular and frequent communications between SRS and INEEL have been established to ensure compatibility of the two efforts.

\subsection{Status}

The project maturity is at Level 5, Engineering Development. The principles and requirements to achieve the desired weld are known. This project is working on joining commercially available hardware with some design engineering and development into a system to support the requirements for welding the SNF canister and inspection system development.

To date, the project has evaluated industry capabilities and ability to fulfill SNF requirements, established weld technical and equipment functional requirements, completed the design of the remote grinding equipment, initiated the prototype software development and testing, and demonstrated the feasibility of eddy current inspection to detect ASME-Type defects in the machined repair cavity surfaces. Currently, the project is performing final testing on the welding equipment and modifying it as needed, for a demonstration in May 2002. 


\subsection{ID02NM41 Funding}

Table 3.4-7 ID02NM41 funding.

\begin{tabular}{||l|l|l|l|l|l|l|l|l|l|l|l|l|l||}
\hline & Oct & Nov & Dec & Jan & Feb & Mar & Apr & May & Jun & Jul & Aug & Sep & Total \\
\hline FY2002 & $\$ 39 \mathrm{k}$ & $\$ 34 \mathrm{k}$ & $\$ 27 \mathrm{k}$ & $\$ 32 \mathrm{k}$ & $\$ 29 \mathrm{k}$ & $\$ 33 \mathrm{k}$ & $\$ 35 \mathrm{k}$ & $\$ 28 \mathrm{k}$ & $\$ 29 \mathrm{k}$ & $\$ 31 \mathrm{k}$ & $\$ 28 \mathrm{k}$ & $\$ 32 \mathrm{k}$ & $\$ 377 \mathrm{k}$ \\
\hline
\end{tabular}

\subsection{SR02NM41 Funding}

Table 3.4-8 SR02NM41 budget spending plan.

\begin{tabular}{||l|l|l|l|l|l|l|l|l|l|l|l|l|l||}
\hline \hline & Oct & Nov & Dec & Jan & Feb & Mar & Apr & May & Jun & Jul & Aug & Sep & Total \\
\hline FY2002 & $\$ 30 \mathrm{k}$ & $\$ 30 \mathrm{k}$ & $\$ 20 \mathrm{k}$ & $\$ 25 \mathrm{k}$ & $\$ 20 \mathrm{k}$ & $\$ 37 \mathrm{k}$ & $\$ 50 \mathrm{k}$ & $\$ 25 \mathrm{k}$ & $\$ 25 \mathrm{k}$ & $\$ 20 \mathrm{k}$ & $\$ 20 \mathrm{k}$ & $\$ 25 \mathrm{k}$ & $\$ 327 \mathrm{k}$ \\
\hline FY2003 & & & & & & & & & & & & & $\$ 450 \mathrm{k}$ \\
\hline FY2004 & & & & & & & & & & & & & $\$ 300 \mathrm{k}$ \\
\hline
\end{tabular}

\subsection{Alignment to Thrust Areas and Key Goals and Priorities}

These projects support Thrust 2, Alternative Approaches to Current High Risk/High Cost Baselines. The general activity started after analysis of repository disposition requirements. If implemented, it will result in a significant decrease to cost of SNF disposal. The lack of this technology may increase disposal costs due to increased number of canister caused by lower SNF loading to accommodate shield plugs for personnel exposure.

These two projects addresses the following key EM goals and priorities:

1. Improve Safety Performance by reducing exposures to personnel working on sealing SNF canisters for shipment

2. Reduce Cost and Time Required to Complete the EM Cleanup Mission by assuring that planned footprint of DOE-SNF in repository can be accommodated

\subsubsection{Project Review Results}

The review team recommended that these projects continue beyond FY 2002. In their opinion, the projects are critical to success of SNF disposition, and they anticipate that the projects will align with ongoing EM priorities. 


\subsubsection{ID02NM44, INEEL HLW/SNF Canister Interaction Project Manager; CH22NM41, ANL HLW/SNF Canister Interaction Studies; and SR02NM42, SRS HLW/SNF Canister Interaction Studies}

\subsubsection{Project Overview}

Because the Repository performance modeling is based, in part, on data for radionuclide colloid formation and transport for DOE-SNF canisters that was measured under different physical parameters than exist in the Yucca Mountain location, the proposed location of the Repository, there is a risk that the transport modeling will not be accepted for these materials. These projects will conduct a series of parametric tests to measure formation and transport of colloids using combined waste forms, waste package materials, and groundwater to simulate the Yucca Mountain location chemistry. These studies will be added to the existing SNF Release Rate studies that have been ongoing since 1997. These additional studies will provide an increased confidence in repository radionuclide transport calculations, and will be used to better defend the repository safety basis, and allow DOE to proceed with interim packaging strategies with a higher confidence level.

\subsection{Scope}

\subsection{ID02NM44 Scope}

Current requirements for the permanent disposal of DOE-owned spent nuclear fuel (DSNF) and defense high-level waste glass (DHLW) specify that they be packaged together in steel canisters and disposed in the proposed repository at Yucca Mountain. In addition, repository acceptance criteria state: "Materials of construction of the DOE SNF canisters and their internals shall be selected to be compatible with waste disposal package materials and with the contained SNF. Canister materials shall not corrode or otherwise chemically attack the waste package from the inside, and they shall not increase rates of degradation of contained SNF or mobilize radionuclides for transport subsequent to waste package breach." To meet these requirements, prior to approval by the Nuclear Regulatory Commission (NRC), models of radionuclide release and transport have been generated for use in the Total System Performance Assessment-Site Recommendation (TSPA-SR) and License Application (LA). The models are based on limited available data from independent corrosion studies of DSNF, DHLW, and canister materials. However, no detailed studies have been performed to determine radionuclide release from these wastes in an interactive co-disposal environment. Based on solution chemistries and corrosion products observed in corrosion studies of the individual components, it is expected that significant material interactions will occur in a co-disposal repository environment. Thus, there is a need to experimentally determine the chemical consequences of co-disposal and to include these results in TSPA models of waste package and waste form corrosion. Although a complex series of interactions is possible in a co-disposal scenario, the most significant interaction - based on previous studies - involves the potential generation and immobilization of radionuclide-associated colloids, accelerated container corrosion, and mobilization of neutron absorbers. These potential effects will be investigated in a series of parametric tests with combined waste forms, waste package materials, and groundwater and the results will be integrated with other experimental projects. Results of the research combined with data from individual component tests (DSNF, DHLW) funded elsewhere will provide critical data inputs in support of the TSPA-LA and subsequent performance confirmation.

\subsection{CH22NM41 Scope}

Models have been developed for use in TSPA-SR to calculate the separate degradation behaviors of DHLW glass and DSNF and to calculate the amounts of radionuclides associated with colloids available for in-drift transport. An in-package chemistry model was developed to represent simultaneous 
DSNF and DHLW dissolution for use in TSPA-SR; however, no data are available to confirm model predictions. The proposed study of the interactions between DHLW glass, DSNF, and the steel container materials will provide data that can be used to evaluate and define the predictions of the in-package chemistry model for DSNF and DHLW glass co-disposal waste packages

The technical scope of this work will provide essential data needed to take into account the interactive effects of spent nuclear fuel and high level waste glass co-disposed in steel canisters to be included in performance assessment calculations. Multiple interactions and products are possible in a codisposal waste package, but the scope of this work is focused on the quantity, composition, and stability of radionuclide-associated colloids, the dissolution and speciation of neutron absorbers, and the rate of waste container degradation. These data needs are addressed by performing a series of batch tests in which various spent fuel waste forms, high level waste glass, canister steel materials, and neutron absorbers interact in EJ-13 groundwater at $90^{\circ} \mathrm{C}$. Materials interactions will be determined by measuring the extent of degradation and colloid generation from one material when exposed to solutions generated during the corrosion of the other materials. This will allow the effects of one material's degradation on the degradation rate and colloid generation of the other material to be distinguished for modeling purposes. Effects of the solution chemistry will be further studied by spiking some leachants with gadolinium or hafnium (proposed neutron absorbers) or by fixing the $\mathrm{pH}$. Addition of gadolinium and hafnium in the test matrices will provide determination of $\mathrm{Gd} / \mathrm{Hf}$ speciation from the dissolved phase to surface-adsorbed phases, precipitated species, colloidal species, and dissolved species.

\subsection{SR02NM42 Scope}

Current requirements for the permanent disposal of DOE-owned spent nuclear fuel (DSNF) and defense high-level waste glass (DHLW) specify that they be packaged together in steel canisters and disposed in the proposed repository at Yucca Mountain. In addition, repository acceptance criteria state: "Materials of construction of the DOE SNF canisters and their internals shall be selected to be compatible with waste disposal package materials and with the contained SNF. Canister materials shall not corrode or otherwise chemically attack the waste package from the inside, and they shall not increase rates of degradation of contained SNF or mobilize radionuclides for transport subsequent to waste package breach." To meet these requirements prior to approval by the Nuclear Regulatory Commission (NRC), models of radionuclide release and transport have been generated for use in the Total System Performance Assessment-Site Recommendation (TSPA-SR) and License Application (LA). The models are based on limited available data from independent corrosion studies of DSNF, DHLW, and canister materials. However, no detailed studies have been performed to determine radionuclide release from these wastes in an interactive co-disposal environment. Based on solution chemistries and corrosion products observed in corrosion studies of the individual components, it is expected that significant material interactions will occur in a co-disposal repository environment. Thus, there is a need to experimentally determine the chemical consequences of co-disposal and to include these results in TSPA models of waste package and waste form corrosion.

Although a complex series of interactions is possible in a co-disposal scenario, the most significant interaction - based on previous studies - involves the potential generation and immobilization of radionuclide-associated colloids, accelerated container corrosion, and mobilization of neutron absorbers. These potential effects will be investigated in a series of parametric tests with combined waste forms, waste package materials, and groundwater. Results of the research will provide critical data inputs in support of the TSPA-LA and subsequent performance confirmation. Effects on the capacity of secondary minerals to retain radionuclides and on the corrosion rate of fuel and/or glass are expected to be less significant. 
The proposed research is a collaborative effort among Argonne National Laboratory (ANL), Savannah River Technology Center (SRTC), and Idaho National Environmental and Engineering Laboratory (INEEL). Batch tests of steel-canister materials with radioactive fuel and glass will be performed at ANL, with a primary emphasis on determining colloid population, radionuclide association with colloids, and colloid stability, and a secondary emphasis on determining corrosion rates. At SRTC, batch tests will be performed with nonradioactive fuel and glass combined with canister materials and neutron absorbers, with a primary emphasis on determining canister corrosion rates and the fate of neutron absorbers, and a secondary emphasis on determining colloidal populations. INEEL will coordinate the studies and reports and provide quality assurance oversight.

\subsection{Technical Solution}

\subsection{ID02NM44 Technical Solution}

Project management will be organized such that the experimental activities are controlled at each laboratory, and oversight will be provided for the integration of the work between sites and with the existing program, which continues previously started studies. Cost and schedule goals as well as project progress will be met at the subtask and project level. Quality assurance programs that meet the QARD are in place at each facility and require a certain level of project monitoring. Included in the project management task is coordination with other tasks within the release rate project that are funded by other sources. Integration with the customers (sites responsible for DSNF, performance appraisal personnel, models, and other YMP personnel) will be ensured through written and verbal communication. Specific reporting and task completion goals will be set before the project is initiated. At a minimum, monthly status reports, semiannual data exchange meetings, and an annual review will be implemented. Costs will be monitored on a monthly basis.

Two specific laboratory needs will be addressed by the research funded by this TTP: SR01-6011, "Interactions Between Spent Nuclear Fuel, Storage Containers, and High-Level Waste in Repository CoDisposal Packages," and ID-S.1.21, "High-Level Waste Glass and Spent Nuclear Fuel Interactions." Results from the experimental portions of the joint proposal, addressed in two complementary TTP's prepared by ANL-E and SRS, will directly resolve the issues of both these needs. However, a larger program is in place to study all aspects of fuel degradation in a repository environment. In order for the data generated from the interaction tests to be applicable to those preparing the performance assessment models, the whole data package must be integrated. The primary purpose of the project management task is to ensure this integration is accomplished. Specific activities required for this assurance is monitoring of the experimental activities and results, review of quality assurance programs, and coordination of communication between interested parties. Organizations that may be included in information exchanges are NSNFP (responsible for the overall fuel degradation work), ANL (experimental laboratory), SRS (experimental laboratory and responsible for SNF and HLW), INEEL (responsible for SNF and HLW), Hanford (responsible for SNF and HLW), YMP (proposed repository site), Sandia (responsible for some performance assessment and modeling tasks), LANL (responsible for some modeling tasks), LLNL (responsible for canister material degradation work), and others as needed.

\subsection{CH22NM41 Technical Solution}

This work will use or modify existing test protocols for studying the corrosion of DSNF and DHLW glass in order to determine the effects of their co-disposal in steel canisters. The results of these tests will be included in performance assessment calculations. As discussed above, multiple interactions and products are possible in a co-disposal waste package, but the scope of this work is focused primarily on the quantity, composition, and stability of radionuclide-associated colloids, and to a lesser extent on the dissolution and speciation of neutron absorbers. The experimental plan, presented in Work Element 
A.0, consists of a series of integrated parametric tests in which various DSNF waste forms, DHLW glass, canister steel materials, and neutron absorbers interact in EJ-13 groundwater at $90^{\circ} \mathrm{C}$ under static batch conditions.

The primary focus of this work (determination of quantity, composition, and stability of radionuclide-associated colloids) will be addressed by performing interaction tests with spent nuclear fuels in the hot-cell facility. The effect of materials interactions will be determined by measuring the extent of degradation and colloid generation from one material when exposed to solutions generated during the corrosion of the other materials. This will allow the effects on waste form degradation rates and colloid generation to be distinguished for modelling purposes. The effects of the solution chemistry will be further studied by spiking some leachants with Gd or Hf or by fixing the $\mathrm{pH}$.

The secondary focus of this work (dissolution and speciation of neutron absorbers) will be addressed in two ways. Current plans for co-disposal waste packages include $\mathrm{Gd}$ and $\mathrm{Hf}$ as neutron absorbers in the structural steel and in some waste forms. Initially, we will add soluble Gd and Hf to tests containing the solid test constituents (DSNF, crushed DHLW glass, Type 304L stainless steel) in groundwater. This will allow determination of $\mathrm{Gd} / \mathrm{Hf}$ speciation from the dissolved phase to surfaceadsorbed phases, precipitated species, colloidal species, and dissolved species. Following that test, ANL will substitute a neutron absorber-modified structural steel material (provided from ongoing development activities at INEEL) for the Type 304L steel coupon and repeat the test in groundwater. In this case, the neutron absorbers must be released from the modified steel prior to interacting with the other corroding constituents. Thus, this test allows determination of the release rate of $\mathrm{Gd} / \mathrm{Hf}$ from modified steel in a codisposal test package, subsequent distribution of the $\mathrm{Gd} / \mathrm{Hf}$, and any differences in speciation from the simple dissolved forms. This comparison is required to test the accuracy of models predicting the fate of neutron absorbers after waste package breach. Our collaborators at SRTC will test neutron absorbers that are an integral part of the melt-dilute waste form. These laboratory tests are required to test the accuracy of models predicting neutron absorber fate. At both laboratories, the effect of $\mathrm{Gd} / \mathrm{Hf}$ on colloid populations will be determined. It is expected that at high $\mathrm{pH}$, Hf will destabilize colloids and significantly alter neutron absorber mobility.

\subsection{SR02NM42 Technical Solution}

The technical scope of this work seeks to provide essential data needed for the effects of DSNF and DHLW glass co-disposed in steel canisters to be included in performance assessment calculations. As discussed above, multiple interactions and products are possible in a co-disposal waste package, but the scope of this work is focused on three primary data needs: (1) the quantity, composition, and stability of radionuclide-associated colloids; (2) the dissolution and speciation of neutron absorbers; and (3) the rate of waste container degradation. The experimental plan presented in this section consists of a series of integrated parametric tests performed at SRTC.

Current requirements for the permanent disposal of DOE-owned spent nuclear fuel (DSNF) and defense high-level waste glass (DHLW) specify that they be packaged together in steel canisters and disposed in the proposed repository at Yucca Mountain. In addition, repository acceptance criteria state: "Materials of construction of the DOE SNF canisters and their internals shall be selected to be compatible with waste disposal package materials and with the contained SNF. Canister materials shall not corrode or otherwise chemically attack the waste package from the inside, and they shall not increase rates of degradation of contained SNF or mobilize radionuclides for transport subsequent to waste package breach." To meet these requirements prior to approval by the Nuclear Regulatory Commission (NRC), models of radionuclide release and transport have been generated for use in the Total System Performance Assessment-Site Recommendation (TSPA-SR) and License Application (LA). The models are based on limited available data from independent corrosion studies of DSNF, DHLW, and canister 
materials. However, no detailed studies have been performed to determine radionuclide release from these wastes in an interactive co-disposal environment. Based on solution chemistries and corrosion products observed in corrosion studies of the individual components, it is expected that significant material interactions will occur in a co-disposal repository environment. Thus, there is a need to experimentally determine the chemical consequences of co-disposal and to include these results in TSPA models of waste package and waste form corrosion.

At SRTC, FY 2002 tests will be performed with an unirradiated Al-based UAlx melt-dilute waste form that contains both $\mathrm{Gd}$ and $\mathrm{Hf}$. This waste form has been metallographically characterized at SRTC in previous waste form development studies. The DWLW glass will be crushed fragments from a previous waste vitrification campaign at Savannah River. The material will be sieved and its size verified by scanning electron microscopy (SEM) prior to use in the tests. Two waste package steels will be tested: carbon steel and 304L. The carbon steel will be used without pretreatment, but the 304L will be preoxidized in water vapor at $200^{\circ} \mathrm{C}$. At both ANL and SRTC, leachant solutions of DHLW will be generated by reacting crushed DHLW glass with EJ-13 groundwater at $90^{\circ} \mathrm{C}$ and multiple surface-area-to-solution-volume ratios. This will result in different solution chemistries (different $\mathrm{pH}$ values, ionic strengths, and amounts of colloids) representative of the effects of different groundwater ingression rates and contacted glass surface areas that may occur in the disposal system.

All proposed tests at ANL and SRTC are static batch tests maintained at $90^{\circ} \mathrm{C}$ in closed vessels. They will be conducted following a modified ASTM C1220, "Standard Test Method for Static Leaching of Monolithic Waste Forms for Disposal of Radioactive Waste" (equivalent to MCC-1), test protocol with monolithic wafers of DSNF, DHLW, and/or steel coupons submerged in EJ-13 or leachant solutions. Some tests will be performed with crushed DHLW instead of wafers. Each test will be interrupted periodically for sampling and evaluation, and if appropriate, the test vessels will be returned to the oven for further reaction. Although the test matrix is different at each laboratory, the general scheme includes tests with different combinations of solid DSNF waste form material, DHLW glass, and waste package substrates, or leachates from those solids, in contact with groundwater. The resulting solutions will be analyzed periodically for $\mathrm{pH}$, Eh, elemental concentrations, and colloids, while the solid substrates will be examined to determine the extent of corrosion.

At SRTC, first-year tests will be performed with an Al-based UAlx melt-dilute waste form that contains neutron absorbers in order to determine the effect of co-disposal interactions on the fate of the neutron absorbers. Two types of steel will be included to determine the corrosion rate of the steel materials in waste form leachates. The first set of tests will examine the effect of steel corrosion on the melt-dilute waste form. Solid melt-dilute wafers will be placed in EJ-13 groundwater with and without coupons of solid carbon steel or 304L. In some tests, steel leachant solutions will be used instead of the solid steel coupons in order to determine the effect of steel solutes and colloids on dissolution of the meltdilute waste form and speciation of the neutron absorbers. Aliquots of the leachant solutions and the test samples (melt-dilute wafer plus steel or steel leachant) will be withdrawn periodically from the test to determine solution elemental composition and colloid population and size distribution. Of particular interest is the distribution of Gd and Hf among dissolved, colloidal, and solid phases. Solution aliquots will be filtered to separate colloidal species; both dissolved and colloidal fractions will be analyzed with inductively coupled plasma-mass spectrometry (ICP-MS), and the fraction of Gd and $\mathrm{Hf}$ in each will be determined. Spalled solid products will be analyzed by SEM or XRD, as appropriate, to determine mineral phases and their Gd or Hf association. The melt-dilute wafer will be weighed at each sampling to provide a rough measure of waste form degradation and then returned to the test vessel for further corrosion.

In the second set of tests, the effect of DHLW corrosion of the melt-dilute waste form will be examined. The setup and analysis scheme for this series is the same as for the first set, except that solid 
DHLW glass fragments and glass leachant will be used instead of the steel coupons and steel leachant. Solutions and solids will be analyzed as in the first series to determine Gd and Hf distribution, solution composition, colloid population, and mineral phases.

\subsection{Status}

This is the initial year on these projects. The projects are at the Advanced Development Stage, where the projects are attempting to expand an inadequate knowledge base on properties of materials in the Yucca Mountain repository environment. This year, the experimental setup has been initiated, but testing has not started due to a delay in the DOE funds disbursement.

\subsection{Funding}

\subsection{ID02NM44 Funding}

Estimates are based on similar tasks within the same project (release rate experiments). Labor will require 250 hours from INEEL at about $\$ 100 / \mathrm{hr}$ (a total of $\$ 25 \mathrm{~K}$ ). Travel will be required for project status meetings and quality assurance reviews. Two trips per laboratory at an estimated $\$ 2.5 \mathrm{~K}$ each will be needed $(\$ 5 \mathrm{~K})$. As the project ramps up in out years, the labor is expected to increase to 400 hours $(\$ 40 \mathrm{~K}$ at $\$ 100 / \mathrm{hr})$ per year and travel will include four trips per year at $\$ 2.5$ each $(\$ 10 \mathrm{~K})$.

\subsection{CH22NM41 Funding}

Table 3.4-9 CH22NM41 budget summary.

\begin{tabular}{||l|l|l|l||}
\hline FY02 & FY03 & FY04 & FY05 \\
\hline$\$ 185 \mathrm{~K}$ & $\$ 350 \mathrm{~K}$ & $\$ 350 \mathrm{~K}$ & $\$ 120 \mathrm{~K}$ \\
\hline
\end{tabular}

Table 3.4-10 CH22NM41 Spending Plan for FY02.

\begin{tabular}{||l|l|l|l|l|l|l|l|l|l|l|l||}
\hline OCT & NOV & DEC & JAN & FEB & MAR & APR & MAY & JUN & JUL & AUG & SEPT \\
\hline 15 & 15 & 15 & 15 & 15 & 15 & 15 & 15 & 15 & 20 & 15 & 15 \\
\hline
\end{tabular}

Co-Funding: None 


\subsection{SR02NM42 Funding}

Table 3.4-11 SR02NM42 life cycle cost estimate (\$K) tasks A \& B.

\begin{tabular}{|c|c|c|c|c|c|c|c|}
\hline \multicolumn{8}{|c|}{ B\&R Code: EW40 } \\
\hline & $\begin{array}{l}\text { Total Activity } \\
\text { To Date }\end{array}$ & $2002 \mathrm{R}$ & $2003 \mathrm{R}$ & $2004 \mathrm{R}$ & $2005 \mathrm{R}$ & All Subs & Total Years \\
\hline $\mathrm{OC}$ & 0 & $\$ 185$ & $\$ 335$ & $\$ 335$ & 0 & 0 & $\$ 855.0$ \\
\hline $\mathrm{CE}$ & 0 & 0 & 0 & 0 & 0 & 0 & 0 \\
\hline GPP & 0 & 0 & 0 & 0 & 0 & 0 & 0 \\
\hline LI & 0 & 0 & 0 & 0 & 0 & 0 & 0 \\
\hline TOTAL & 0 & $\$ 185$ & $\$ 335$ & $\$ 335$ & 0 & 0 & $\$ 855.0$ \\
\hline FTEs & 0 & 0.7 & 1.25 & 1.25 & 0 & 0 & 3.2 \\
\hline
\end{tabular}

Table 3.4-12 SR02NM42 spend plan (\$K).

\begin{tabular}{|l|l|c|c|c|c|c|c|c|c|c|c|c|c|c|c||}
\hline $\begin{array}{l}\text { FY- } \\
2002\end{array}$ & $\begin{array}{l}\text { PY- } \\
\text { CO }\end{array}$ & OCT & NOV & DEC & JAN & FEB & MAR & APR & MAY & JUN & JUL & AUG & SEP & $\begin{array}{l}\text { FY- } \\
\text { CO }\end{array}$ & TOTAL \\
\hline & 0 & 15 & 15 & 15 & 15 & 15 & 20 & 15 & 15 & 15 & 15 & 15 & 15 & 0 & 185 \\
\hline
\end{tabular}

\subsection{Alignment to Thrust Areas and Key Goals and Priorities}

These projects support Thrust 2, Alternative Approaches to Current High Risk/High Cost Baselines. Without the data that these projects will provide, there is risk of the licensing authorities rejecting the license conditions. Also, there would be rework costs to re-analyze the problem or gather data at a later date.

These projects support the following key EM goals and priorities.

1. Improve Safety Performance by assuring licensing basis for DOE-SNF disposition in repository

2. Reduce Cost and Time Required to Complete the EM Cleanup Mission by assuring that performance issues of EM-SNF in repository are adequately addressed.

\subsubsection{Project Review Results}

The review panel recommended that an external panel review the need for these projects, and that any future funding should be pursued under Basic Science.

\subsubsection{SR02NM51, Determination of Radiolysis Effects for Water on Spent Nuclear Fuel; and ID02NM45, Modeling of Radiolytic Gas Generation in Metal Oxyhydroxides}

\subsubsection{Project Overview}

SNF in storage canisters must be dried to prevent excessive corrosion and gas generation in the sealed canister because any bound water has the potential to generate gas by radiolysis in an SNF canister. 
However, a standard to define adequate levels of "dry" does not exist. These projects will perform irradiation tests on systems important to SNF storage and disposal. They will begin with aluminum systems, and move to others in the out years. During these tests, they will see if radiolytic gases are formed, and determine the Gibb's energy of formation. They will perform semi-empirical analytical modeling of the reaction sequences to calculate Gibb's values with the test data. With this information, they will help to develop American Society of Testing and Materials (ASTM) standards to codify the drying activities.

Knowledge about the radiolysis effects will help improve safety and reduce the risk associated with SNF site storage, transportation, and repository disposal. It should eliminate need to measure water content for SNF. The ASTM guide will help assure the Nuclear Regulatory Commission (NRC) and gain stakeholder acceptance of SNF drying processes used for damaged and high burnup fuels.

\subsection{SR02NM51 Scope}

The overall scope of this work for the INEEL and SRTC sites will provide essential data needed for the basis for a drying/stabilization standard for DOE Spent Nuclear Fuel. The drying/stabilization treatments would provide the sufficient and necessary steps for removal of water from the fuel in a storage/disposal system to avoid additional corrosion reactions and gas generation that could lead to pressurization of the sealed canisters, or hydride formation and embrittlement of cask or fuel components.

\subsection{ID02NM45 Scope}

The overall scope of this work for the INEEL and SRTC sites will provide essential data needed for the basis for a drying/stabilization standard for DOE Spent Nuclear Fuel. The drying/stabilization treatments would provide the sufficient and necessary steps for removal of water from the fuel in a storage/disposal system to avoid additional corrosion reactions and gas generation that could lead to pressurization of the sealed canisters, or hydride formation and embrittlement of cask or fuel components.

Free and bound water is present on the surfaces of most DOE SNF upon retrieval from basin storage systems. Each fuel-owner site is developing drying specifications and treatments as the fuels and fuel rubble materials are placed into interim storage canisters and/or "road-ready" disposal canisters to avoid chemical reactions leading to corrosion, gas build-up, and materials reconfiguration. It is nearly impossible to remove all water from the fuel with conventional drying treatments, especially if the water is trapped or is chemically bound (e.g., metal oxyhydroxides and hydrated oxides) in the fuel.

\subsection{Technical Solution}

\subsection{SR02NM51 Technical Solution}

The ultimate objective is to develop and issue an ASTM standard guide for drying DOE SNF using the results from previous drying tests at SRTC, INEEL, and Hanford, together with the results from the tests and analyses in this testing and analysis program.

Free and bound water is present on the surfaces of most DSNF upon retrieval from basin storage systems. Each fuel-owner site is developing drying specifications and treatments as the fuels and fuel rubble materials are placed into interim storage canisters and/or "road-ready" disposal canisters to avoid chemical reactions leading to corrosion, gas build-up, and materials reconfiguration. It is nearly impossible to remove all water from the fuel with conventional drying treatments, especially if the water is trapped or is chemically bound (e.g., metal oxyhydroxides and hydrated oxides) in the fuel. 
Literature data on the efficiency of hydrogen production $\left(\mathrm{GH}_{2}\right)$ by radiolysis of water are rather limited. The available data suggest that the magnitude of $\mathrm{GH}_{2}$ may vary, and may be dependent on the physical and chemical states of the 'water' (i.e., bulk water, water vapor, physisorbed and chemisorbed water), the matrix material, and the dimensions of the sample. Recent literature suggests that recombination of radiolysis products are favored in bulk systems. This would suggest that the mean free path of the radiolysis product (i.e., the hydrogen radical) is one of the determinants of the value of $\mathrm{GH}_{2}$. If this is true, it seems reasonable that in a system of low density or short dimension, such as water vapor or physisorbed water, the hydroxylion $\left(\mathrm{OH}^{-}\right)$is relatively free to leave the vicinity of the broken bond, and would favor the production of hydrogen. Conversely, a condensed system, such as liquid water or a hydrated crystal, would limit the mobility of the radical species and favor the re-formation of the broken bond. In most crystalline metal oxyhydroxides or hydrated oxides, the mobility of the hydrogen radical through the crystalline lattice is most likely extremely slow, comparable to the hydrogen diffusion rate through the material, thereby increasing the probability of recombination. Therefore, the $\mathrm{GH} 2$ value for oxyhydroxides and hydrated oxides may depend on the intrinsic diffusivity of the matrix and the physical size or specific surface area, in addition to the intrinsic bond strength of the material.

The metal oxyhydroxide systems to be investigated in the project are present on many DSNF that have been in basin storage either from oxidation of the fuel/clad materials themselves or from sludge deposits. These systems include aluminum, uranyl, and iron oxyhydroxides. These systems include compounds (e.g. Boehmite, $\mathrm{AlO}(\mathrm{OH})$ and Goethite, $\mathrm{FeO}(\mathrm{OH})$ that require high temperatures (much greater than $200^{\circ} \mathrm{C}$ ) to dehydrate and those (e.g. Bayerite, $\left.\mathrm{Al}(\mathrm{OH})_{3}\right)$ that dehydrate at slightly elevated temperatures $\left(<200^{\circ} \mathrm{C}\right)$ that could be used in drying operations of SNF. A comparison of the production of radiolytic gases in these types of compounds would be used to provide a foundation to estimate formation of radiolytic gases in other metal oxyhydroxide systems. The data and information from this task would provide the technical basis that can be used to complete the development of a drying standard for SNF.

The FY02 workscope for SRTC initiates the experimental program and provides data on $\mathrm{H}_{2}$ production in mixed alpha/gamma fields of several predominant metal oxyhydroxide systems that are found as corrosion debris on DOE SNF.

The FY02 tests will focus initially on the use of pure $\mathrm{Al}(\mathrm{OH})_{3}$ and $\mathrm{AlOOH}$ materials, for which the water and hydroxyl content, elemental and phase composition, crystallinity, and particle size will be determined. Following the tests with the pure bayerite and boehmite, tests will be initiated on uranium oxides, such as $\mathrm{UO}_{2}(\mathrm{OH})_{2}$ and $\mathrm{UO}_{2}(\mathrm{OH})_{2} \bullet \mathrm{H}_{2} \mathrm{O}$. Tests with iron oxides, such as $\mathrm{Fe}(\mathrm{OH})_{3}$ and $\mathrm{FeOOH}$ will be initiated in FY03. The FY02-FY04 test program will investigate radiolysis as a function of temperature, radiation exposure and exposure rate (104-106 R/hr), and specific surface area (particle size).

The tests in FY02 will be conducted at the ambient temperature of the $106 \mathrm{R} / \mathrm{hr}$ gamma cell $\left(70^{\circ} \mathrm{C}\right)$. Blank and control tests may involve the testing of pure water vapor environments and physisorbed water to aid the analysis of the solid phase testing. The gamma cell field tests will be performed with and without an alpha source (e.g., ${ }^{238} \mathrm{U}$ ) next to powder specimens of the oxyhydroxide systems in evacuated capsules to be placed in a gamma field. The existing SRTC irradiation capsule design will be modified for instrumentation with $\mathrm{H}_{2}$ sensors to measure $\mathrm{H}_{2}$ generation during the irradiation. A full analysis of the gas species will be performed following the irradiation. Pre- and post-irradiation analyses of the oxide products will be performed by XRD, SEM and TEM and a detailed description of the alteration phases will be provided.

Project management will involve all oversight and reporting activities associated with the performance of the technical tasks described in this document. Included in this task is preparation of 
Technical Task Plans, monthly reporting, cost and schedule control, assurance of quality controls, test oversight, coordination between test laboratories, participation in ASTM reviews, and interface activities with the Nuclear Materials Focus Area (NMFA). As part of this effort monthly reports will be written and submission $\left(15^{\text {th }}\right.$ of each month) to Chris Dahl at INEEL. Additionally, this task will encompass NMFA reporting meetings, which will also be coordinated through INEEL.

\subsection{ID02NM45 Technical Solution}

In FY02 the INEEL will provide the initial analytic modeling of the effects of ionizing radiation, including potential radiolytic modifications of the dehydration reaction pathways for the aluminum oxyhydroxide system. The analytic models generated will then be validated and adjusted with the test data from SRTC, for use as the basis for similar models for the Fe and U systems. The specific FY02 scope is expected to include:

1. Perform an updated literature review of radiation effects and dehydration reaction technical data on metal oxyhydrate systems of interest.

2. Assist SRTC with the planning and statistical experiment design of irradiation tests on metal oxyhydroxide systems.

3. Generate mathematical models for the interaction of potential aluminum oxyhydroxides with alpha and gamma radiation and provide outputs as a function of system variables.

4. Assist in the analysis and interpretation of SRTC test outputs.

5. Correlate SRTC test data with INEEL model data to determine the probable recombination coefficients for hydrated species affected by radiation.

6. Co-author SRTC letter report on initial testing and analysis of gaseous species from aluminum oxyhydroxide material.

This INEEL work scope involves careful collaboration with the SRS work scope (TTP SR02NM51).

\subsection{Status}

The project maturity is Level 2, Applied Research. These projects will develop enhanced technical information that will be used to construct of evaluative models. There is little information on radiolysis in SNF containers due to water and no application methodology exists. These projects are just starting due to a delay in releasing FY 2002 funding. 


\subsection{Funding}

\subsection{SR02NM51 Funding}

\section{BUDGET SUMMARY}

Life Cycle Cost Estimate (\$K)

Table 3.4-13 SR02NM51 EM-50 funding B\&R code: EW4010.

\begin{tabular}{||l|l|l|l|l|l|l||}
\hline $\begin{array}{l}\text { TOTAL } \\
\text { ACTIVITY }\end{array}$ & TO DATE & 2003 & 2004 & 2005 & TOTAL & $\begin{array}{l}\text { RANGE OF CERTAINTY } \\
{[+/-\%]}\end{array}$ \\
\hline TOTAL & $255 \mathrm{~K}$ & $285 \mathrm{~K}$ & $285 \mathrm{~K}$ & & & \\
\hline
\end{tabular}

Table 3.4-14 SR02NM51 spend plan (\$K).

\begin{tabular}{||l|r|r|r|r|r|r|r|r|r|r|r|r|r|r||}
\hline $\begin{array}{l}\text { NMFA } \\
\text { FUNDING }\end{array}$ & PY-CO & OCT & NOV & DEC & JAN & FEB & MAR & APR & MAY & JUN & JUL & AUG & SEP & FY-CO TOTAL \\
\hline $\begin{array}{l}\text { JOINT } \\
\text { FUNDING }\end{array}$ & 0 & 0 & 0 & 0 & 0 & 0 & 0 & 0 & 0 & 0 & 0 & 0 & 0 & 0 \\
\hline
\end{tabular}

\subsection{ID02NM45 Funding}

Table 3.4-15 ID02NM45 Task A - activity-based estimate (\$K)FY 2002.

\begin{tabular}{||l|l||}
\hline WORK ELEMENT A.1 & $\$ 5 \mathrm{~K}$ \\
\hline Work Element A.2 & $\$ 49 \mathrm{~K}$ \\
\hline Work Element A.3 & $\$ 40 \mathrm{~K}$ \\
\hline Work Element A.4 & $\$ 31 \mathrm{~K}$ \\
\hline TOTAL & $\$ 125 \mathrm{~K}$ \\
\hline
\end{tabular}

\subsection{Alignment to Thrust Areas and Key Goals and Priorities}

These projects support Thrust 2, Alternative Approaches to Current High Risk/High Cost Baselines. This alternative approach to current high risk, high cost baseline eliminates need for extensive re-treatment of SNF containers after interim storage. The data developed will help to reduce risk and may reduce drying requirements and cost.

These projects support the key EM goal and priority 1. Improve Safety Performance by assuring licensing basis for EM-SNF disposition in repository. The data from this program will improve the safe storage of SNF, and the correct use of models should prevent over-pressurization events. 


\subsubsection{Project Review Results}

The review team recommended that these projects continue in FT 2002. They believed they to be critical to the success of SNF disposition, and they anticipated that they would align with ongoing EM priorities.

\subsubsection{ID02NM42, Investigating the Corrosion Resistance of New Alloys; and AL22NM41, Microstructure/Mechanical Properties Investigation for New Alloys to Control Nuclear Criticality}

\subsubsection{Project Overview}

Interim storage and final disposition of EM SNF in the standardized canister will require structural inserts fabricated from neutron absorbing materials to maximize SNF loading in the canister. Also, the next generation of transport casks may require neutron absorbing structural materials. These projects will investigate possible new alloys for use in the standardized SNF canisters. They will measure the mechanical properties of an alloy for ASTM standard development and ASME Code acceptance, determine the alloy's microstructural features that control mechanical properties, perform laboratory corrosion testing to measure base corrosion performance of the alloy and resistance to localized corrosion, and determine the effect of the alloy microstructure (gadolinide second phase) on corrosion performance.

With the new alloy, they should be able to decrease the number of SNF packages going to the repository, along with reduced handling and materials costs. The new neutron absorber material could also be used in other applications where structural integrity is an issue.

\subsection{Scope}

The Department of Energy has over 200 types of Spent Nuclear Fuel (SNF) that it has to manage in wet storage, interim dry storage, transportation, and final disposition in the proposed national repository. The fuel management approach for DOE SNF is to package it in the DOE standardized canister. Criticality control measures in the form of canister inserts fabricated from a corrosion resistant, neutron absorbing material are needed in some of the SNF canisters because of the fuel enrichment and total quantity of fissile material. Water moderates fast neutrons emitted from the SNF, yielding a higher percentage of neutrons capable of initiating fission. Water may enter a fuel canister from incompletely dried SNF and during handling in storage and transfer basins. Long-term storage includes the possibility of water intrusion. Criticality control for enriched SNF in repository disposal is particularly problematic in that the SNF may become more reactive as it degrades from its initial geometry and product form. The structural neutron absorbing material must corrode (dissolve) at a rate comparable to the standardized canister structural material and the SNF cladding, improving the likelihood that it would be present to minimize criticality even in the event that the system degrades completely, as is postulated in permanent disposal.

Acceptance of the DOE SNF for disposal will rely on the ability to show, with sufficient levels of confidence, that the inclusion of DOE SNF will not impact the repository overall performance based on the proposed Nuclear Regulatory Commission (NRC) regulation (10 CFR 63). An important objective of geologic disposal is keeping the fissionable material in a condition such that a self-sustaining nuclear chain reaction (criticality) is highly unlikely. A low probability of a criticality is primarily met by the fact that the waste package, in conjunction with the drip shield, will not breach until well beyond the 10,000 years regulatory time period. However, a methodology has been developed by the DOE Office of Civilian Radioactive Waste Management for evaluating criticality potential for HLW and SNF (referred to collectively as the waste form) after the repository is sealed and permanently closed (postclosure phase). 
This methodology includes deploying criticality controls necessary to ensure these low probabilities are maintained through the regulatory period ( $>10,000$ years.). This requirement cannot be met without a suitable neutron absorber in the DOE standardized canister.

To minimize risk associated with storing DOE-owned SNF, various legal and policy directives are required to mange DOE SNF. However, long-term stewardship includes a complex-wide environmental management approach that ensures the DOE honors long-term commitments as well. The DOE approach includes emplacement of SNF into interim storage while implementing cost-effective preparations to achieve both interim safety and authorization for shipment off-site. The U.S. Congress charged the DOE with managing the geologic disposal of high-level radioactive waste (HLW) and SNF through the Nuclear Waste Policy Act of 1987. Following interim storage at each of the DOE sites, it is proposed that the DOE SNF be emplaced in a national repository along with the commercial SNF and high-level waste, which the DOE must also dispose of. EM under various inter-state agreements is also required to address both short-term and long-term stewardship of the SNF. Therefore, DOE must ensure long-term objectives are implemented during short-term commitments as an integral part of their management of SNF. By ensuring these long-term objectives are meet, reduced costs, occupational health, and safety risks will be reduced.

In October 1994, the Defense Nuclear Facilities Safety Board (DNFSB) identified a need to clearly "define the path forward" for SNF. One of the purposes of establishing the Office of Spent Nuclear Fuel Management was to address this issue. Actions assigned included (1) development and implementation to address DNFSB-identified vulnerabilities, (2) formulation of program requirements, and (3) development of a process for placing DOE-owned SNF in a geological repository.

In 1996, a technology integration plan was issued to establish a common and consistent technical basis for developing technology, integrating DOE complex-wide efforts, and developing timely, costeffective technical solutions for DOE SNF management. The plan used a systematic methodology to (a) identify SNF technology development needs, (b) identify the associated cost and schedules, and (c) prioritize the identified technology needs. Since issuance of the plan, as part of the formulation of program requirements, an EM/RW memorandum of agreement between the Assistant Secretary for Environmental Management (EM) and the Director Office of Civilian Radioactive Waste Management (RW) defines CRWMS (Civilian Radioactive Waste Management System Management) requirements applicable to DOE SNF. The EM/RW Memorandum of Agreement also requires EM to use the Civilian Radioactive Management System Waste Acceptance System Requirements Document (WASRD) requirements for preparing the SNF so that it is acceptable to RW for disposal in a monitored geologic repository. The WASRD defines the acceptance criteria for commercial SNF and government-owned nuclear materials expected to be received by the CRWMS, as well as system-level performance. The current repository requirements to address long-term criticality controls have been identified in a methodology defined in the Disposal Criticality Analysis Methodology Topical Report (CRWMS M\&O 2000e). This methodology is required to demonstrate acceptable criticality control for canisters and the waste packages in which they are disposed. The methodology identifies advanced neutron materials that are highly corrosion resistant and have long-lived neutron-absorbing capabilities.

\subsection{Technical Solution}

\subsection{ID02NM42 Technical Solution}

The first year of corrosion testing will entail investigations of one Ni-Cr-Mo-Gd alloy type developed in previous work. These tests will employ standard ASTM electrochemical testing procedures and additional testing procedures described in the literature for determining the best candidates for further study. 
The solution compositions chosen for the work are arrived at by considering between the very specific chemistry of the Yucca Mountain aquifer and standard solution compositions, which have the inherent value of providing a benchmark for comparison with a large database of previous testing. Because these materials are novel in composition, the case for using standard solutions is strong, as the data will be of more general interest outside the Yucca Mountain project. In addition, the composition of the solution that would contact the neutron absorbing inserts during a breach of the waste package/standardized canister is not absolutely determined. Thus, our initial test solutions will use chloride as the aggressive ion, the expected aggressor in most environmental circumstances where alloys such as stainless steels and Ni-based alloys that rely on passivity for corrosion resistance. Other potentially inhibiting ions, which may complicate the testing results, are not being considered for these initial experiments. Specifically, our testing will focus on two sodium chloride concentrations: dilute ( 0.05 molar) and concentrated (1.0 molar). Three $\mathrm{pH}$ values will be used in these initials tests, spanning from mildly acidic to mildly basic. Additional testing will be performed in acidic, $\mathrm{NaCl}$ solutions to compare results with Nuclear Regulatory Commission generated data. Thus, samples will be tested in a matrix of eight solutions in the initial year's work. Testing will be performed at room temperature $\left(30^{\circ} \mathrm{C}\right)$, as container breach is expected to occur on a time scale exceeding the time needed for fuel cooling.

The testing procedures will closely follow ASTM standard methods G5 and G61 for cyclic potentiodynamic measurement of current as a function of potential. These standard techniques will be modified by techniques described in the literature that are being used to study the corrosion resistance of candidate materials for the proposed Yucca Mountain waste package that will contain commercial reactor and DOE SNF. The electrochemical testing will focus on the effect of the gadolinium addition on the passive corrosion rate and localized corrosion tendencies. The tests will define the corrosion potential breakdown potential and repassivation potential of these alloys on a short- and long-term basis. We will use this information to make initial predictions of the probability of leaching the gadolinium out of the alloy microstructure. The anodic current density of these alloys will be measured, and a passive corrosion rate will then be calculated. These tests will be supplemented with weight loss, chemical, and microscopic analysis to determine the effect of the test on the sample. Gravimetric analysis of the test samples offers a simple determination of corrosion rate and serves as a performance comparison between samples. Chemical analysis of the testing medium using atomic absorption spectroscopy will supplement the weight loss data in quantitatively determining the elements dissolved by corrosion. Microscopic analysis by optical and electron microcopies will also be performed to aid in this characterization, specifically to determine the pitting morphology (depth and occurrence) and to determine which phases are specifically attacked. This work beyond the corrosion tests will aid in further developing the alloys in the last two years.

\subsection{AL22NM41 Technical Solution}

Interim and long-term storage of DOE spent nuclear fuel will require container structural inserts made from neutron absorbing materials to maximize fuel loading. The neutron absorbing alloys, which are currently being developed for this application, must meet American Society for Testing and materials (ASTM) and American Society for Mechanical Engineers (ASME) code requirements. The work here executes a metallurgical development program to enhance the fabrication and determine the mechanical properties of Ni-Cr-Mo-based alloys that are alloyed with varying levels of Gd. For FY-2002, we will determine base metal mechanical properties, and begin ASTM and ASME codification of the new alloys. This task is a joint project with NMFA TTP ID02NM42, which is investigating the corrosion properties of the new alloys. 


\section{Work Element A-1: Determine Base Metal Mechanical Properties}

The database of mechanical properties required for ASME B\&PV Code applications includes, at a minimum, tensile testing and Charpy vee-notch (CVN) impact testing. For the tensile testing, the tests must be conducted at temperature intervals up to and exceeding those expected in service, and must be statistically valid. For the Ni-Cr-Mo-Gd alloys, we expect that at least two alloy heats will be available for testing (note that the compositions of the heats are being developed in the current program). The progress of testing depends on the availability of plate material, and is required as refinements to the alloy production process are developed and incorporated.

Testing will be conducted in two orientations (longitudinal and transverse) relative to the plate rolling direction. The temperature range for this testing will be determined by analysis of the various possible repository canister configurations and SNF loading.

CVN impact testing will be conducted in the T-L sample orientation (long axis oriented in the transverse plate direction and fracture path in the rolling direction) as this is generally the lowest impact energy orientation. ASME B\&PV Subcommittee III (Nuclear) generally requires a minimum of 20 Joule impact energy over the range of expected operating temperatures. Although it has not yet been demonstrated that the developmental Ni-Cr-Mo-Gd alloys meet this requirement for impact toughness, experience with borated stainless steels at a similar volume fraction of secondary constituents indicates that the Ni-Cr-Mo-Gd alloys should be capable of meeting the requirements. Moreover, the experience gained in the current fiscal year should provide guidance for hot rolling practice and composition control capable of producing sufficient impact energies.

Experience with past ASME Code Case submissions indicates that other data sets may be required as the Code Case progresses through the various subcommittees and subgroups of Section III. The requests for other data would be expected to include (1) low-cycle fatigue properties (particularly in the event that that the Ni-Cr-Mo-Gd alloys are considered for transportation applications), (2) thermal expansion properties, and (3) elastic moduli.

\section{Work Element A-2: ASTM and ASME Codification of the New Alloys}

Two primary activities are associated with incorporating a new material into the B\&PV Code. The first is to adopt an American Society for Testing and Materials (ASTM) specification for the alloy(s). This activity is already underway but can be expected to continue throughout FY02. This work element includes developing the specification and travel to ASTM committee meetings. Second, though the mechanical properties database for the base materials will not be completed until third quarter FY02, we expect that interaction with the ASME Committees will begin early in the fiscal year. Alerting the Committee to proposed Code Case will ensure that appropriate testing is conducted throughout the year and will minimize delays associated with incomplete data sets. or the generation of additional data should the Committee require it. ASME meets three times per year, so that appreciable travel is associated with this work element.

\subsection{Status}

These projects are at the Engineering Development stage. Previous work has identified the proposed neutron absorbing material. This work scope is to verify properties and be able to gain code acceptance as a construction material. So far the projects have procured the test material and begun vacuum arc remelting of the material under NSNFP development funding. Initial charpy impact testing of samples from FY 2001 program is complete using NMFA funding. These tests were needed to set ingot rolling parameters for the FY 2002 program. 


\subsection{Funding}

\subsection{ID02NM42 Funding}

Table 3.4-16 ID02NM42 consolidated funding and basis.

\begin{tabular}{||l|c|c|c|c||}
\hline COST ELEMENT & PRIOR YEARS $(\$ K)$ & FY 2002 $(\$ K)$ & FY 2003 $(\$ K)$ & FY 2004 (\$K) \\
\hline Labor & $\$ 0.0$ & $\$ 100.0$ & $\$ 320.00$ & $\$ 480$ \\
\hline Travel & $\$ 0.0$ & $\$ 10.0$ & $\$ 20.0$ & $\$ 20.0$ \\
\hline Subcontracts & $\$ 0.0$ & $\$ 10.0$ & $\$ 30.0$ & $\$ 10.0$ \\
\hline $\begin{array}{l}\text { Supplies / } \\
\text { Materials }\end{array}$ & $\$ 0.0$ & $\$ 10.0$ & $\$ 20.0$ & $\$ 20.0$ \\
\hline Total & $\$ 0.0$ & $\$ 130$ & $\$ 262.7$ & $\$ 530.0$ \\
\hline
\end{tabular}

Basis of Estimates:

- Material costs: - The material costs are based pricing of test ingots of Ni-Cr-Mo-Gd alloys procured in FY2001. There are also sample costs included for alloy 22 for comparison purposes and additional laboratory supplies such as chemicals and replacement parts for electrochemical instrumentation subject to degradation during the testing.

- Labor estimates based on costs for the three PI's and associated laboratory personnel.

- Trips: One trip for two people to Sandia National Lab for technical consultation with development partner.

\subsection{AL22NM41 Funding}

\section{BUDGET SUMMARY}

Table 3.4-17 AL22NM41 life cycle cost estimate (\$K) task A.

\begin{tabular}{||l|l|l|l|l|l|l||}
\hline B\&R CODE & $\begin{array}{l}\text { TOTAL ACT TO } \\
\text { DATE: }\end{array}$ & FY 2002 & FY 2003 & FY 2004 & FY 2005 & TOTAL \\
\hline $\begin{array}{l}\text { EM-50 Funding: } \\
\text { EW4010 }\end{array}$ & $\$ 0 \mathrm{~K}$ & $\$ 120 \mathrm{~K}$ & $\$ 377 \mathrm{~K}$ & $\$ 260 \mathrm{~K}$ & $\$ 0 \mathrm{~K}$ & $\$ 757 \mathrm{~K}$ \\
\hline $\begin{array}{l}\text { Co-Funding } \\
820101000\end{array}$ & $\$ 35 \mathrm{~K}$ & $\$ 50 \mathrm{~K}$ & $\$ 20 \mathrm{~K}$ & $\$ 0 \mathrm{~K}$ & $\$ 0 \mathrm{~K}$ & $\$ 105 \mathrm{~K}$ \\
\hline $\begin{array}{l}\text { RELATED } \\
\text { TASKS }\end{array}$ & $\$ 361 \mathrm{~K}$ & $\$ 175 \mathrm{~K}$ & $\$ 66 \mathrm{~K}$ & $\$ 0 \mathrm{~K}$ & $\$ 0 \mathrm{~K}$ & $\$ 602 \mathrm{~K}$ \\
\hline
\end{tabular}


Table 3.4-18 AL22NM41 Task A - activity-based estimate (\$K) FY 2002.

\begin{tabular}{||l|l||}
\hline WORK ELEMENT A & $\$ 6 \mathrm{~K}$ \\
\hline Work Element A.1 & $\$ 84 \mathrm{~K}$ \\
\hline Work Element A.2 & $\$ 30 \mathrm{~K}$ \\
\hline TOTAL & $\$ 120 \mathrm{~K}$ \\
\hline
\end{tabular}

Table 3.4-19 AL22NM41 Task A - activity-based estimate (\$K).

\begin{tabular}{||l|l|l|l||}
\hline & $\begin{array}{l}\text { PRIOR } \\
\text { YEARS }\end{array}$ & $\begin{array}{l}\text { FY } \\
2002\end{array}$ & $\begin{array}{l}\text { FY } \\
2003\end{array}$ \\
\hline LABOR & $\$ 0 \mathrm{~K}$ & $\$ 65 \mathrm{~K}$ & $\$ 0 \mathrm{~K}$ \\
\hline Travel & $\$ 0 \mathrm{~K}$ & $\$ 15 \mathrm{~K}$ & $\$ 0 \mathrm{~K}$ \\
\hline Subcontracts & $\$ 0 \mathrm{~K}$ & $\$ 0 \mathrm{~K}$ & $\$ 0 \mathrm{~K}$ \\
\hline Supplies/Materials & $\$ 0 \mathrm{~K}$ & $\$ 40 \mathrm{~K}$ & $\$ 0 \mathrm{~K}$ \\
\hline TOTAL & $\$ 0 \mathrm{~K}$ & $\$ 120 \mathrm{~K}$ & $\$ 0 \mathrm{~K}$ \\
\hline
\end{tabular}

Basis of Estimate:

The labor estimates are based on performing similar mechanical and weldment properties testing, weld process development, and alloy codification in a borated stainless steel development performed at Sandia National Laboratory. The costs associated with supplies/materials are primarily associated with machining of test samples.

Additional Costs:

No additional costs have been identified at this time.

Table 3.4-20 AL22NM41 spend plan (\$K).

\begin{tabular}{|c|c|c|c|c|c|c|c|c|c|c|c|c|c|c|c|}
\hline & $\begin{array}{l}\text { PY- } \\
\text { CO }\end{array}$ & $\mathrm{OCT}$ & $\mathrm{NOV}$ & DEC & JAN & FEB & MAR & APR & MAY & JUN & JUL & AUG & SEP & $\begin{array}{l}\mathrm{FY}- \\
\mathrm{CO}\end{array}$ & TOTAL \\
\hline \begin{tabular}{|l|} 
NMFA \\
FUNDING
\end{tabular} & $\$ 0 \mathrm{~K}$ & $\$ 8 \mathrm{~K}$ & $\$ 8 \mathrm{~K}$ & $\$ 13 \mathrm{~K}$ & $\$ 13 \mathrm{~K}$ & $\$ 13 \mathrm{~K}$ & $\$ 12 \mathrm{~K}$ & $\$ 10 \mathrm{~K}$ & $\$ 8 \mathrm{~K}$ & $\$ 8 \mathrm{~K}$ & $\$ 9 \mathrm{~K}$ & $\$ 8 \mathrm{~K}$ & $\$ 8 \mathrm{~K}$ & $\$ 0 \mathrm{~K}$ & $\$ 120 \mathrm{~K}$ \\
\hline \begin{tabular}{|l|} 
JOINT \\
FUNDING
\end{tabular} & $\$ 0 \mathrm{~K}$ & $\$ 24.0$ & $\$ 22.9$ & $\$ 25.11$ & 22. & $25.4 \mathrm{~K}$ & 22.21 & $\$ 31.3 \mathrm{~K}$ & $\$ 25.2 \mathrm{~K}$ & $\$ 23.4 \mathrm{H}$ & $\$ 28.31$ & $\$ 24.1 \mathrm{~K}$ & $\$ 30.9 \mathrm{~K}$ & $\$ 0 \mathrm{~K}$ & $\$ 305 \mathrm{~K}$ \\
\hline
\end{tabular}

Note: Joint funding numbers include total for entire project. Joint funding directly relating to Task A are approximately $20 \%$ of joint funding expenditures.

\subsection{Alignment to Thrust Areas and Key Goals and Priorities}

These projects support Thrust 2, Alternative Approaches to Current High Risk/High Cost Baselines. They expect that use of this new allow as structural material and for criticality control will result in a significant decrease to the cost for SNF disposal. Without this technology, criticality physics dictate an increased number of SNF canisters, with the attendant increases in fabrication and handling costs, and a potential to generate more canisters than can be accommodated in the planned repository. 
These projects support the following key EM goals and priorities:

1. Improve Safety Performance by providing positive criticality control for DOE-EM SNF

2. Reduce Cost and Time Required to Complete the EM Cleanup Mission by assuring that planned footprint $\mathrm{f}$ DOE-SNF in repository can be accommodated

\subsubsection{Project Review Results}

The review team recommended that these projects continue in FY 2003. They said that this new alloy is critical to success of SNF disposition, and they anticipate the project to align with ongoing EM priorities. 


\section{ASTD PROJECTS}

\subsection{OH12NM31, Fernald ASTD Project, Waste Materials Processing System for the Fernald Site}

\subsubsection{Project Overview}

There are approximately 2300 drums of various enriched restricted uranium compounds and residues that need to be dispositioned from the Fernald site in the near future to support closure schedules. This Accelerated Site Technology Deployment (ASTD) project will deploy an integrated system for receiving, mixing, and blending enriched restricted nuclear material with Fernald pit wastes, thereby creating a fissile-excepted material under 45CFR173. By doing this, they expect to accelerate the disposition schedule by 27 months, produce direct cost savings of $\$ 4$ million and life-cycle cost savings of \$15-18 million, and reduce volume of materials being disposed as waste. The project was selected for ASTD funding in December 2001, and the funding is in place

\subsubsection{Alignment to Thrust Areas and Key Goals and Priorities}

This project supports Thrust 1, Closure Site Support. Disposition of this group of nuclear materials is critical path.

This project supports the following key EM goals and priorities

2. Reduce the cost \& time required to complete the EM mission

3. Close Rocky Flats, Fernald, and Mound by 2006

4. Consolidate nuclear materials out of EM sites by 2004

7. Shrink the EM footprint

8. Get Wastes to disposal facilities quickly

\subsection{RF02NM30, Rocky Flats ASTD Project, Disassembly and Disposition of Classified Shapes at Rocky Flats}

\subsubsection{Project Overview}

The Rocky Flats contract requires decontaminating, decommissioning, and demolition of plutonium processing and industrial areas by the end of December 2006. Their Integrated Closure Project Baseline (ICPB) delineates the pathways and schedules for disposition of all Rocky Flats Special Nuclear Material (SNM) except one category of weapons components (12 items). Both the composition and configuration of these components are classified, and these weapons components have no conventional baseline technology. Disposition of these components is essential to site closure.

This ASTD project will ship components to Lawrence Livermore National Laboratory (LLNL), where they will disassemble the components and recover the fissile material using a LLNL process. Then they will process the non-SNM parts in a sanitization furnace to alter their classified shape.

The project was selected for ASTD funding in December 2001, and the funding is in place. 


\subsubsection{Alignment to Thrust Areas and Key Goals and Priorities}

This project supports Thrust 1, Closure Site Support. It ensures that Rocky Flats has the necessary technology and technical support to meet their closure schedules.

This project supports the following key EM goals and priorities:

1. Improve Safety Performance - It is better to apply resources to risk, by driving down or eliminating risk by work we do rather than avoiding or delaying this work

2. Reduce Cost and Time required to complete the EM Cleanup Mission

3. Close Rocky Flats by 2006

4. Consolidate Nuclear Material Out of EM Sites by 2004 - It will deinventory nuclear materials from Rocky Flats

7. Shrink the EM Footprint 


\section{APPENDIX A: REVIEW PANEL MEMBERS}

\begin{tabular}{||l|l||}
\hline NAME & AFFILIATION \\
\hline Doyle Batt & Idaho National Engineering and Environmental Laboratory \\
\hline Rowland Felt & DOE Idaho Operations Office \\
\hline Brent Ives & Lawrence Livermore National Laboratory \\
\hline Jay Kunze & Idaho State University \\
\hline Roger Pressentin & DOE Richland Operations Office \\
\hline Al Riechman & Savannah River Site \\
\hline William Rigot & Savannah River Site \\
\hline Wallace Schulz & Independent Consultant \\
\hline John Sokol & Bechtel Jacobs \\
\hline Victor Taylor & DOE Ohio Field Office \\
\hline Gary Thompson & Rocky Flats Environmental Technology Site \\
\hline Donald Vieth & Independent Consultant \\
\hline Stanley Wolf & DOE Headquarters \\
\hline \hline
\end{tabular}




\section{APPENDIX B: REVIEW PANEL RECOMMENDATIONS}

April 8, 2002

CCN 30864

Mr. Kenneth K. Osborne

U.S. Department of Energy

Idaho Operations Office

850 Energy Drive, MS 1235

Idaho Falls, ID 83401-1563

Mr. Gary D. Roberson

U.S. Department of Energy

Albuquerque Operations Office

PO Box 5400

Albuquerque, NM 87185-5400

CONTRACT NO. DE-AC07-99ID13727 - NUCLEAR MATERIALS FOCUS AREA MID-YEAR

REVIEW OBSERVATIONS

Dear Mr. Osborne and Mr. Roberson:

The Project Review Results Panel observations from the NMFA Mid-Year Review are attached. This panel consisted primarily of members of the NMFA End User Steering Committee and the NMFA Technical Advisory Group.

The tables contain the summary comments and recommendations of the review panel, grouped by NMFA product lines. General panel observations and comments regarding the NMFA "vision" and Office and Science and Technology restructuring are also provided.

Sincerely,

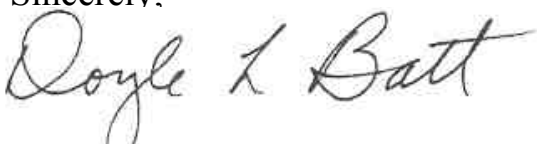

Doyle L. Batt, Chairman

NMFA End User Steering Committee

PWF:cf

Attachment 
Mr. Kenneth K. Osborne

Mr. Gary D. Roberson

March 19, 2002

CCN 30864

Page 2

cc: $\quad$ C. D. Cutler, MS 3810

R. Felt, DOE-ID, MS 1220

R. J. Hoyles, DOE-ID, MS 1221

B. Ives, LLNL

J. Kunze, ISU

R. Pressentin, DOE-RL

A. Riechman, SRS

W. Rigot, SRS

W. Schulz

J. Sokol, Bechtel Jacobs

V. Taylor, DOE-Ohio

G. Thompson, RFETS

D. Vieth

S. Wolf, DOE-HQ

bcc: P. W. Fuhrman, MS 3404

Correspondence Control, MS 3106

Doyle L. Batt File

Uniform File Code: 7650

Disposition Authority:

Retention Schedule:

NOTE: Original disposition authority, retention schedule, and Uniform Filing Code applied by the sender may not be appropriate for all recipients. Make adjustments as needed. 
Project Recommendations and Comments by Product Line

\begin{tabular}{|c|c|c|c|}
\hline \multicolumn{4}{|l|}{ Material Processing } \\
\hline Project(s) Title & TTP Number(s) & $\begin{array}{l}\text { Continue } \\
\text { Beyond } \\
\text { FY'02 }\end{array}$ & Comments/Recommendations \\
\hline $\begin{array}{l}\text { Prevention of Precipitation of } \\
\text { Unwanted Solids }\end{array}$ & SR11NM12 & & $\begin{array}{ll}\text { - } & \text { Allow to complete in FY '02 } \\
\text { - } & \text { Future funding should be pursued under } \\
& \text { Basic Science } \\
\end{array}$ \\
\hline $\begin{array}{l}\text { Single Step Distillation } \\
\text { Process for Pu Oxides } \\
\text { Containing Chlorides }\end{array}$ & RL31NM13 & & - $\quad$ Allow to complete in FY '02 \\
\hline $\begin{array}{l}\text { Dry Blending for Isotopic } \\
\text { Dilution }\end{array}$ & $\begin{array}{l}\text { FT01AR01 } \\
\text { ID72NM31 }\end{array}$ & $\sqrt{ }$ & $\begin{array}{ll}\text { - } & \text { Applied Research (NETL) funded project } \\
\text { - } & \text { Continue as required if User Site pull exists } \\
\text { - } & \text { Anticipate alignment to ongoing EM } \\
& \text { priorities }\end{array}$ \\
\hline Russian Checkbook (Gubka) & HQ06T222 & & 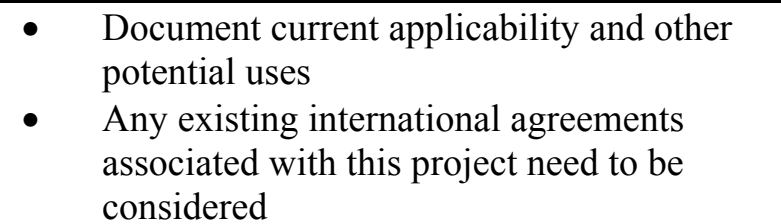 \\
\hline $\begin{array}{l}\text { Optimal Pu Precipitation for } \\
\text { Stabilization Feed } \\
\text { Preparation }\end{array}$ & RL31NM11 & & - $\quad$ Allow to complete in FY'02 \\
\hline
\end{tabular}

\begin{tabular}{|c|c|c|c|}
\hline \multicolumn{4}{|c|}{ Packaging, Transportation, \& Storage } \\
\hline Project(s) Title & TTP Number(s) & $\begin{array}{l}\text { Continue } \\
\text { Beyond } \\
\text { FY '02 }\end{array}$ & Comments/Recommendations \\
\hline Fernald Repackaging System & OH11NM21 & $\sqrt{ }$ & $\begin{array}{ll}- & \text { Allow to continue in FY '02 } \\
\text { - } & \text { Recommend continuation beyond FY '02 if } \\
& \text { User Site pull exists and appropriate co- } \\
& \text { funding is provided } \\
\end{array}$ \\
\hline $\begin{array}{l}\text { Automated Packaging- } \\
\text { Robotics (SNL Support) }\end{array}$ & AL21NM21 & & $\begin{array}{ll}\text { - } & \text { Allow to complete in FY '02 } \\
\text { - } & \text { Continue beyond FY '02 if User Site pull } \\
\text { exists }\end{array}$ \\
\hline $\begin{array}{l}\text { Automated Packaging - } \\
\text { LANL Engineering \& } \\
\text { Support }\end{array}$ & AL11NM22 & & $\begin{array}{ll}- & \text { Allow to complete in FY '02 } \\
\text { - } & \text { Continue beyond FY '02 if User Site pull } \\
\text { exists }\end{array}$ \\
\hline $\begin{array}{l}\text { Alpha Radiolysis for }{ }^{233} \mathrm{U} \\
\text { Oxides }\end{array}$ & OR01NM21 & $\sqrt{ }$ & $\begin{array}{ll}\text { - } & \text { Fund to complete as planned in FY '03 } \\
\text { - } & \text { Future funding should be pursued under } \\
\text { Basic Science }\end{array}$ \\
\hline
\end{tabular}




\begin{tabular}{|c|c|c|c|}
\hline \multicolumn{4}{|l|}{ Spent Nuclear Fuel } \\
\hline Project(s) Title & TTP Number(s) & $\begin{array}{l}\text { Continue } \\
\text { Beyond } \\
\text { FY'02 }\end{array}$ & Comments/Recommendations \\
\hline $\begin{array}{l}\text { Weld and NDE Development } \\
\text { for SNF Canisters }\end{array}$ & $\begin{array}{l}\text { ID02NM41, } \\
\text { SR02NM41 }\end{array}$ & $\sqrt{ }$ & $\begin{array}{ll}- & \text { Critical to success of SNF disposition } \\
\text { - } & \text { Anticipated to align with ongoing EM } \\
\text { priorities }\end{array}$ \\
\hline $\begin{array}{l}\text { HLW/SNF/Canister } \\
\text { Interaction Studies }\end{array}$ & $\begin{array}{l}\text { CH22NM41 } \\
\text { SR02NM42 } \\
\text { ID02NM44 }\end{array}$ & & $\begin{array}{ll}- & \text { Recommend review by external panel to } \\
\text { assess need } \\
\text { - } \\
\text { Future funding should be pursued under } \\
\text { Basic Science }\end{array}$ \\
\hline Radiolysis Effects for SNF & $\begin{array}{l}\text { SR02NM51 } \\
\text { ID02NM45 }\end{array}$ & $\sqrt{ }$ & $\begin{array}{ll}- & \text { Critical to success of SNF disposition } \\
\text { - } & \text { Anticipated to align with ongoing EM } \\
\text { priorities }\end{array}$ \\
\hline $\begin{array}{l}\text { Enhancement Reactivitiy } \\
\text { Factor for CVD of N- } \\
\text { Reactor Fuel }\end{array}$ & RL32NM41 & & - $\quad$ Allow to complete in FY '02 \\
\hline $\begin{array}{l}\text { New Alloys to Control } \\
\text { Nuclear Criticality }\end{array}$ & $\begin{array}{l}\text { AL22NM41 } \\
\text { ID02NM42 }\end{array}$ & $\sqrt{ }$ & $\begin{array}{ll}- & \text { Critical to success of SNF disposition } \\
\text { - } & \text { Anticipated to align with ongoing EM } \\
\text { priorities }\end{array}$ \\
\hline
\end{tabular}

\begin{tabular}{|l|l|l|l||}
\hline \hline \multicolumn{2}{||l|}{ Stabilization } & \multicolumn{1}{|c|}{$\begin{array}{l}\text { Continue } \\
\text { Beyond } \\
\text { PY' } \mathbf{0 2}\end{array}$} & Comments/Recommendations \\
\hline \hline $\begin{array}{l}\text { Plutonium Furnace Load-Out } \\
\text { System }\end{array}$ & RL31NM12 & & $\bullet \quad \begin{array}{l}\text { Project technical scope complete as } \\
\text { presented } \\
\text { Program should conduct a Lessons- } \\
\text { Learned critique regarding project } \\
\text { execution relating to co-funding and } \\
\text { deployment commitment }\end{array}$ \\
\hline Implementation of Moisture & SR11NM13 & AL11NM13 & $\begin{array}{l}\text { Complete as proposed } \\
\text { Switch from SFE to TGA/MS deployment } \\
\text { at SRS }\end{array}$ \\
\hline Technical Assistance & ID02NM11 & & $\begin{array}{l}\text { Complete FY '02 moisture measurement } \\
\text { efforts (good job!) } \\
\text { Support additional technical assistance as } \\
\text { needed if User Site pull exists }\end{array}$ \\
\hline
\end{tabular}




\section{Review Panel General Observations}

- End user involvement in the Focus Area has improved in response to last year's recommendations.

- However, it was evident in some cases that the user was not fully integrated and the resulting outcome was not satisfactory.

- Continue to emphasize end user involvement and commitment during projects.

- Technical assistance programs were extremely valuable and need to be woven into the structure of the new OST Thrust Areas.

- Deliverables, customers and products should be fully identified prior to the start of projects.

- Business metrics relative to return on investment and schedule acceleration need to be managed.

- Maturation and efficacy of the NMFA organization has been noticeable over the several year period of its operation, and this was particularly evident at the mid-year review.

\section{Review Panel Comments Regarding the "Vision" of NMFA}

- Overall, the NMFA "Vision" as presented appears reasonable.

- The success of the Thrust Areas approach for expediting cleanup is dependent upon strategy and tactics of implementation without impacting ongoing programs.

- Better Integration is needed between basic science, technology application, and project development efforts.

- Small Sites need to be an identified element and integrated into Thrust 1.

- Closure Facilities (e.g.; PFP, F-Canyon) need to be included in Thrust 1.

- Technical experts need to be identified (database), funded, and made available when needed for technical assistance efforts.

- Technical assistance must also be included in Thrust 2 .

- Technical support should be provided to activities to resolve the uranium hexafluoride problems at DOE facilities in Oak Ridge, Paducah, and Portsmouth should be considered. 


\section{APPENDIX C: REVIEW PANEL COMMENTS}

This appendix contains the combined comments and scores from the individual TAG and EUSC reviewers, captured on the questionnaire form that was provided to them. Hand written comments that were too difficult to read, and for which the reviewer could not be contacted for clarification, were not included. 
Programmatic Review Score Sheet for Nuclear Material Focus Area

AL11NM13- Implementation of Moisture Measurement Technology for Nuclear Materials Stabilization; SR11NM13 - Implementation of Moisture Measurement Technology for Nuclear Materials Stabilization

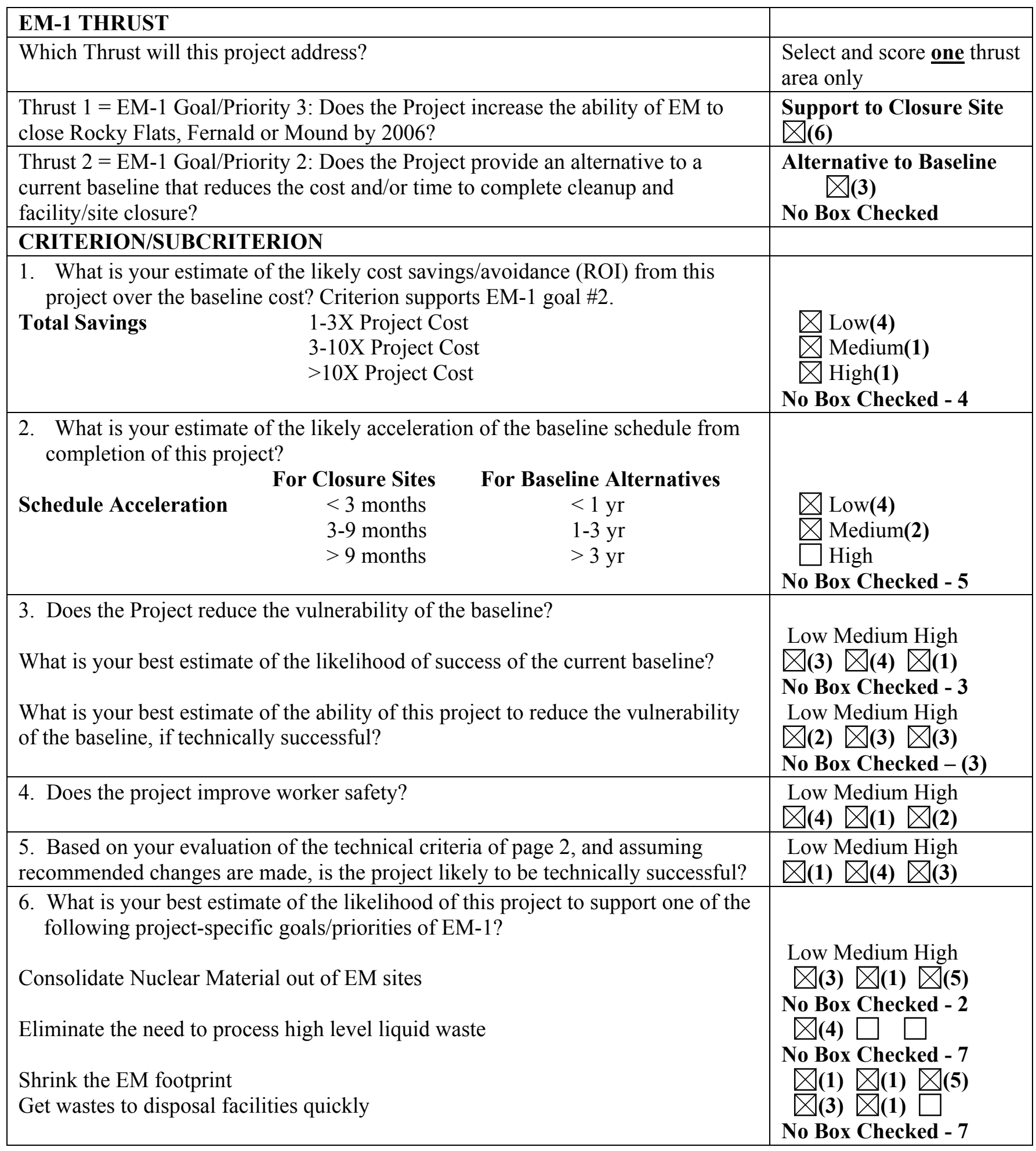


Technical Review Criteria for the Nuclear Material Focus Area FY 2002 Mid-Year Review

Do you agree that this project is based on sound scientific and engineering principles? Are there any fatal flaws? What changes should we make?

-Appears flawed based on SRS decisions.

-Yes.

-The basic science behind this project was satisfactory. The execution of the project left a great deal to be desired. It was not the best in terms of executing a scientific investigation. Results can be salvaged from this effort.

-Yes, weak end user acceptance at Hanford. Some unresolved issues of deployment of NMA to Hanford and TGA-MS to SRS.

-Looks like it, fatal flaw - may not really need to measure moisture, stop any further work?

-Yes. No.

-Ok - but difficult techniques to utilize.

-I agree. My major concern with all of these methods (SFE,ThA, MS NMA, etc.) is that they are attempting to measure small amounts $0.5 w t . \%$, of moisture in oxide materials. The variance in measurements is sometimes larger than the reported value. SFE doesn't remove all moisture and NMA suffers from interference from some elements.

Do you agree that the project can meet the identified needs of end user sites? Can the technology be effectively deployed at the site? If not, what changes should we make?

-SRS appears to be using different equipment?

- Yes.

-Yes.

-Don't really know if meets needs, don't really know if technology can be deployed.

-Yes, depends on user acceptance of demo/deployment.

-The project could have met the users needs. It took some salvage efforts to achieve that need.

- Are deployable.

-The current plan is to do thermal stabilization in dry boxes and package the stabilized material as quickly as practical. But moisture driven off oxides and inleakage of air into the drybox could still be a problem.

Based on the information available, do you believe that this project as planned can be successfully deployed to meet the schedule requirements of the identified end users? Should the project be continued or not? If not, what changes should we make?

-Continue \& complete as modified.

-Project complete as plan/modified.

-Yes, for SRS.

-Really don't know if technology can be successfully deployed.

-Yes, depends on user confidence of results, note potential for process qualification is of higher user interest.

-The project was only moderately successful.

-It appears that no additional NMFA funding is needed; implementation should be funded, though they are bargaining for help from NMFA.

-It is also planned to qualify a process and conditions so that not every batch will have to be analyzed. But some analysis will still be required and that brings the moisture measurement accuracy issue back. 
Are you aware of any other technology or approach that might be applicable to the stated end user needs? If so, what is that technology, and where has it been deployed? Is it likely to be more successful than the current project at meeting the needs of the end users?

$-T G A / M S$

- No.

-Not aware.

-This project involves 3 alternatives, NMA still needs benchmarking.

-So far there has been little pressure increase noted from gas generation in the containers. $\mathrm{H}_{2}$ and $\mathrm{O}_{2}$ recombine. The design process 699 psi has never been approached, much less the applied 4000 psi burst pressure. Some thought might be given to showing that $0.5 w t . \%$ moisture isn't a problem. Permitted moisture levels might be increased. 


\section{Programmatic Review Score Sheet for Nuclear Material Focus Area}

ID02NM42 - Investigating the Corrosion Resistance of New Alloys; AL22NM41 Microstructure/Mechanical Properties Investigation for New Alloys to Control Nuclear Criticality

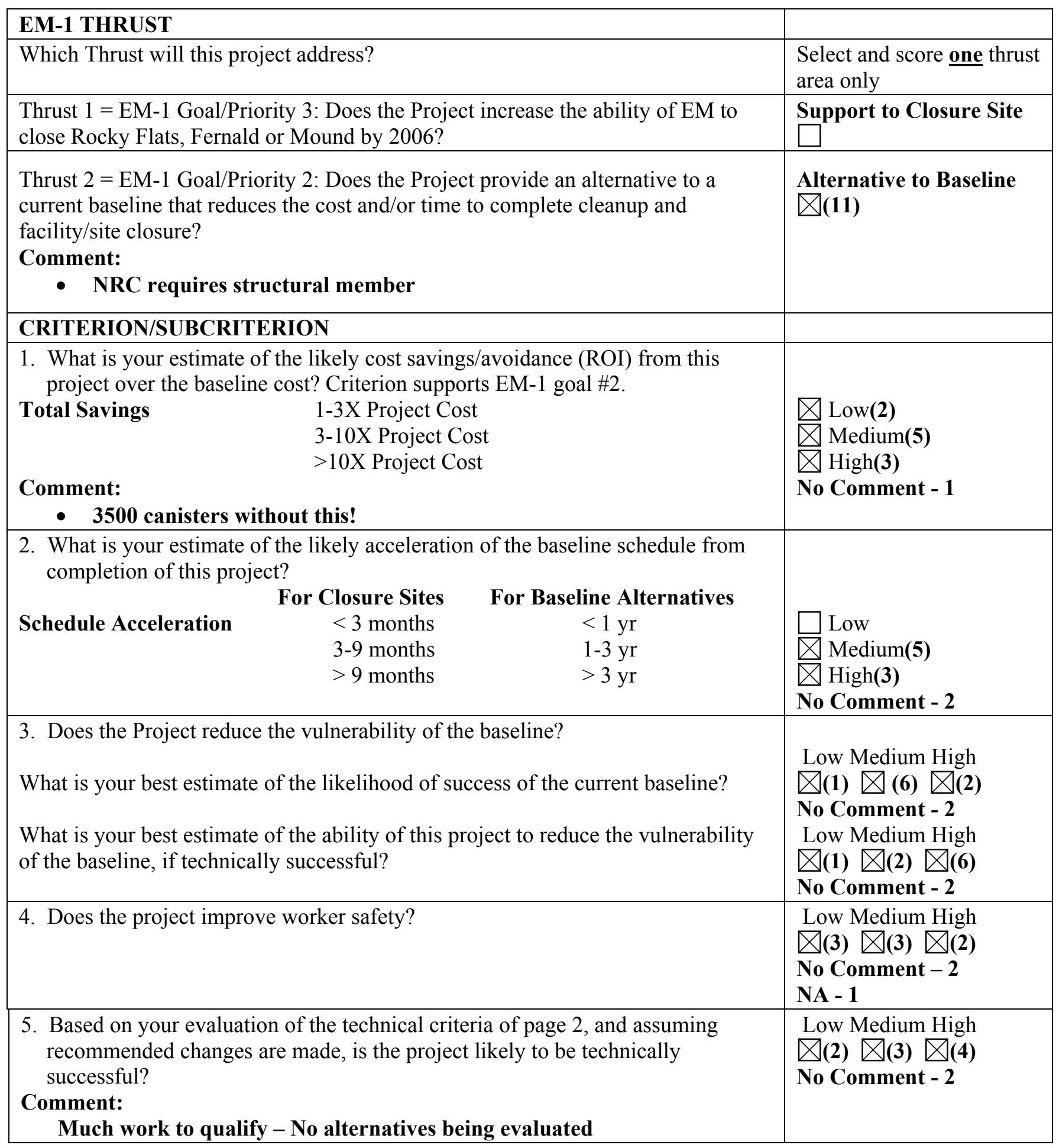


6. What is your best estimate of the likelihood of this project to support one of the following project-specific goals/priorities of EM-1?

Consolidate Nuclear Material out of EM sites

Eliminate the need to process high level liquid waste

Shrink the EM footprint

Get wastes to disposal facilities quickly

Low Medium High

$\bigotimes(1) \bigotimes(3) \bigotimes(4)$

No Comment - 3

$\bigotimes(5)$

No Comment 6

$\bigotimes(1) \bigotimes(3) \bigotimes(3)$

No Comment 4

$\bigotimes(1) \bigotimes(4) \bigotimes(4)$

No Comment - 2

Technical Review Criteria for the Nuclear Material Focus Area FY 2002 Mid-Year Review

Do you agree that this project is based on sound scientific and engineering principles? Are there any fatal flaws? What changes should we make?

-Yes.

-Yes. No fatal flaws, make no change.

$-\mathrm{OK}$.

$-\mathrm{OK}$.

-Yes.

-Yes, Ni Gd compound.

-Looks $\mathrm{OK}$.

-Yes.

-This project proposes to spend \$1.6794M through 2004 to develop a new alloy. The technical approach appears to be sound. If standard metallurgical and corrosion studies' methods are followed, the technical information should be suitable to answer the technical questions about the usefulness of the alloy.

Do you agree that the project can meet the identified needs of end user sites? Can the technology be effectively deployed at the site? If not, what changes should we make?

-Maybe.

-Yes. Yes, Make no change.

$-\mathrm{OK}$.

-A must, and there appears to be no "show stoppers" to date.

- Yes.

-Yes.

-Yes.

-Yes. Can readily reduce basin footprint at SRS.

-Since the project developing the material is the one responsible for implementing the solution, it should meet the end users need. The technology should be able to be deployed without difficulty if it meets the requirements. 
Based on the information available, do you believe that this project as planned can be successfully deployed to meet the schedule requirements of the identified end users? Should the project be continued or not? If not, what changes should we make?

-Yes.

-Yes. Continue. Make no change.

-Yes.

-Use of Beads should be considered.

-Needs to have high priority on schedule.

-Yes.

-Some risk in alloy selection. None is acceptable thus far. Should be able to.

-Yes. Continue.

-If the project is executed by technically competent people, it should be successfully deployed.

Are you aware of any other technology or approach that might be applicable to the stated end user needs? If so, what is that technology, and where has it been deployed? Is it likely to be more successful than the current project at meeting the needs of the end users?

-No, for overall, challenge.

- No. No.

-None.

- No.

- No.

- No.

- No.

-Use beads, or make foam of pressed powder? Certified material from ASTM w/known properties, would use more packages w/o neutron absorber.

-Are other alternatives like void filling substances being considered? 
Programmatic Review Score Sheet for Nuclear Material Focus Area

FT01AR01 - Dry Blending for Isotopic Dilution (Applied Research)

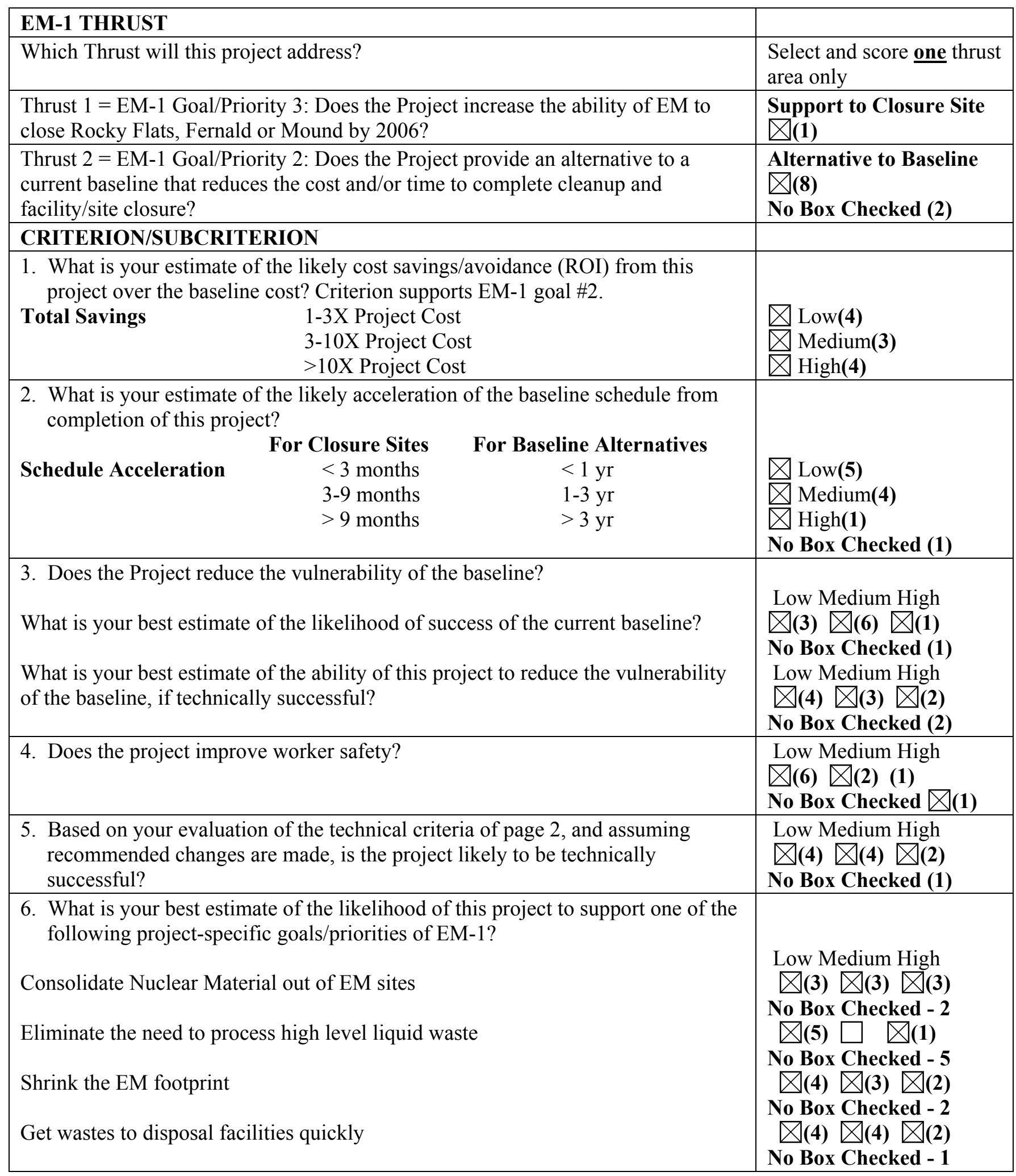




\section{Technical Review Criteria for the Nuclear Material Focus Area FY 2002 Mid-Year Review}

Do you agree that this project is based on sound scientific and engineering principles? Are there any fatal flaws? What changes should we make?

-No. Aqueous path for HEU.

-Reduces Safeguards and Security.

-Yes. Equipment just being built.

-Yes.

-Yes.

-This is another project and is one that is based on sound scientific and engineering principles, but one that is a rediscovery of technology that is already in use in the nuclear fuel industry. It has a specific application of providing specific input to a conceptual design.

-Complete as planned.

Do you agree that the project can meet the identified needs of end user sites? Can the technology be effectively deployed at the site? If not, what changes should we make?

-Probably, continue-cannot stop NETL.

-Total need is questionable.

-Yes.

-Yes.

-Yes.

-There is no technical reason that this project cannot be successfully executed. Only the competence of the PI can limit the success.

-Agree.

Based on the information available, do you believe that this project as planned can be successfully deployed to meet the schedule requirements of the identified end users? Should the project be continued or not? If not, what changes should we make?

- No.

-Good technology, but can it be deployed?

- Yes.

-OK. None.

-Yes. Continue, but not funded by NETL.

-This is not for deployment - it is to provide specific information necessary to designing of process flow sheet.

-Agree.

Are you aware of any other technology or approach that might be applicable to the stated end user needs? If so, what is that technology, and where has it been deployed? Is it likely to be more successful than the current project at meeting the needs of the end users?

- No.

-Commercial fuel fabricators have used this technology for 30 years.

-Sounds like Alternative Fuel Project that Nuclear Fuel Services is pursuing. Fluor Fernald is contracting with NFS.

-None. Funding seems $O K$ to get it finished.

-There should be commercially available blending equipment.

-May be reinventing commercially available equipment?

- No.

-There is other technology that can do this job.

-Commercial equipment probably would have done job, but project money ahs been allocated and project should be continued to completion. 


\section{Programmatic Review Score Sheet for Nuclear Material Focus Area HQ06T222 - Gubka}

\begin{tabular}{|c|c|}
\hline EM-1 THRUST & \\
\hline Which Thrust will this project address? & $\begin{array}{l}\text { Select and score one thrust } \\
\text { area only }\end{array}$ \\
\hline $\begin{array}{l}\text { Thrust } 1=\text { EM-1 Goal/Priority 3: Does the Project increase the ability of EM to } \\
\text { close Rocky Flats, Fernald or Mound by } 2006 ?\end{array}$ & $\begin{array}{l}\text { Support to Closure Site } \\
\text { 囚(9) } \\
\text { Checked both boxes - } 2\end{array}$ \\
\hline $\begin{array}{l}\text { Thrust } 2 \text { = EM-1 Goal/Priority 2: Does the Project provide an alternative to a } \\
\text { current baseline that reduces the cost and/or time to complete cleanup and } \\
\text { facility/site closure? }\end{array}$ & $\begin{array}{l}\text { Alternative to Baseline } \\
\text { \(6) } \\
\text { Checked both boxes - } 2\end{array}$ \\
\hline CRITERION/SUBCRITERION & \\
\hline $\begin{array}{l}\text { 1. What is your estimate of the likely cost savings/avoidance (ROI) from this } \\
\text { project over the baseline cost? Criterion supports EM-1 goal \#2. } \\
\text { Total Savings } \\
\begin{array}{l}\text { 1-3X Project Cost } \\
\text { 3-10X Project Cost } \\
\text { >10X Project Cost }\end{array}\end{array}$ & $\begin{array}{l}\bigotimes \text { Low(6) } \\
\bigotimes \text { Medium(3) } \\
\text { \High(2) } \\
\text { No Box Checked - 2 }\end{array}$ \\
\hline $\begin{array}{l}\text { 2. What is your estimate of the likely acceleration of the baseline schedule from } \\
\text { completion of this project? } \\
\begin{array}{ccc}\text { For Closure Sites } & \text { For Baseline Alternatives } \\
\text { Schedule Acceleration } & <3 \text { months } & <1 \mathrm{yr} \\
3-9 \text { months } & 1-3 \mathrm{yr} \\
& >9 \text { months } & >3 \mathrm{yr}\end{array}\end{array}$ & $\begin{array}{l}\bigotimes \text { Low(6) } \\
\text { \Medium(2) } \\
\text { \High(2) } \\
\text { No Box Checked - 2 }\end{array}$ \\
\hline $\begin{array}{l}\text { 3. Does the Project reduce the vulnerability of the baseline? } \\
\text { What is your best estimate of the likelihood of success of the current baseline? } \\
\text { What is your best estimate of the ability of this project to reduce the vulnerability } \\
\text { of the baseline, if technically successful? }\end{array}$ & $\begin{array}{l}\text { Low Medium High } \\
\bigotimes(3) \bigotimes(5) \bigotimes(2) \\
\text { No Box Checked - } 2 \\
\text { Low Medium High } \\
\bigotimes(4) \bigotimes(5) \bigotimes(2) \\
\text { No Box Checked - } 1\end{array}$ \\
\hline 4. Does the project improve worker safety? & $\begin{array}{l}\text { Low Medium High } \\
\bigotimes(5) \bigotimes(3) \bigotimes(2) \\
\text { No Box Checked } 2\end{array}$ \\
\hline $\begin{array}{l}\text { 5. Based on your evaluation of the technical criteria of page } 2 \text {, and assuming } \\
\text { recommended changes are made, is the project likely to be technically } \\
\text { successful? }\end{array}$ & $\begin{array}{l}\text { Low Medium High } \\
\bigotimes(2) \square \square(8) \\
\text { No Box Checked - } 2\end{array}$ \\
\hline
\end{tabular}


6. What is your best estimate of the likelihood of this project to support one of the following project-specific goals/priorities of EM-1?

$$
\begin{aligned}
& \text { Consolidate Nuclear Material out of EM sites } \\
& \text { Eliminate the need to process high level liquid waste } \\
& \text { Shrink the EM footprint } \\
& \text { Get wastes to disposal facilities quickly }
\end{aligned}
$$

\section{Technical Review Criteria for the Nuclear Material Focus Area FY 2002 Mid-Year Review}

Do you agree that this project is based on sound scientific and engineering principles? Are there any fatal flaws? What changes should we make?

-Yes. Quick and dirty.

-Yes.

-Good application of simple method. If it can be made in larger batches.

-It works.

-For small scale, quantity appears viable.

-Yes.

-Not Sure.

-Yes.

-Trivial science, presenter says high school chemistry - I agree, stop project at end of FY'02.

-The science underlying this project may be valid. It needs to be clearly defined and demonstrated.

-The project needs to present the feasible study as proposed then present good technical information, rather than past various stories.

- Sound. Capability demonstrated.

Do you agree that the project can meet the identified needs of end user sites? Can the technology be effectively deployed at the site? If not, what changes should we make?

-Yes.

-Yes! Especially small sites!

-Yes. Demonstrated in Russia.

-Demonstrations support.

-Satisfies small niche market. Could be applied elsewhere.

-Need more information on applicability.

-Yes.

-No. No.

-This product, if properly advanced could be quite useful. Some sites are considering it for limited and special applications.

-I think it can meet some limited needs. It would be a better technology than some for immobilizing/stabilizing material that someone might want to recover later. 
Based on the information available, do you believe that this project as planned can be successfully deployed to meet the schedule requirements of the identified end users? Should the project be continued or not? If not, what changes should we make?

-Yes.

-The sooner the better!

-Yes, there are other applications proposed for follow-on funding.

-Yes. Yes.

-Yes.

-Enhance interface w/end users to assure applicability.

-Yes. Continue.

- No. Stop.

-It can be successfully, but limited in its deployment. It is going to be used to clean up small quantities of liquid waste.

-I think it can be deployed successfully.

Are you aware of any other technology or approach that might be applicable to the stated end user needs? If so, what is that technology, and where has it been deployed? Is it likely to be more successful than the current project at meeting the needs of the end users?

-Adsorption on silica gel and other absorbents.

-Only some, if processing capability exists.

-Probably.

- No.

-Lots of alternatives available.

- No.

-Lots of other well-known sorbents, long used for same purpose, e.g., vermiculite, etc.

-I believe there are other options that can be used. I believe this should be documented, but finished. If someone else wants to use this and additional data are needed, perhaps funding could be provided via the non-proliferation monies. 


\section{Programmatic Review Score Sheet for Nuclear Material Focus Area \\ ID02NM11/ID01NM12 - Technical Assistance - Moisture Measurement}

\begin{tabular}{|c|c|}
\hline EM-1 THRUST & \\
\hline Which Thrust will this project address? & $\begin{array}{l}\text { Select and score one thrust } \\
\text { area only }\end{array}$ \\
\hline $\begin{array}{l}\text { Thrust } 1=\text { EM-1 Goal/Priority 3: Does the Project increase the ability of EM to } \\
\text { close Rocky Flats, Fernald or Mound by } 2006 ?\end{array}$ & $\begin{array}{l}\text { Support to Closure Site } \\
\bigotimes(7)\end{array}$ \\
\hline $\begin{array}{l}\text { Thrust } 2=\text { EM-1 Goal/Priority 2: Does the Project provide an alternative to a } \\
\text { current baseline that reduces the cost and/or time to complete cleanup and } \\
\text { facility/site closure? }\end{array}$ & $\begin{array}{l}\text { Alternative to Baseline } \\
\square\end{array}$ \\
\hline CRITERION/SUBCRITERION & \\
\hline $\begin{array}{l}\text { 1. What is your estimate of the likely cost savings/avoidance (ROI) from this } \\
\text { project over the baseline cost? Criterion supports EM-1 goal \#2. } \\
\text { Total Savings } \\
\qquad \begin{array}{l}\text { 1-3X Project Cost } \\
\text { 3-10X Project Cost }\end{array}\end{array}$ & $\begin{array}{l}\bigotimes \text { Low(2) } \\
\bigotimes \text { Medium(2) } \\
\bigotimes \text { High(1) } \\
\text { No Box Checked - 2 }\end{array}$ \\
\hline 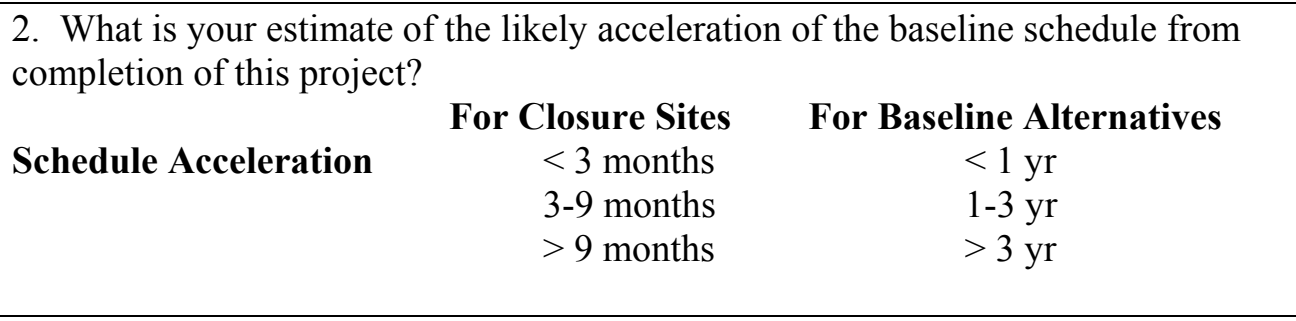 & $\begin{array}{l}\bigotimes \text { Low(1) } \\
\bigotimes \text { Medium(3) } \\
\bigotimes \text { High(1) } \\
\text { No Box Checked - 2 }\end{array}$ \\
\hline $\begin{array}{l}\text { 3. Does the Project reduce the vulnerability of the baseline? } \\
\text { What is your best estimate of the likelihood of success of the current baseline? } \\
\text { What is your best estimate of the ability of this project to reduce the vulnerability } \\
\text { of the baseline, if technically successful? }\end{array}$ & $\begin{array}{l}\text { Low Medium High } \\
\square(1) \square(2) \bigotimes(2) \\
\text { No Box Checked - } 2 \\
\text { Low Medium High } \\
\square \square(2) \square(3) \\
\text { No Box Checked - } 2\end{array}$ \\
\hline 4. Does the project improve worker safety? & $\begin{array}{l}\text { Low Medium High } \\
\bigotimes(2) \bigotimes(2) \square \\
\text { No Box Checked - } 2\end{array}$ \\
\hline $\begin{array}{l}\text { 5. Based on your evaluation of the technical criteria of page } 2 \text {, and assuming } \\
\text { recommended changes are made, is the project likely to be technically } \\
\text { successful? }\end{array}$ & $\begin{array}{l}\text { Low Medium High } \\
\square \unrhd(\mathbf{1}) \bigotimes(\mathbf{3}) \\
\text { No Box Checked - } 2\end{array}$ \\
\hline $\begin{array}{l}\text { 6. What is your best estimate of the likelihood of this project to support one of the } \\
\text { following project-specific goals/priorities of EM-1? } \\
\text { Consolidate Nuclear Material out of EM sites } \\
\text { Eliminate the need to process high level liquid waste } \\
\text { Shrink the EM footprint } \\
\text { Get wastes to disposal facilities quickly }\end{array}$ & $\begin{array}{l}\text { Low Medium High } \\
\square \square \square(5) \\
\text { No Box Checked - } 5 \\
\square(2) \square \square \\
\text { No Box Checked - } 5 \\
\square \text { (1) \(3) } \\
\text { No Box Checked - } 3 \\
\square(1) \square \text { (1) } \\
\text { No Box Checked - } 5\end{array}$ \\
\hline
\end{tabular}




\section{Technical Review Criteria for the Nuclear Material Focus Area FY 2002 Mid-Year Review}

Do you agree that this project is based on sound scientific and engineering principles? Are there any fatal flaws? What changes should we make?

-Yes. Yes.

-Done.

Do you agree that the project can meet the identified needs of end user sites? Can the technology be effectively deployed at the site? If not, what changes should we make?

- Yes.

-Effectively carried out.

Based on the information available, do you believe that this project as planned can be successfully deployed to meet the schedule requirements of the identified end users? Should the project be continued or not? If not, what changes should we make?

-Continue on site by site bases funded by sites as needs arise.

-No continuation is proposed.

Are you aware of any other technology or approach that might be applicable to the stated end user needs? If so, what is that technology, and where has it been deployed? Is it likely to be more successful than the current project at meeting the needs of the end users? 


\section{Programmatic Review Score Sheet for Nuclear Material Focus Area \\ ID02NM41 - Weld and NDE Technique \& Equipment Development for DOE Standardized SNF Canister; SR02NM41 - Weld Optimization to Minimize Potential for Age-Related Degradation of DOE Standardized SNF Canister Closure Welds}

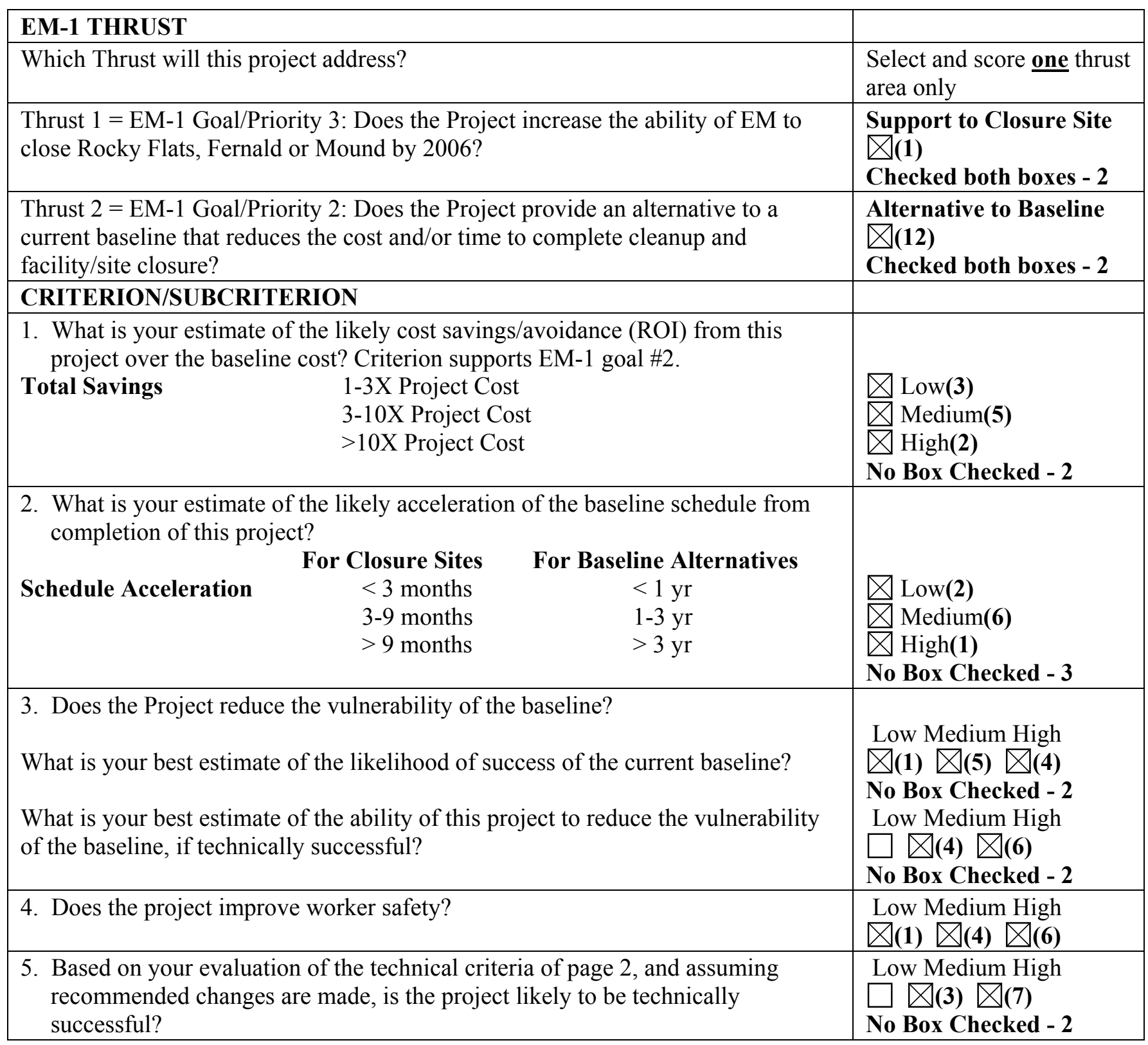




6. What is your best estimate of the likelihood of this project to support one of the
following project-specific goals/priorities of EM-1?
Consolidate Nuclear Material out of EM sites
Eliminate the need to process high level liquid waste
Shrink the EM footprint
Get wastes to disposal facilities quickly

\section{Technical Review Criteria for the Nuclear Material Focus Area FY 2002 Mid-Year Review}

Do you agree that this project is based on sound scientific and engineering principles? Are there any fatal flaws? What changes should we make?

-Definitely doable.

-This is an elementary project that relies on well established technology. It is primarily an application development. The objective is to develop a remote welding approach so the shield plug can be removed from the top of the canister and the weld joint be properly designed to minimize residual stresses that would promote SSC in stainless steel.

-Yes.

-Yes. No.

-Agree.

-Good approach to improve process - no flaws - no changes recommended.

-Yes.

-Yes. No fatal flaws, make no changes.

-Program should continue.

Do you agree that the project can meet the identified needs of end user sites? Can the technology be effectively deployed at the site? If not, what changes should we make?

-Yes. Easily.

-Since INEEL is responsible for Spent Fuel Program, when this is developed there should be a commitment to implement the technology application they have developed.

-Yes.

-Yes. Yes.

-Yes.

-Yes. Yes - deployment should be expected.

-Yes.

-Yes. Yes, make no changes.

-Project can meet identified needs. 
Based on the information available, do you believe that this project as planned can be successfully deployed to meet the schedule requirements of the identified end users? Should the project be continued or not? If not, what changes should we make?

-Continue.

-The project is scheduled to spend \$1,077 K through 2004. If they can solve the problem in that time frame, they should be required to give the money back.

-Yes.

-Yes.

-Yes.

-Yes.

-Yes, mainly a funding issue.

-Absolutely continue, make no changes.

-Project should continue.

Are you aware of any other technology or approach that might be applicable to the stated end user needs? If so, what is that technology, and where has it been deployed? Is it likely to be more successful than the current project at meeting the needs of the end users?

-None.

- No.

- No.

-There are current NRC applications, but loss in integrity of fuel dictates additional material to increase design merge for transportation and storage.

-Good approach.

-Not aware of other technologies/equipment. Unique application to SNF (high radiation). 
Programmatic Review Score Sheet for Nuclear Material Focus Area

ID02NM42 - Investigating the Corrosion Resistance of New Alloys; AL22NM41 Microstructure/Mechanical Properties Investigation for New Alloys to Control Nuclear Criticality

\begin{tabular}{|c|c|}
\hline EM-1 THRUST & \\
\hline Which Thrust will this project address? & $\begin{array}{l}\text { Select and score one thrust } \\
\text { area only }\end{array}$ \\
\hline $\begin{array}{l}\text { Thrust } 1=\text { EM-1 Goal/Priority 3: Does the Project increase the ability of EM to } \\
\text { close Rocky Flats, Fernald or Mound by } 2006 ?\end{array}$ & $\begin{array}{l}\text { Support to Closure Site } \\
\square\end{array}$ \\
\hline $\begin{array}{l}\text { Thrust } 2=\mathrm{EM}-1 \text { Goal/Priority } 2 \text { : Does the Project provide an alternative to a } \\
\text { current baseline that reduces the cost and/or time to complete cleanup and } \\
\text { facility/site closure? } \\
\text { Comment: Reduced \# of packages because of - Doyle Batt } \\
\text { NRC requires structural member - Al Riechman }\end{array}$ & $\begin{array}{l}\text { Alternative to Baseline } \\
\bigotimes(11)\end{array}$ \\
\hline CRITERION/SUBCRITERION & \\
\hline $\begin{array}{l}\text { 1. What is your estimate of the likely cost savings/avoidance (ROI) from this } \\
\text { project over the baseline cost? Criterion supports EM-1 goal \#2. } \\
\text { Total Savings } \\
\text { 1-3X Project Cost } \\
\text { 3-10X Project Cost } \\
\text { > } \\
\begin{array}{l}\text { Comment: } \\
\text { 3500 canisters without this! }\end{array}\end{array}$ & $\begin{array}{l}\bigotimes \text { Low(2) } \\
\bigotimes \text { Medium(5) } \\
\bigotimes \text { High(3) } \\
\text { No Comment - } 1\end{array}$ \\
\hline $\begin{array}{l}\text { 2. What is your estimate of the likely acceleration of the baseline schedule from } \\
\text { completion of this project? } \\
\begin{array}{rrr} & \text { For Closure Sites } & \text { For Baseline Alternatives } \\
\text { Schedule Acceleration } & <3 \text { months } & <1 \mathrm{yr} \\
3-9 \text { months } & 1-3 \mathrm{yr} \\
& >9 \text { months } & >3 \mathrm{yr}\end{array}\end{array}$ & $\begin{array}{l}\square \text { Low } \\
\square \text { Medium(5) } \\
\square \text { High(3) } \\
\text { No Comment - 2 }\end{array}$ \\
\hline $\begin{array}{l}\text { 3. Does the Project reduce the vulnerability of the baseline? } \\
\text { What is your best estimate of the likelihood of success of the current baseline? } \\
\text { What is your best estimate of the ability of this project to reduce the vulnerability } \\
\text { of the baseline, if technically successful? }\end{array}$ & 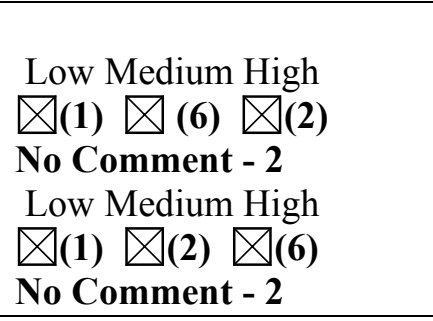 \\
\hline 4. Does the project improve worker safety? & $\begin{array}{l}\text { Low Medium High } \\
\square(3) \bigotimes(3) \bigotimes(2) \\
\text { No Comment - } 2 \\
\text { NA - } 1\end{array}$ \\
\hline $\begin{array}{l}\text { 5. Based on your evaluation of the technical criteria of page } 2 \text {, and assuming } \\
\text { recommended changes are made, is the project likely to be technically } \\
\text { successful? } \\
\text { Comment: } \\
\text { - Much work to qualify - No alternatives being evaluated }\end{array}$ & $\begin{array}{l}\text { Low Medium High } \\
\bigotimes(2) \bigotimes(3) \bigotimes(4) \\
\text { No Comment - 2 }\end{array}$ \\
\hline
\end{tabular}


6. What is your best estimate of the likelihood of this project to support one of the following project-specific goals/priorities of EM-1?

Consolidate Nuclear Material out of EM sites

Eliminate the need to process high level liquid waste

Shrink the EM footprint

Get wastes to disposal facilities quickly

Low Medium High

$\bigotimes(1) \bigotimes(3) \square(4)$

No Comment - 3

$\bigotimes(5)$

No Comment 6

$\bigotimes(1) \bigotimes(3) \bigotimes(3)$

No Comment 4

$\bigotimes(1) \bigotimes(4) \bigotimes(4)$

No Comment - 2

Technical Review Criteria for the Nuclear Material Focus Area FY 2002 Mid-Year Review

Do you agree that this project is based on sound scientific and engineering principles? Are there any fatal flaws? What changes should we make?

- Yes.

-Yes. No fatal flaws, make no change.

$-\mathrm{OK}$.

$-\mathrm{OK}$.

-Yes.

-Yes, Ni Cd compound.

-Looks OK.

-Yes.

-This project proposes to spend \$1.6794M through 2004 to develop a new alloy. The technical approach appears to be sound. If standard metallurgical and corrosion studies' methods are followed, the technical information should be suitable to answer the technical questions about the usefulness of the alloy.

-Agree.

Do you agree that the project can meet the identified needs of end user sites? Can the technology be effectively deployed at the site? If not, what changes should we make?

-Maybe.

-Yes. Yes, Make no change.

$-\mathrm{OK}$.

-A must, and there appears to be no "show stoppers" to date.

- Yes.

-Yes.

-Yes.

-Yes. Can readily reduce basin footprint at SRS.

-Since the project developing the material is the one responsible for implementing the solution, it should meet the end users need. The technology should be able to be deployed without difficulty if it meets the requirements.

-Agree. 
Based on the information available, do you believe that this project as planned can be successfully deployed to meet the schedule requirements of the identified end users? Should the project be continued or not? If not, what changes should we make?

-Yes.

-Yes. Continue. Make no change.

-Yes.

-Use of Beads should be considered.

-Needs to have high priority on schedule.

-Yes.

-Some risk in alloy selection. None is acceptable thus far. Should be able to.

-Yes. Continue.

-If the project is executed by technically competent people, it should be successfully deployed.

-Project should be continued until problems are solved.

Are you aware of any other technology or approach that might be applicable to the stated end user needs? If so, what is that technology, and where has it been deployed? Is it likely to be more successful than the current project at meeting the needs of the end users?

- No. For overall, challenge.

- No. No.

-None.

- No.

- No.

- No.

- No.

-Use beads, or make foam of pressed powder? Certified material from ASTM w/known properties, would use more packages w/o neutron absorber.

-Are other alternatives like void-filling-substances being considered? 
Programmatic Review Score Sheet for Nuclear Material Focus Area

IDO2NM44 - INEEL HLW/SNF Canister Interaction Project Manager; CH22NM41 - ANL HLW/SNF Canister Interaction Studies; SR02NM42 - SRS HLW/SNF Canister Interaction Studies

\begin{tabular}{|c|c|}
\hline EM-1 THRUST & \\
\hline Which Thrust will this project address? & $\begin{array}{l}\text { Select and score one } \\
\text { thrust area only }\end{array}$ \\
\hline $\begin{array}{l}\text { Thrust } 1 \text { = EM-1 Goal/Priority 3: Does the Project increase the ability of EM to } \\
\text { close Rocky Flats, Fernald or Mound by } 2006 ?\end{array}$ & $\begin{array}{l}\text { Support to Closure } \\
\text { Site } \bigotimes(1) * \text { review } \\
\text { checked } 2 \text { boxes }\end{array}$ \\
\hline $\begin{array}{l}\text { Thrust } 2=\text { EM-1 Goal/Priority 2: Does the Project provide an alternative to a } \\
\text { current baseline that reduces the cost and/or time to complete cleanup and } \\
\text { facility/site closure? }\end{array}$ & $\begin{array}{l}\text { Alternative to } \\
\text { Baseline } \bigotimes(11) * \\
\text { *reviewer checked } 2 \\
\text { boxes } \\
\text { No Comment - } 1\end{array}$ \\
\hline CRITERION/SUBCRITERION & $\begin{array}{l}\text { Candidate for EMSP } \\
\text { - D. Batt }\end{array}$ \\
\hline $\begin{array}{l}\text { 1. What is your estimate of the likely cost savings/avoidance (ROI) from this } \\
\text { project over the baseline cost? Criterion supports EM-1 goal \#2. } \\
\text { Total Savings } \\
\qquad \begin{array}{l}\text { 1-3X Project Cost } \\
\text {-10X Project Cost }\end{array} \\
\text { >10X Project Cost } \\
\text { Comments - } \\
\text { - No box checked - comment - "not clear" } \\
\text { - Checked Low - comment was "if any" } \\
\text { - No box checked- comment was "no cost savings" }\end{array}$ & $\begin{array}{l}\bigotimes \text { Low(5) } \\
\bigotimes \text { Medium(1) } \\
\bigotimes \text { High(1) } \\
\text { No Box Checked - 5 }\end{array}$ \\
\hline $\begin{array}{l}\text { 2. What is your estimate of the likely acceleration of the baseline schedule } \\
\text { from completion of this project? } \\
\text { For Closure Sites For Baseline Alternatives }\end{array}$ & \\
\hline $\begin{array}{rr}\text { Schedule Acceleration } & <3 \text { months } \\
3-9 \text { months } & <1 \mathrm{yr} \\
>9 \text { months } & 1-3 \mathrm{yr} \\
& >3 \mathrm{yr} \\
\text { Comments - } & \\
\text { - No box checked, comment - "not clear" } \\
\text { - Low box checked, comment "if any" } \\
\text { - No box checked, comment - "none" }\end{array}$ & $\begin{array}{l}\bigotimes \text { Low(3) } \\
\bigotimes \text { Medium(2) } \\
\text { \High(1) } \\
\text { No Box Checked - } 5\end{array}$ \\
\hline $\begin{array}{l}\text { 3. Does the Project reduce the vulnerability of the baseline? } \\
\text { What is your best estimate of the likelihood of success of the current baseline? } \\
\text { What is your best estimate of the ability of this project to reduce the } \\
\text { vulnerability of the baseline, if technically successful? }\end{array}$ & $\begin{array}{l}\text { Low Medium High } \\
\bigotimes(\mathbf{3}) \bigotimes(\mathbf{3}) \square \\
\text { No Box Checked - } 6 \\
\text { Low Medium High } \\
\bigotimes(\mathbf{5}) \bigotimes(\mathbf{2}) \square \\
\text { No Box Checked - } 5\end{array}$ \\
\hline $\begin{array}{l}\text { 4. Does the project improve worker safety? } \\
\text { Comments - } \\
\text { - No Box Checked, comment "no" } \\
\text { - No Box Checked, comment "NA" }\end{array}$ & $\begin{array}{l}\text { Low Medium High } \\
\bigotimes(\mathbf{6}) \bigotimes(\mathbf{1}) \bigotimes(1) \\
\text { No Box Checked - } \\
\text { (4) }\end{array}$ \\
\hline
\end{tabular}




\begin{tabular}{|c|c|}
\hline $\begin{array}{l}\text { 5. Based on your evaluation of the technical criteria of page } 2 \text {, and assuming } \\
\text { recommended changes are made, is the project likely to be technically } \\
\text { successful? } \\
\text { Comments - } \\
\text { - No Box Checked, comment "no" }\end{array}$ & $\begin{array}{l}\text { Low Medium High } \\
\bigotimes(\mathbf{6}) \bigotimes(\mathbf{3}) \square \\
\text { No Box Checked - } 3\end{array}$ \\
\hline $\begin{array}{l}\text { 6. What is your best estimate of the likelihood of this project to support one of } \\
\text { the following project-specific goals/priorities of EM-1? }\end{array}$ & \\
\hline Consolidate Nuclear Material out of EM sites & $\begin{array}{l}\text { Low Medium High } \\
\bigotimes(\mathbf{6}) \bigotimes(\mathbf{1}) \bigotimes(\mathbf{1}) \\
\text { No Box Checked - } 4\end{array}$ \\
\hline Eliminate the need to process high level liquid waste & $\underset{\text { No Box Checked - } 5}{\square(6)}$ \\
\hline Shrink the EM footprint & $\bigotimes(5) \bigotimes(1) \bigotimes(1)$ \\
\hline Get wastes to disposal facilities quickly & $\begin{array}{c}\bigotimes(5) \bigotimes(1) \bigotimes(1) \\
\text { No Box Checked - 5 }\end{array}$ \\
\hline
\end{tabular}

Technical Review Criteria for the Nuclear Material Focus Area FY 2002 Mid-Year Review

Do you agree that this project is based on sound scientific and engineering principles? Are there any fatal flaws? What changes should we make?

-Do not agree. Project is not (apparently) aware of all the extensive work done previously on formation/life/transport props of colloids. DOE should convene panel of experts (Acadame/Nat'l Lab) to lay out proper exceptional program.

-Interesting research, but importance to NMFA is not clear.

-Sounds like based on theory only.

-No. Needs a good Science \& Technology review before it goes forward. This may be fatally

flawed.

-Yes.

-This project proposes to spend \$1,000K + through 2005 to understand colloidal. It may have good science as its underpinning but the information is of speculative value. It is not obvious that transport of radionuclides by colloidal mechanism is a significant issue. This issue has been studied by Yucca Mountain and there is no evidence that these studies indicate a sensitivity for this type of transport.

-No. Colloid transport and formation a mute issue.

-Major question if this is really needed.

-Project appears to be sound. Work should be done.

Do you agree that the project can meet the identified needs of end user sites? Can the technology be effectively deployed at the site? If not, what changes should we make?

-No. No. See my comments on above question, Do not move until convene expert panel \& get their

-Not at all clear that this is an issue, why should this focus area fund this?

-Deployment is not the issue.

- No.

- No.

-I'm not convinced of the user driver for this research. Is Pu migration really likely?

Yes.

-It is not clear who the end users are and there is no evidence of a demand pull for the acquisition of the information proposed.

-No. No, get data from 1950's tests at Hanford.

-Part of release rate program. 
-It appears that there is a great deal of work to be done in an area where there is considerable disagreement on the extent/reality of the problem. Suggestions below.

Based on the information available, do you believe that this project as planned can be successfully deployed to meet the schedule requirements of the identified end users? Should the project be continued or not? If not, what changes should we make?

-No. Continue if expert panel says should.

-Project should be rebaselined to, first, determine need once scientific consensus is resolved.

-Not a deployable project.

- No.

- No.

-See comment on previous question.

-Yes. Yes continue, but review by panel before additional dollars spent in out years.

-This project will spend a lot of dollars and it is not clear what the deliverable is, how it will be used or who will use it.

- No.

-Suggestions below.

Are you aware of any other technology or approach that might be applicable to the stated end user needs? If so, what is that technology, and where has it been deployed? Is it likely to be more successful than the current project at meeting the needs of the end users?

- No. No.

-Don't believe this project resolves any problems.

- No.

-Hanford Lab studies on retention of high level waste and Pu waste on Soil columns.

-Work should be done to see if colloid formation and radionuclide is really a problem. A great deal of work has been done on this. I'd suggest convening a conference of technical experts to review literature and assess what should be done. This work might better be done in the Science program. 
Programmatic Review Score Sheet for Nuclear Material Focus Area

OH11NM21 - Fernald Repackaging System; AL21NM21 - Automated Packaging of Nuclear Material-Robotics; AL11NM22 - Automated Packaging of Nuclear Materials

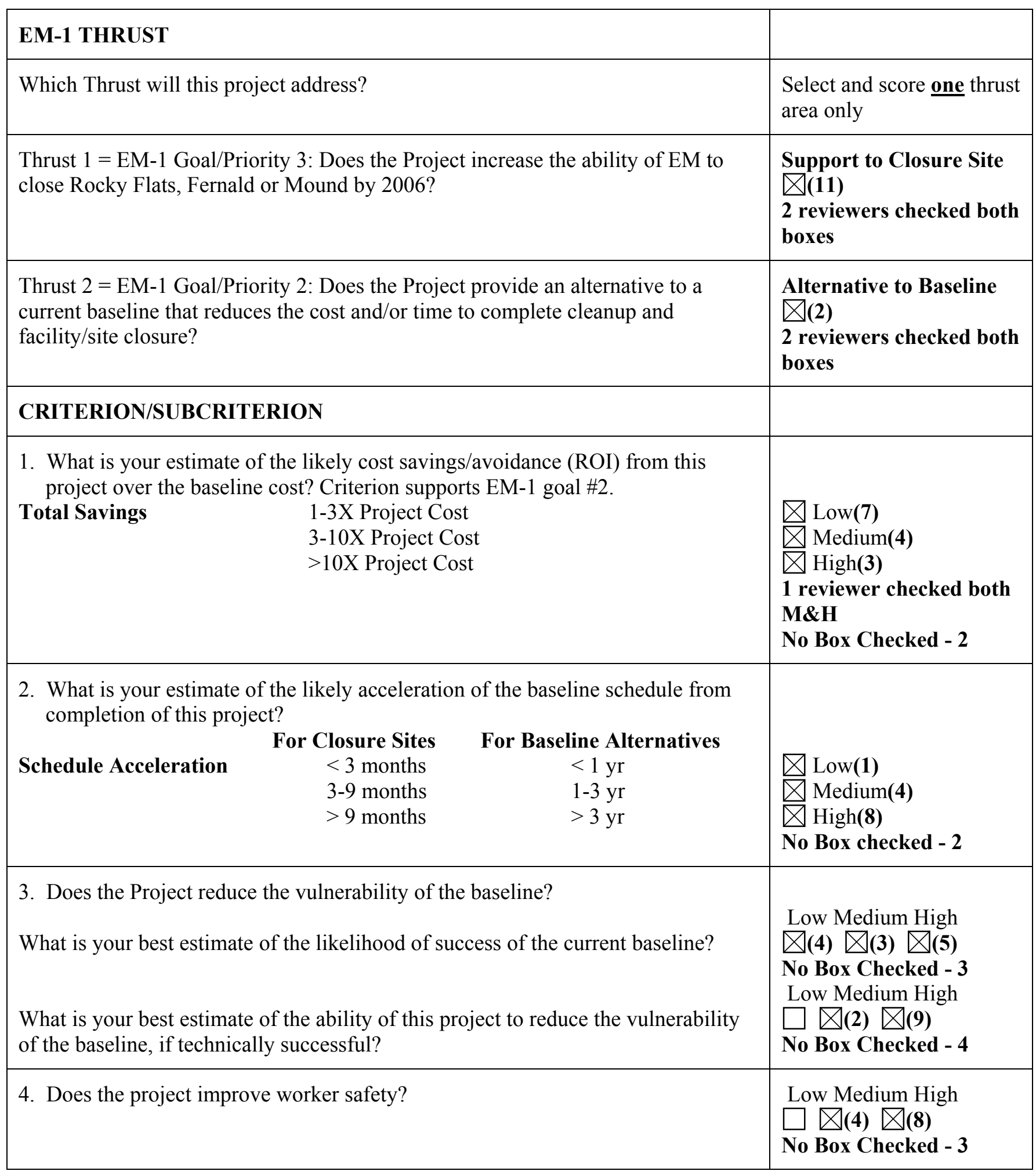




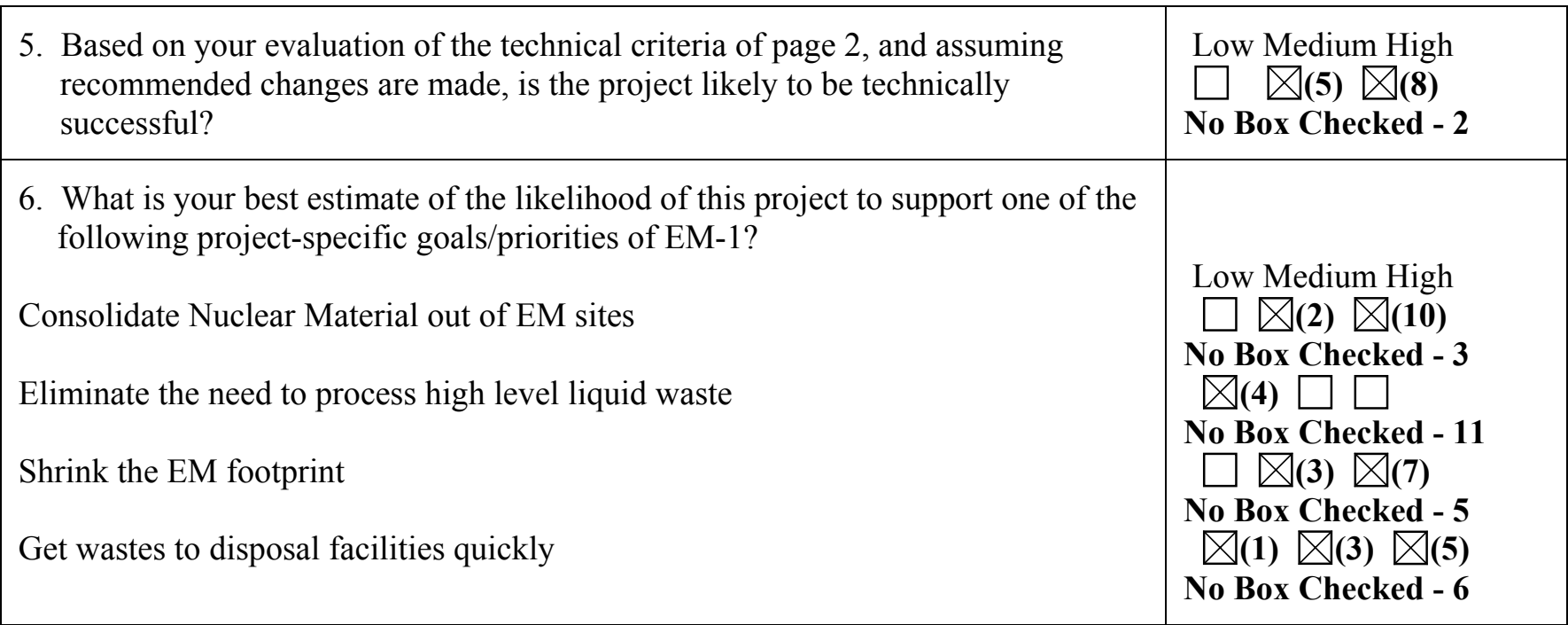

\section{Technical Review Criteria for the Nuclear Material Focus Area FY 2002 Mid-Year Review}

Do you agree that this project is based on sound scientific and engineering principles? Are there any fatal flaws? What changes should we make?

- Yes. Technology cross over with dry blending.

- (AL21NM21) This project is a straightforward engineering design effort and equipment fabrication by $S N L$.

- Yes. No.

- Yes. Flaws are in political realm.

- Yes. No apparent fatal flaws. No changes to make.

- (OH11NM21) Yes.

- (AL11NM22-AL21NM21) Yes.

- Agree. Appears to have lack of end user buy in.

- Gas collection capability may be useful to SRS.

- Agree. OH11NM21 is to continue in FY'02. Both AL21NM21 and AL11NM22 are to complete in - FY'02. All could continue if the site wants the technology.

- Yes. No. Go for it.

Do you agree that the project can meet the identified needs of end user sites? Can the technology be effectively deployed at the site? If not, what changes should we make?

- Users may not use all aspects of equipment.

- (AL11NM22) There is an open question whether the end user wants the support at LANL.

- Well tied to end user.

- Yes. Unknown.

-Yes.Deployed@NFS.

- (OH11NM21) Yes.

- (AL11NM22-AL21NM21) Yes.

- Yes. Yes. No Changes.

- Yes.

- Yes. Yes.

- Yes. Yes.

- I believe the project can meet the identified needs. Some decision should be made on the basis of whether the site will implement the technology once developed. The technology could continue to be developed for use elsewhere in any case, based on funding availability and priorities. 
Based on the information available, do you believe that this project as planned can be successfully deployed to meet the schedule requirements of the identified end users? Should the project be continued or not? If not, what changes should we make?

- Drum draining may not be used - thermal monitoring system, puncturing will be used-Don't recommend FY'03 work (Technical Support).

- (AL11NM22) If there is coordination and cooperation, there is no reason why the project cannot be successful. Deliverables to LANL need to be adequately defined.

- Some reluctance to deploy a few of the items in this TTP.

- (AL21NM21) The project as planned can be successful. The presentation of the information made it very difficult to explain and understand.

- Yes.

- Yes. Yes.

- Yes. Continue. Make no changes.

- (OH11NM21) Yes. Continue FY'02. Recommend continuation FY '03 \& '04.

- (AL11NM22-AL21NM21) Yes. Continue for FY'02.

- Yes.

- Yes.

- Drum draining - not sure will implement - (technology push, not operations pull in this case. If demonstrate no schedule slippage may do, concern about eliminating jobs, too. Thermal monitoring may not get used.

- If the dates identified are firm can help FEMP if they want it! I think the technology should be implemented for safety.

- Yes. Yes.

Are you aware of any other technology or approach that might be applicable to the stated end user needs? If so, what is that technology, and where has it been deployed? Is it likely to be more successful than the current project at meeting the needs of the end users?

- No.

- No.

- Alternatives are being reviewed, but, currently the only viable disposition path.

$-N o$.

- (OH11NM21) No.

- (AL11NM22-AL21NM21) No.

- HANDSS-55 Drum handling system at SRS.

- No, but some reluctance to drum draining and thermal monitoring. FY'03 - ? deployment support?

- Not aware of other technology that would be implement in time.

- No, finish in FY'02. 
Programmatic Review Score Sheet for Nuclear Material Focus Area

OH11NM21 - Fernald Repackaging System

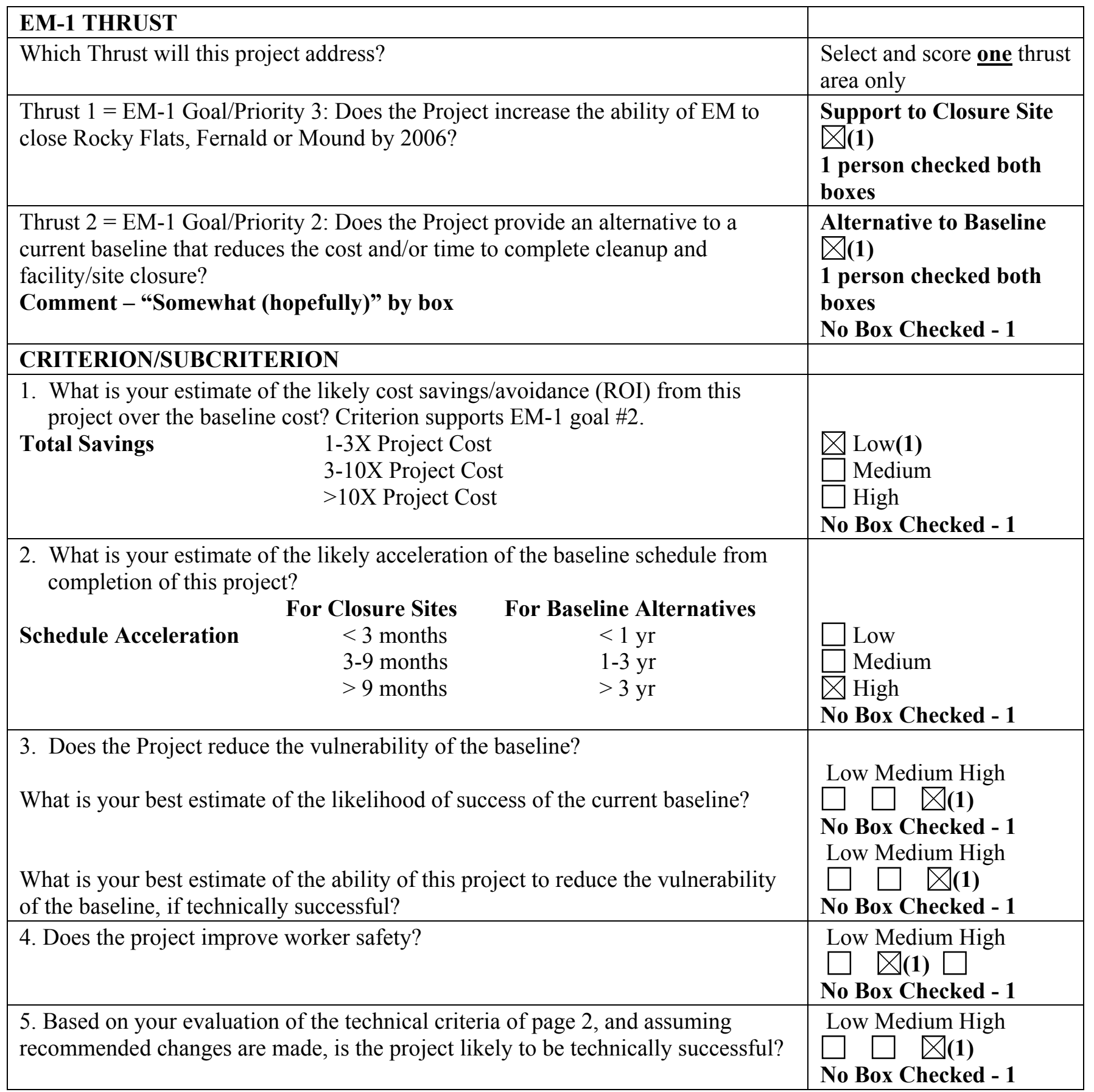




6. What is your best estimate of the likelihood of this project to support one of the
following project-specific goals/priorities of EM-1?
Consolidate Nuclear Material out of EM sites
Eliminate the need to process high level liquid waste
Shrink the EM footprint
Get wastes to disposal facilities quickly

\section{Technical Review Criteria for the Nuclear Material Focus Area FY 2002 Mid-Year Review}

Do you agree that this project is based on sound scientific and engineering principles? Are there any fatal flaws? What changes should we make?

\section{- Reasonable.}

Do you agree that the project can meet the identified needs of end user sites? Can the technology be effectively deployed at the site? If not, what changes should we make?

- Can be deployed.

- The project needs to end users needs based on discussion text does not confirm this situation.

Based on the information available, do you believe that this project as planned can be successfully deployed to meet the schedule requirements of the identified end users? Should the project be continued or not? If not, what changes should we make?

- Seems to be on schedule.

- Because of the overall simplicity of the blending effort, it should be successful. However, it is still possible to experience failure.

Are you aware of any other technology or approach that might be applicable to the stated end user needs? If so, what is that technology, and where has it been deployed? Is it likely to be more successful than the current project at meeting the needs of the end users?

- No. 
Programmatic Review Score Sheet for Nuclear Material Focus Area

OR01NM21 - Alpha Radiolysis Studies for U-233 Oxides

\begin{tabular}{|c|c|}
\hline EM-1 THRUST & \\
\hline Which Thrust will this project address? & $\begin{array}{l}\text { Select and score one thrust } \\
\text { area only }\end{array}$ \\
\hline $\begin{array}{l}\text { Thrust } 1=\text { EM-1 Goal/Priority 3: Does the Project increase the ability of EM to } \\
\text { close Rocky Flats, Fernald or Mound by } 2006 ?\end{array}$ & $\begin{array}{l}\text { Support to Closure Site } \\
\text { \(9)} \\
\text { No Box Checked }-3 \\
\text { Checked } 2 \text { boxes }-2\end{array}$ \\
\hline $\begin{array}{l}\text { Thrust } 2=\text { EM-1 Goal/Priority 2: Does the Project provide an alternative to a } \\
\text { current baseline that reduces the cost and/or time to complete cleanup and } \\
\text { facility/site closure? }\end{array}$ & $\begin{array}{l}\text { Alternative to Baseline } \\
\text { \(4) } \\
\text { Checked } 2 \text { boxes - } 2\end{array}$ \\
\hline CRITERION/SUBCRITERION & \\
\hline $\begin{array}{l}\text { 1. What is your estimate of the likely cost savings/avoidance (ROI) from this } \\
\text { project over the baseline cost? Criterion supports EM-1 goal \#2. } \\
\text { Total Savings 1-3X Project Cost } \\
\text { 3-10X Project Cost } \\
\quad>10 X \text { Project Cost }\end{array}$ & $\begin{array}{l}\bigotimes \text { Low(6) } \\
\bigotimes \text { Medium(2) } \\
\square \text { High } \\
\text { No Boxes Checked } 5\end{array}$ \\
\hline $\begin{array}{l}\begin{array}{l}\text { 2. What is your estimate of the likely acceleration of the baseline schedule from } \\
\text { completion of this project? }\end{array} \\
\begin{array}{ccc} & \text { For Closure Sites } & \text { For Baseline Alternatives } \\
\text { Schedule Acceleration } & <3 \text { months } & <1 \mathrm{yr} \\
& 3-9 \text { months } & 1-3 \mathrm{yr} \\
& >9 \text { months } & >3 \mathrm{yr}\end{array}\end{array}$ & $\begin{array}{l}\bigotimes \text { Low(5) } \\
\bigotimes \text { Medium(2) } \\
\square \text { High } \\
\text { No Boxes Checked - } 5\end{array}$ \\
\hline $\begin{array}{l}\text { 3. Does the Project reduce the vulnerability of the baseline? } \\
\text { What is your best estimate of the likelihood of success of the current baseline? } \\
\text { What is your best estimate of the ability of this project to reduce the vulnerability } \\
\text { of the baseline, if technically successful? }\end{array}$ & $\begin{array}{l}\text { Low Medium High } \\
\bigotimes(2) \bigotimes(4) \bigotimes(2) \\
\text { No Box Checked -5 } \\
\text { Low Medium High } \\
\bigotimes(1) \bigotimes(3) \bigotimes(4) \\
\text { No Box Checked - } 5\end{array}$ \\
\hline 4. Does the project improve worker safety? & $\begin{array}{l}\text { Low Medium High } \\
\bigotimes(4) \bigotimes(4) \bigotimes(1) \\
\text { No Box Checked - } 4\end{array}$ \\
\hline $\begin{array}{l}\text { 5. Based on your evaluation of the technical criteria of page } 2 \text {, and assuming } \\
\text { recommended changes are made, is the project likely to be technically } \\
\text { successful? }\end{array}$ & $\begin{array}{l}\text { Low Medium High } \\
\bigotimes(2) \bigotimes(3) \bigotimes(4) \\
\text { No Box Checked - } 4\end{array}$ \\
\hline
\end{tabular}




6. What is your best estimate of the likelihood of this project to support one of the
following project-specific goals/priorities of EM-1?
Consolidate Nuclear Material out of EM sites
Eliminate the need to process high level liquid waste
Shrink the EM footprint
Get wastes to disposal facilities quickly

\section{Technical Review Criteria for the Nuclear Material Focus Area FY 2002 Mid-Year Review}

Do you agree that this project is based on sound scientific and engineering principles? Are there any fatal flaws? What changes should we make?

- Yes. No, no changes.

- This is a basic science experiment that is not rigorous or complicated.

- Yes. No.

$-\mathrm{OK}$.

- Yes.

- Looks like it, can't see any fatal flaw, make no changes.

- Yes.

- This does not appear to be a technology application, but a pure science need.

- Yes. Only modeling.

- Yes.

- Fund to complete - essentially $\$ 45 K$ for report and cleanup.

Do you agree that the project can meet the identified needs of end user sites? Can the technology be effectively deployed at the site? If not, what changes should we make?

- Yes.

- It will satisfy the end users need. The output is scientific information that helps define the level of an operational risk. It is not an operations limiting effect.

- Yes. Yes.

- Not directly, but would be useful at several sites.

- Yes. Yes, none.

- Yes.

- Can be of some benefit to OR \& RFETS.

- No. No user pull - important to ORNL for save storage.

- Yes.

- Privatization of $\boldsymbol{U}-233$ ?

- If additional work on this much-studied phenomenon is desirable, I suggest it be done under EMSP.

Based on the information available, do you believe that this project as planned can be successfully deployed to meet the schedule requirements of the identified end users? Should the project be continued or not? If not, what changes should we make?

- Yes.

- There is no reason to believe that this project will not be successful.

- Yes, fund recommended.

- Not too directly tied to end users. 
- Yes. Continue, just to complete limited technology.

- Continue funding to closure in FY'02 (\$45K).

- No. Funding limited.

- No.

- Yes.

Are you aware of any other technology or approach that might be applicable to the stated end user needs? If so, what is that technology, and where has it been deployed? Is it likely to be more successful than the current project at meeting the needs of the end users?

- LANL work - RF work.

- Not necessarily, though modified approaches may be developed.

- No. No.

$-N o$.

$-N o$.

- Again, an ideal candidate for EMSP. 
Programmatic Review Score Sheet for Nuclear Material Focus Area

RL31NM11 -Optimal Plutonium Precipitation for Stabilization Feed Preparation

\begin{tabular}{|c|c|}
\hline EM-1 THRUST & \\
\hline Which Thrust will this project address? & $\begin{array}{l}\text { Select and score one thrust } \\
\text { area only }\end{array}$ \\
\hline $\begin{array}{l}\text { Thrust } 1=\text { EM-1 Goal/Priority 3: Does the Project increase the ability of EM to } \\
\text { close Rocky Flats, Fernald or Mound by } 2006 ?\end{array}$ & $\begin{array}{l}\text { Support to Closure Site } \\
\bigotimes(1)\end{array}$ \\
\hline $\begin{array}{l}\text { Thrust } 2 \text { = EM-1 Goal/Priority 2: Does the Project provide an alternative to a } \\
\text { current baseline that reduces the cost and/or time to complete cleanup and } \\
\text { facility/site closure? }\end{array}$ & $\begin{array}{l}\text { Alternative to Baseline } \\
\bigotimes(4) \\
\text { No box checked - } 1\end{array}$ \\
\hline CRITERION/SUBCRITERION & \\
\hline $\begin{array}{l}\text { 1. What is your estimate of the likely cost savings/avoidance (ROI) from this } \\
\text { project over the baseline cost? Criterion supports EM-1 goal \#2. } \\
\text { Total Savings } \\
\qquad \begin{array}{l}\text { 1-3X Project Cost } \\
\text { 3-10X Project Cost }\end{array} \\
\text { >10X Project Cost } \\
\text { - But they want } \mathbf{\$ 4 6 0} \text { K more - others on TAG disagree - marked High } \\
\text { Box and commented that it was "According to the End Users" }\end{array}$ & $\begin{array}{l}\bigotimes \text { Low(2) } \\
\bigotimes \text { Medium(3) } \\
\bigotimes \operatorname{High(1)}\end{array}$ \\
\hline 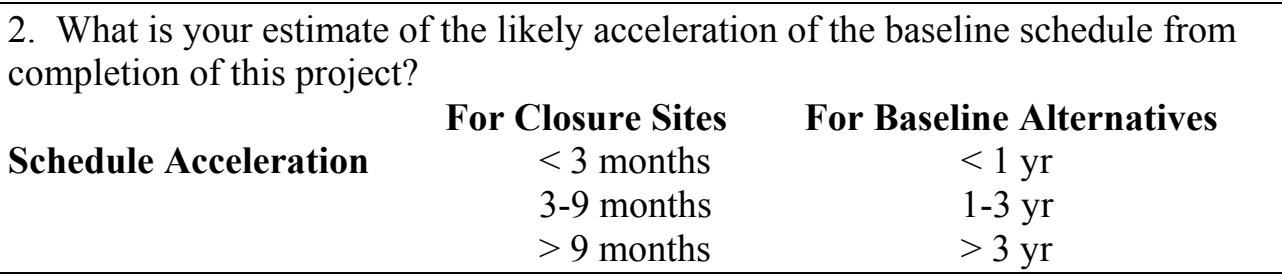 & $\begin{array}{l}\bigotimes \text { Low(1) } \\
\bigotimes \text { Medium(4) } \\
\bigotimes \text { High(1) } \\
\end{array}$ \\
\hline $\begin{array}{l}\text { 3. Does the Project reduce the vulnerability of the baseline? } \\
\text { What is your best estimate of the likelihood of success of the current baseline? } \\
\text { What is your best estimate of the ability of this project to reduce the vulnerability } \\
\text { of the baseline, if technically successful? }\end{array}$ & $\begin{array}{l}\text { Low Medium High } \\
\bigotimes(\mathbf{1}) \bigotimes(2) \bigotimes(2) \\
\text { No Box Checked - } 1 \\
\text { Low Medium High } \\
\square \bigotimes(\mathbf{1}) \bigotimes(5)\end{array}$ \\
\hline 4. Does the project improve worker safety? & $\begin{array}{l}\text { Low Medium High } \square \\
\text { (1) } \square(\mathbf{4}) \square \\
\text { No Box Checked - } 1\end{array}$ \\
\hline $\begin{array}{l}\text { 5. Based on your evaluation of the technical criteria of page } 2 \text {, and assuming } \\
\text { recommended changes are made, is the project likely to be technically successful? }\end{array}$ & $\begin{array}{l}\text { Low Medium High } \\
\square \square(\mathbf{1}) \bigotimes(\mathbf{5})\end{array}$ \\
\hline $\begin{array}{l}\text { 6. What is your best estimate of the likelihood of this project to support one of the } \\
\text { following project-specific goals/priorities of EM-1? } \\
\text { Consolidate Nuclear Material out of EM sites } \\
\text { Eliminate the need to process high level liquid waste } \\
\text { Shrink the EM footprint } \\
\text { Get wastes to disposal facilities quickly }\end{array}$ & 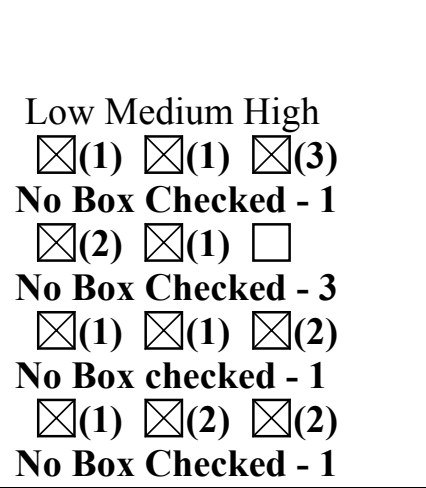 \\
\hline
\end{tabular}




\section{Technical Review Criteria for the Nuclear Material Focus Area FY 2002 Mid-Year Review}

Do you agree that this project is based on sound scientific and engineering principles? Are there any fatal flaws? What changes should we make?

-Successful.

-Some questions on this, but the work appears to have had significant success.

-Cover-up for major technical goof by EM, by using Hydroxide PPT. The whole project is a make work project - all of the technology was available in 50's-60's.

-Well-understood scientific principles.

-Yes. Miscellaneous solutions may present problems.

-This project has a strong technical base in terms of applying chemical processing technology that was developed in the past. It is a project to recover from a technical decision forced by political and social distrust of the motives of the government. There is a fatal flaw, potentially, if they add silica to minimize moisture uptake - not clear whether Savannah River can process material containing silica.

-Project is to be complete in March of this year. Should be completed.

Do you agree that the project can meet the identified needs of end user sites? Can the technology be effectively deployed at the site? If not, what changes should we make?

-Deployable, Scheduled for completion in 5 months, to be immediately deployed.

-Yes.

- Yes.

-The project can meet the requirements of end users. Need to make sure the materials are processed in line that has adequate humidity control so product can be packaged for shipment.

-No Change.

Based on the information available, do you believe that this project as planned can be successfully deployed to meet the schedule requirements of the identified end users? Should the project be continued or not? If not, what changes should we make?

-Yes, appears to be very successful.

-Yes, It's over now.

-Yes. Almost complete now. Deployment on going.

-The technology has been successfully deployed in the past. This is a technical assistance/political recovery project. It will end on schedule this year.

Are you aware of any other technology or approach that might be applicable to the stated end user needs? If so, what is that technology, and where has it been deployed? Is it likely to be more successful than the current project at meeting the needs of the end users?

-TAG chemists claim there are better methods.

-40 yrs. of operating oxalate precipitation at PFP.

$-N o$.

-No changes. 
Programmatic Review Score Sheet for Nuclear Material Focus Area

RL31NM12 - Plutonium Thermal Treatment Furnace Load-Out System

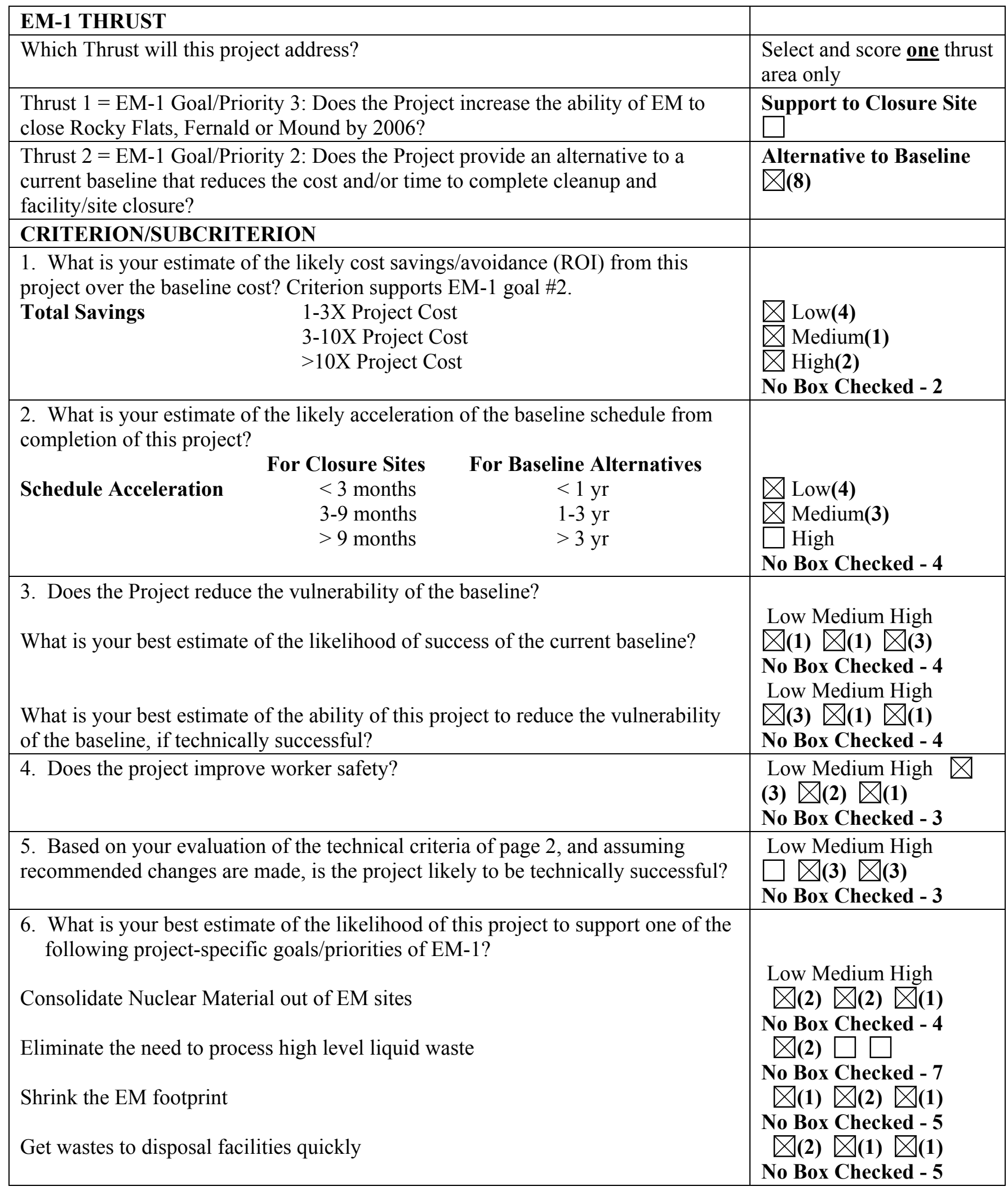




\section{Technical Review Criteria for the Nuclear Material Focus Area FY 2002 Mid-Year Review}

Do you agree that this project is based on sound scientific and engineering principles? Are there any fatal flaws? What changes should we make?

- Straightforward project.

- This project was a simple straightforward engineering project. It has been successfully executed from the design and fabrication perspective.

- Yes. No.

- Yes.

- Good project, end user has lost energy for installing it because of other process restrictions. Good Engineering - addressed a significant time problem.

- Project complete.

Do you agree that the project can meet the identified needs of end user sites? Can the technology be effectively deployed at the site? If not, what changes should we make?

- Seems that the need was not effectively analyzed before the start of the project.

- As planned, this design would have met the needs of the end user.

- Yes. Deployment dependant on user convenience/opportunity-possible lack of sufficiently defined baseline process led to perception that furnace time was choke point in process - now chokepoint may be elsewhere in process (bagless transfer).

- Yes, but initial schedule driver is reduced.

- Deployment not scheduled.

Based on the information available, do you believe that this project as planned can be successfully deployed to meet the schedule requirements of the identified end users? Should the project be continued or not? If not, what changes should we make?

- Appears deployment is uncertain - Project is ready, i.e., work is complete, no follow on funding needed, lesson to be learned.

- The base line production line was changed and the configuration of the new system prohibited the users of the device as constructed. It is now collecting dust in the warehouse-BAD EXAMPLE OF PLANNING AND EXECUTION.

- Deployment contingent on user convenience/opportunity - would require shutdown of processing would require work inside contaminated glovebox to install so user is reluctant to install if not strictly needed.

- Complete to closure as planned.

- Should finish it out and deploy where you can.

- Now have 2 thermal lines, not just one.

- No. Not being deployed - will require adding capacity to 460 project. 
Are you aware of any other technology or approach that might be applicable to the stated end user needs? If so, what is that technology, and where has it been deployed? Is it likely to be more successful than the current project at meeting the needs of the end users?

- No.

- Needs to be studied to understand what went wrong.

- No.

- Other limiting factors (bagless loadout) some site reluctances since through put limiting.

- No.

- Problems were discussed at the meeting. It is unfortunate that the work was done apparently without considering the entire flowsheet, i.e., looking for "bottlenecks" elsewhere. But most of us have inadvertently done that at some time or another. We usually don't "learn" lessons - we endure them. 
Programmatic Review Score Sheet for Nuclear Material Focus Area

RL31NM13 - Single Step Distillation Process for Plutonium Oxides Containing Chlorides

\begin{tabular}{|c|c|}
\hline EM-1 THRUST & \\
\hline Which Thrust will this project address? & $\begin{array}{l}\text { Select and score one thrust } \\
\text { area only }\end{array}$ \\
\hline $\begin{array}{l}\text { Thrust } 1=\text { EM-1 Goal/Priority 3: Does the Project increase the ability of EM to } \\
\text { close Rocky Flats, Fernald or Mound by } 2006 ?\end{array}$ & $\begin{array}{l}\text { Support to Closure Site } \\
\bigotimes(1)\end{array}$ \\
\hline $\begin{array}{l}\text { Thrust } 2=\text { EM-1 Goal/Priority 2: Does the Project provide an alternative to a } \\
\text { current baseline that reduces the cost and/or time to complete cleanup and } \\
\text { facility/site closure? }\end{array}$ & $\begin{array}{l}\text { Alternative to Baseline } \\
\bigotimes(5)\end{array}$ \\
\hline CRITERION/SUBCRITERION & \\
\hline $\begin{array}{l}\text { 1. What is your estimate of the likely cost savings/avoidance (ROI) from this } \\
\text { project over the baseline cost? Criterion supports EM-1 goal \#2. } \\
\text { Total Savings } \\
\qquad \begin{array}{l}\text { 1-3X Project Cost } \\
\text { 3-10X Project Cost } \\
>10 X \text { Project Cost }\end{array}\end{array}$ & $\begin{array}{l}\bigotimes \text { Low(4) } \\
\bigotimes \text { Medium(1) } \\
\square \text { High } \\
\text { No Box Checked - 1 }\end{array}$ \\
\hline 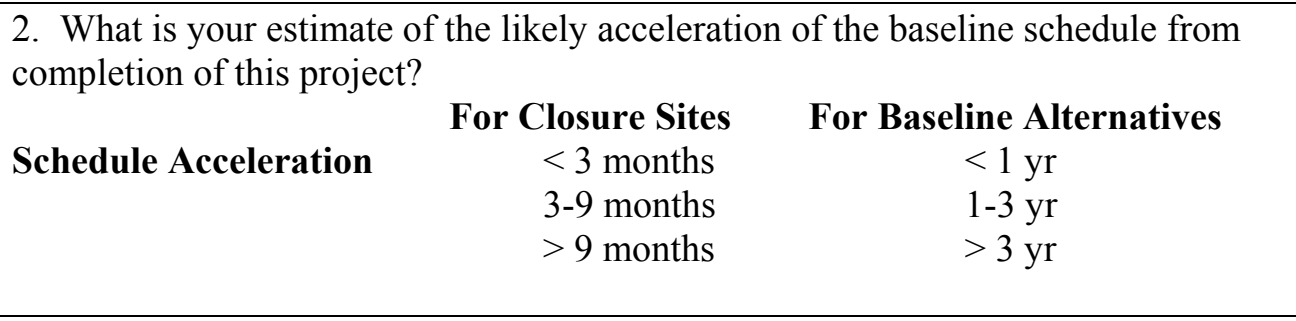 & $\begin{array}{l}\bigotimes \text { Low(4) } \\
\bigotimes \text { Medium(1) } \\
\square \text { High } \\
\text { No Box Checked - 1 }\end{array}$ \\
\hline $\begin{array}{l}\text { 3. Does the Project reduce the vulnerability of the baseline? } \\
\text { What is your best estimate of the likelihood of success of the current baseline? } \\
\text { What is your best estimate of the ability of this project to reduce the vulnerability } \\
\text { of the baseline, if technically successful? }\end{array}$ & $\begin{array}{l}\text { Low Medium High } \\
\square(4) \square \square(1) \\
\text { No Box Checked - } 1 \\
\text { Low Medium High } \\
\bigotimes(2) \square(2) \square(1) \\
\text { No Box Checked - } 1\end{array}$ \\
\hline 4. Does the project improve worker safety? & $\begin{array}{l}\text { Low Medium High } \\
\bigotimes(2) \bigotimes(3) \square \\
\text { No Box Checked - } 1\end{array}$ \\
\hline $\begin{array}{l}\text { 5. Based on your evaluation of the technical criteria of page } 2 \text {, and assuming } \\
\text { recommended changes are made, is the project likely to be technically successful? }\end{array}$ & $\begin{array}{l}\text { Low Medium High } \\
\bigotimes(3) \bigotimes(2) \square \\
\text { No Box Checked - } 1\end{array}$ \\
\hline $\begin{array}{l}\text { 6. What is your best estimate of the likelihood of this project to support one of the } \\
\text { following project-specific goals/priorities of EM-1? } \\
\text { Consolidate Nuclear Material out of EM sites } \\
\text { Eliminate the need to process high level liquid waste } \\
\text { Shrink the EM footprint } \\
\text { Get wastes to disposal facilities quickly }\end{array}$ & 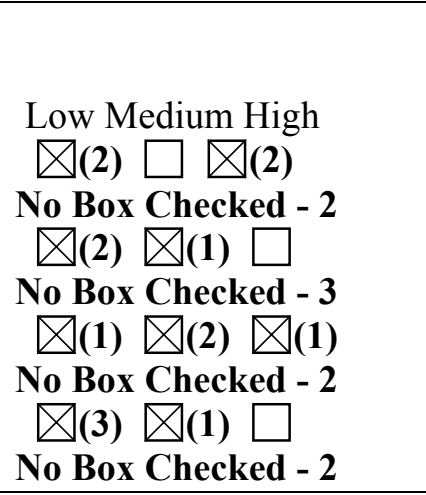 \\
\hline
\end{tabular}




\section{Technical Review Criteria for the Nuclear Material Focus Area FY 2002 Mid-Year Review}

Do you agree that this project is based on sound scientific and engineering principles? Are there any fatal flaws? What changes should we make?

- Some question it.

- Good idea to process salts. Fatal flaw is equipment corrosion problem.

- The basic principles in this project are only partially understood. They are not consistent with a successfully project. If the product contains quantities of $\mathrm{MgCl}_{2}$ the moisture uptake will be significant. A little analysis would indicate that this project is not likely to be successful from a systems perspective.

- Continue to completion in FY'02.

Do you agree that the project can meet the identified needs of end user sites? Can the technology be effectively deployed at the site? If not, what changes should we make?

- Scheduled for completion next month.

- Yes. Questionable deployment.

- For the application considered, this technology cannot be successfully employed.

- Project can't eliminate all Ci - without going to a vacuum distillation system probably not then. Stop process.

Based on the information available, do you believe that this project as planned can be successfully deployed to meet the schedule requirements of the identified end users? Should the project be continued or not? If not, what changes should we make?

- Should work, but product may not meet DOE Standard 3013.

- Complete in March.

- This is not a successful project from the point of view of making a measurable project, you have to get rid of chlorides - especially the $\mathrm{Mg} \& \mathrm{Ca}$.

- Consider using a dry glove box system to drive off water and package the stabilized material in a low humidity atmosphere before the material re-absorbs moisture.

Are you aware of any other technology or approach that might be applicable to the stated end user needs? If so, what is that technology, and where has it been deployed? Is it likely to be more successful than the current project at meeting the needs of the end users?

$-\mathrm{Mg} \mathrm{C}_{2} \mathrm{H}_{2} \mathrm{O}$ could be a problem - Potential corrosions fairly stable to $1000^{\circ} \mathrm{C} .950^{\circ} \mathrm{C}$ is not always good enough to remove all the $\mathrm{H}_{2} \mathrm{O}$.

- The washing project may be best case with its drawbacks.

- As noted above, if $\mathrm{H}_{2} \mathrm{O}$ isn't present, chloride corrosion will be eliminated or at least greatly reduced. 


\section{Programmatic Review Score Sheet for Nuclear Material Focus Area \\ RL32NM41 - Enhancement Reactivity Factor for Cold Vacuum Drying (CVD) Processing of N- Reactor SNF}

\begin{tabular}{|c|c|}
\hline EM-1 THRUST & \\
\hline Which Thrust will this project address? & $\begin{array}{l}\text { Select and score one thrust } \\
\text { area only }\end{array}$ \\
\hline $\begin{array}{l}\text { Thrust } 1=\text { EM-1 Goal/Priority 3: Does the Project increase the ability of EM to } \\
\text { close Rocky Flats, Fernald or Mound by } 2006 ?\end{array}$ & $\begin{array}{l}\text { Support to Closure Site } \\
\square\end{array}$ \\
\hline $\begin{array}{l}\text { Thrust } 2=\text { EM-1 Goal/Priority } 2: \text { Does the Project provide an alternative to a } \\
\text { current baseline that reduces the cost and/or time to complete cleanup and } \\
\text { facility/site closure? }\end{array}$ & $\begin{array}{l}\text { Alternative to Baseline } \\
\square(6)\end{array}$ \\
\hline CRITERION/SUBCRITERION & \\
\hline $\begin{array}{l}\text { 1. What is your estimate of the likely cost savings/avoidance (ROI) from this } \\
\text { project over the baseline cost? Criterion supports EM-1 goal \#2. } \\
\text { Total Savings } \\
\qquad \begin{array}{l}\text { 1-3X Project Cost } \\
\text {-10X Project Cost }\end{array} \\
\text { 10X Project Cost }\end{array}$ & $\begin{array}{l}\bigotimes \text { Low(3) } \\
\square \text { Medium } \\
\text { High(3) }\end{array}$ \\
\hline $\begin{array}{l}\begin{array}{l}\text { 2. What is your estimate of the likely acceleration of the baseline schedule from } \\
\text { completion of this project? }\end{array} \\
\begin{array}{ccc} & \text { For Closure Sites } & \text { For Baseline Alternatives } \\
\text { Schedule Acceleration } & <3 \text { months } & <1 \mathrm{yr} \\
& 3-9 \text { months } & 1-3 \mathrm{yr} \\
& >9 \text { months } & >3 \mathrm{yr}\end{array}\end{array}$ & $\begin{array}{l}\bigotimes \text { Low(4) } \\
\bigotimes \operatorname{Medium(1)} \\
\bigotimes \operatorname{High(1)}\end{array}$ \\
\hline $\begin{array}{l}\text { 3. Does the Project reduce the vulnerability of the baseline? } \\
\text { What is your best estimate of the likelihood of success of the current baseline? } \\
\text { What is your best estimate of the ability of this project to reduce the vulnerability } \\
\text { of the baseline, if technically successful? }\end{array}$ & 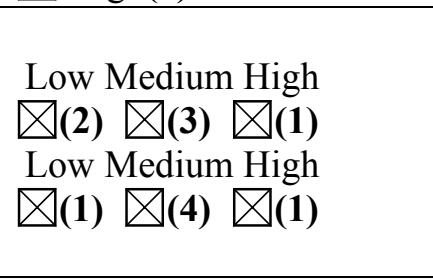 \\
\hline 4. Does the project improve worker safety? & $\begin{array}{l}\text { Low Medium High } \\
\bigotimes(\mathbf{4}) \square \square(\mathbf{1}) \\
\text { No Box Checked - } 1\end{array}$ \\
\hline $\begin{array}{l}\text { 5. Based on your evaluation of the technical criteria of page } 2 \text {, and assuming } \\
\text { recommended changes are made, is the project likely to be technically } \\
\text { successful? }\end{array}$ & $\begin{array}{l}\text { Low Medium High } \\
\bigotimes(\mathbf{1}) \bigotimes(\mathbf{2}) \bigotimes(\mathbf{3})\end{array}$ \\
\hline $\begin{array}{l}\text { 6. What is your best estimate of the likelihood of this project to support one of the } \\
\text { following project-specific goals/priorities of EM-1? } \\
\text { Consolidate Nuclear Material out of EM sites } \\
\text { Eliminate the need to process high level liquid waste } \\
\text { Shrink the EM footprint } \\
\text { Get wastes to disposal facilities quickly }\end{array}$ & 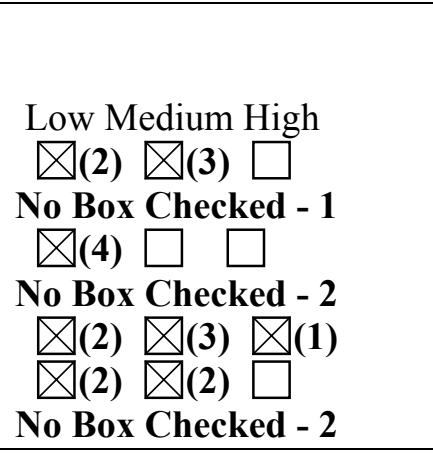 \\
\hline
\end{tabular}




\section{Technical Review Criteria for the Nuclear Material Focus Area FY 2002 Mid-Year Review}

Do you agree that this project is based on sound scientific and engineering principles? Are there any fatal flaws? What changes should we make?

- Scheduled to be completed by end of FY' 02.

- Results to date?

- Yes. Good approach that should have been done 5 years ago.

- Yes.

- The project is based on sound scientific and engineering principles in understanding the kinetics of reaction of $\mathrm{UH}_{3}$. It does not appear that there are any fatal flaws. The course should be maintained in order to obtain the data on the proposal schedule. Schedule is important if this project is to achieve the impact forecasted.

- None, program nearing completion, should be continued. (Scheduled to be complete end FY'02.

Do you agree that the project can meet the identified needs of end user sites? Can the technology be effectively deployed at the site? If not, what changes should we make?

- Yes. Already proven.

- Definitely.

- Yes. Yes.

- Perhaps.

- The project can meet the need of the end user in reducing the schedule and cost of drying the spent fuel prior to packaging.

- Agree.

Based on the information available, do you believe that this project as planned can be successfully deployed to meet the schedule requirements of the identified end users? Should the project be continued or not? If not, what changes should we make?

- Yes.

- Appears to be on schedule - Continue, It is almost finished. No future funding needed.

- Proceed ASAP.

- Yes. Complete in May' '02.

- This project only has one customer and it can be readily deployed. It only requires that the time and temperature at an ongoing process be changed.

- Agree.

Are you aware of any other technology or approach that might be applicable to the stated end user needs? If so, what is that technology, and where has it been deployed? Is it likely to be more successful than the current project at meeting the needs of the end users?

- No.

$-N A$.

- Much of basic work was done by P\&PL 3-5 years ago - Not generally accepted by contractor. This is a technology need that was ignored.

- No.

- There is no completing technology that can effect the change proposed.

-No-complete task. 


\section{Programmatic Review Score Sheet for Nuclear Material Focus Area}

SR02NM51 - Determination of Radiolysis Effects for Water on Spent Nuclear Fuel; ID02NM45 Analytic Modeling of Ionizing Radiation Effects to Water on Spent Nuclear Fuel

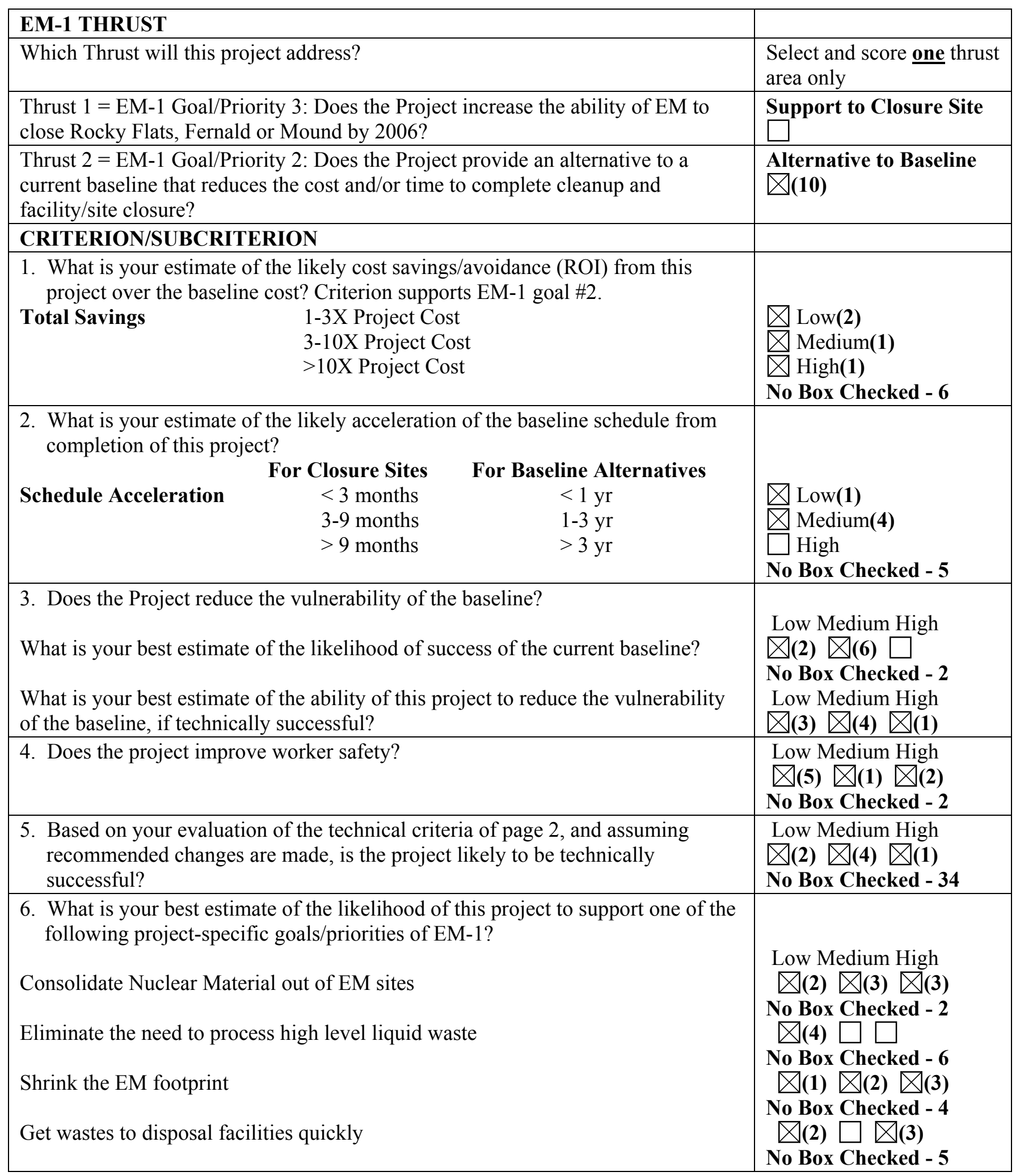




\section{Technical Review Criteria for the Nuclear Material Focus Area FY 2002 Mid-Year Review}

Do you agree that this project is based on sound scientific and engineering principles? Are there any fatal flaws? What changes should we make?

- No. Pressurization not a problem - overly conservative assumptions. Experience with $P u \&{ }^{233} U$ \& radiation damage of $\mathrm{H}_{2} \mathrm{O}$ from reactors should be reviewed.

This project proposes to devise a standard method to remove water from spent fuel. The concept is basic and needed. The information on the experiments to be conducted on spent fuel elements is extremely limited. There is limited basis to determine if the experimental method will yield the data required to provide an authoritative specification of the process.

- Yes. No fatal flaws, make no changes.

- Yes.

- Ok.

- No. I don't believe this is a real problem and am not sure what we're trying to solve. It seems like we're trying to prove a negative.

- Yes.

- Agree that is sound and should continue.

Do you agree that the project can meet the identified needs of end user sites? Can the technology be effectively deployed at the site? If not, what changes should we make?

- No.

- There is modest evidence that the experimental method will develop the data required, there is limited description of the deliverables necessary to achieve the authoritative information to allow - for the test to be deployed.

- Yes. Yes, make no changes.

- Not sure that political will accept / $400 \mathrm{lb}$. Vs $5 \mathrm{lb}$. Pressure.

- No. Need to better define strategic goal.

- Yes. Yes.

- Agree.

Based on the information available, do you believe that this project as planned can be successfully deployed to meet the schedule requirements of the identified end users? Should the project be continued or not? If not, what changes should we make?

- No.

- There is modest evidence that the test will be successful.

- Yes. Continue, make no changes.

- OK.

- No changes seem appropriate.

- Low confidence.

- Yes. Continue.

- Continue. 
Are you aware of any other technology or approach that might be applicable to the stated end user needs? If so, what is that technology, and where has it been deployed? Is it likely to be more successful than the current project at meeting the needs of the end users?

- Lots of it.

- None. No.

- Desiccants were dismissed in the discussion. It is not clear why desiccants shouldn't be used.

- No.

$-N o$.

- Comments were made that a great deal of work was done in the 40's and 50's that is relevant and probably should review this and also consider effect of new requirements, e.g., NQA-1 on acceptability of information. 
Programmatic Review Score Sheet for Nuclear Material Focus Area

SR11NM12 - Prevention of Precipitation of Unwanted Solids During Canyon Dissolution

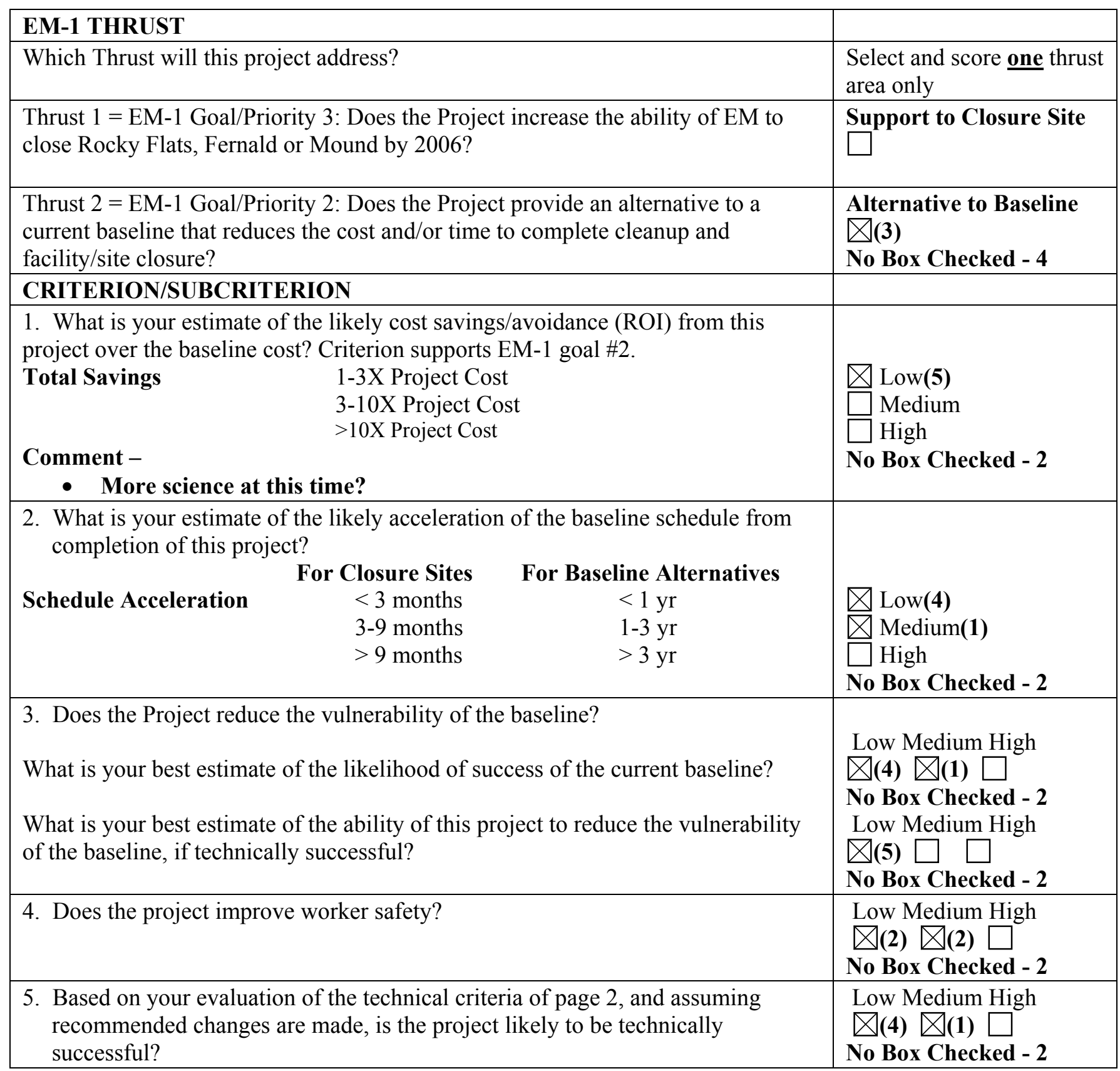


6. What is your best estimate of the likelihood of this project to support one of the following project-specific goals/priorities of EM-1?

$$
\begin{aligned}
& \text { Consolidate Nuclear Material out of EM sites } \\
& \text { Eliminate the need to process high level liquid waste } \\
& \text { Shrink the EM footprint } \\
& \text { Get wastes to disposal facilities quickly }
\end{aligned}
$$

\section{Technical Review Criteria for the Nuclear Material Focus Area FY 2002 Mid-Year Review}

Do you agree that this project is based on sound scientific and engineering principles? Are there any fatal flaws? What changes should we make?

- Solids are wastes that can be flushed to the tank farms.

- Do not agree - Changes: 1. Abandon approach \& devise alternative scheme to solubilize candidate solids, Or - If don't abandon present approach, transfer project to DOE Science Program.

- More science needed.

- Science OK-much more work needed.

- There are many unknowns and technology applications are not readily apparent.

- The concept of a method to model chemical systems based on thermodynamics is fundamentally sound in principle. There are a variety of methods in existence. Application of this to chemical systems for nuclear material processing is a good approach - the question is the effort required to gather the specific data necessary to cover all of the different systems expected at SRS.

- Project is based on sound scientific and engineering principles. Problem is the complexity of the system being evaluated, e.g., depending on the materials being processed, especially those with many constituents, unexpected and non-predictable reactions can/will occur, resulting in solids formation.

Do you agree that the project can meet the identified needs of end user sites? Can the technology be effectively deployed at the site? If not, what changes should we make?

- No.

- No. No, see my comments about changes, in question \#1.

- No. This is a basic science need as opposed to technology application.

- The project might be able to meet some of the needs of the end user since the end user is doing it.

- The question is how reliable the results will be over how many of the systems to be processed will be saved.

- Complicated systems, more fundamental research needed. Project scheduled to be complete in FY'02. 
Based on the information available, do you believe that this project as planned can be successfully deployed to meet the schedule requirements of the identified end users? Should the project be continued or not? If not, what changes should we make?

- No.

- Do not continue - see my comments about changes, in question \#1.

- No.

- It can be partially successful-complete success is a question.

- I doubt this can be successful in short term. If this is to be continued, should be under EMSP.

Are you aware of any other technology or approach that might be applicable to the stated end user needs? If so, what is that technology, and where has it been deployed? Is it likely to be more successful than the current project at meeting the needs of the end users?

- Solids have been flushed to the waste tanks for years.

- Yes. Other technology. Yes.

- No.

- There are experimental methods that may provide the information on a more reliable basis.

- No, except do - if at all - under EMSP. Some thought might also be given to material pretreatment if problematic materials could be dealt with before subjecting the materials to the main/baseline process. 


\section{APPENDIX D: MEETING AGENDA}

\begin{tabular}{|c|c|c|}
\hline \multicolumn{3}{|c|}{$\begin{array}{c}\text { February 13-14, } 2002 \\
\text { Hotel Santa Fe } \\
1501 \text { Paseo de Peralta } \\
\text { Santa Fe, NM } 87501 \\
\text { (505) } 982-1200\end{array}$} \\
\hline \multicolumn{3}{|c|}{ Agenda for Wednesday, February 13} \\
\hline Time & Activity & Speaker(s) \\
\hline 8:30-8:45 & Welcome, Introduction, Objectives & Stan Wolf \\
\hline $8: 45-9: 45$ & Office of Science \& Technology Restructuring & Teresa Fryberger \\
\hline $9: 45-10: 15$ & FY02 NMFA Program Overview & Ken Osborne \\
\hline $10: 15-10: 30$ & FY02 Nuclear Materials Transition & G.D. Roberson \\
\hline 10:30-11:15 & $\begin{array}{l}\text { Review Panel Session (closed meeting to discuss } \\
\text { review objectives, criteria, and methodology) }\end{array}$ & --- \\
\hline 11:15-12:45 PM & Lunch (on your own) & ---- \\
\hline $12: 45-3: 00$ & Spent Nuclear Fuel Product Line FY02 Projects & Phil Wheatley \\
\hline $3: 00-3: 15$ & Break & ---- \\
\hline $3: 15-4: 45$ & Material Processing Product Line FY02 Projects & Alice Murray \\
\hline $4: 45 \ldots$ & $\begin{array}{l}\text { Review Panel Session (closed meeting to discuss } \\
\& \text { score projects presented) }\end{array}$ & --- \\
\hline \multicolumn{3}{|c|}{ Agenda for Thursday, February 14} \\
\hline$\overline{T \text { Time }}$ & Activity & Speaker(s) \\
\hline $8: 30-10: 00$ & $\begin{array}{l}\text { Packaging, Transportation, \& Storage Product } \\
\text { Line FY02 Projects }\end{array}$ & Marty Molecke \\
\hline 10:00-10:15 & Break & ---- \\
\hline 10:15-11:30 & Stabilization Product Line FY02 Projects & Kevin Ramsey \\
\hline 11:30-1:00 PM & $\begin{array}{l}\text { Lunch (working lunch for review panel; other } \\
\text { participants on your own) }\end{array}$ & ---- \\
\hline 1:00-1:45 & ASTD Projects & $\begin{array}{l}\text { Jerry Boak; Gary } \\
\text { Polansky }\end{array}$ \\
\hline $1: 45-2: 30$ & Nuclear Materials Vision & G.D. Roberson \\
\hline $2: 30-2: 45$ & Break & ---- \\
\hline $2: 45-4: 30$ & Review Panel Closeout Session - closed meeting & ---- \\
\hline 4:30-5:00 & Summary and Closing & Doyle Batt; Ken Osborne \\
\hline
\end{tabular}




\section{APPENDIX E: MEETING ATTENDEES}

\begin{tabular}{|c|c|c|c|}
\hline NAME & PHONE & E-MAIL & SITE \\
\hline Batt, Doyle & (208) 526-0185 & doy@inel.gov & INEEL(EUSC) \\
\hline Boak, Jerry & (505) 845-0835 & jmboak@lanl.gov & LANL \\
\hline Bonner, Bill & (509) $372-6263$ & bill.bonner@PNL.gov & PNNL \\
\hline Booth, Chip & (304) 253-8674 & cbooth@iuoeiettc.org & IUOE \\
\hline Bossart, Steven & (304) 285-4643 & sboss@netl.doe.gov & NETL \\
\hline Chase, Stephen & (202) 585-3789 & Stephen.chase@nnsa.doe.gov & DOE-HQ \\
\hline Chipman, Nate & (208) 526-1424 & chipna@,inel.gov & INEEL \\
\hline Dahl, Chris & (208) 526-3583 & dahl@inel.gov & INEEL \\
\hline Dunham, Tracy & $(505) 845-9776$ & tmdunha@sandia.gov & SNL \\
\hline Dworzak, Wolfgang & $(505) 667-0542$ & wdworzak@lanl.gov & LANL \\
\hline Eller, P. Gary & (505) 667-7111 & P_gary_eller@lanl.gov & LANL \\
\hline Erickson, Randy & $(505) 667-4950$ & rerickson@1anl.gov & LANL \\
\hline Felt, Rowland & (208) 526-8241 & feltre@,inel.gov & DOE-EH (TAG) \\
\hline Fryberger, Teresa & (301) 903-7260 & Teresa.fryberger@em.doe.gov & DOE-HQ \\
\hline Fuhrman, Paul & (208) 526-3196 & Fuhrpw@inel.gov & INEEL \\
\hline Glasper, Marcus & (509) 372-4012 & Marcus_J_Glasper@rl.gov & DOE-RL \\
\hline Helt, Jim & (630) 252-7335 & jhelt@anl.gov & Argonne \\
\hline Hirons, Tom & (505) 844-1904 & Hirons_Thomas_j@lanl.gov & LANL \\
\hline Hulet, Greg & (208) 526-0283 & hag@inel.gov & INEEL \\
\hline Ives, Brent & (925) 423-2636 & Ives1@1ln1.gov & LLNL (EUSC) \\
\hline Jenison, Mary & (301) 903-7914 & mary.jenison@em.doe.gov & DOE-HQ \\
\hline Jenks, Brian & (505) 845-4959 & bjenks@doeal.gov & DOE-AL \\
\hline Kunze, Jay & (208) 282-2902 & kunzejay@isu.edu & $(\mathrm{TAG})$ \\
\hline Low, Jim & $(505) 845-5458$ & jlow@doeal.gov & DOE-AL \\
\hline Maloney, Dave & (303) 966-7566 & David.Maloney@rfets.gov & RFETS (EUSC) \\
\hline Mason, Richard & (505) 665-4493 & remason@1anl.gov & LANL \\
\hline Massey, Ramoncita & (505) 845-4675 & rmassey@doeal.gov & DOE-AL \\
\hline McBride, Kathy & (208) 526-7557 & kxm@inel.gov & INEEL \\
\hline Mishra, George & (803) 725-7239 & George.mishra@ssrs.gov & DOE-SR \\
\hline Molecke, Martin & (505) 8443487 & mamolec@sandia.gov & SNL \\
\hline
\end{tabular}




\begin{tabular}{|c|c|c|c|}
\hline NAME & PHONE & E-MAIL & SITE \\
\hline Murray, Alice & (803) 725-0440 & Alice.murray@srs.gov & WSRC \\
\hline Oakley, Donald & (202) 586-6382 & Donald.Oakley@verizon.net & FSU \\
\hline Osborne, Kenny & (208) 526-0805 & osbornkk@doe.id.gov & DOE-ID \\
\hline Parks, Dave & (208) 526-0486 & dcp@inel.gov & INEEL \\
\hline Patteson, Ray & (505) 844-1904 & rpattes@sandia.gov & SNL \\
\hline Polansky, Gary & (505) 845-5805 & gfpolan@sandia.gov & SNL \\
\hline Pressentin, Roger & (509) 376-1291 & roger.a.pressentin@rl.gov & DOE-RL (EUSC) \\
\hline Ramsey, Kevin & (505) 665-0024 & kbramsey@lanl.gov & LANL \\
\hline Reichman, Al & (803) 725-1116 & Alan.reichman@srs.gov & WSRC \\
\hline Rigot, William & (803) 952-4981 & William.rigot@srs.gov & WSRC \\
\hline Roberson, Gary (G.D.) & $(505) 845-5805$ & groberson@doeal.gov & DOE-AL \\
\hline Robertson, David & (509) 375-3793 & De_Robertson@pnl.gov & PNNL \\
\hline Sala, David & (505) 453-6794 & sala@sprintmail.com & Sala \& Assoc. \\
\hline Schulz, Wallace & (505) 856-7928 & not available & (TAG) \\
\hline \multicolumn{4}{|l|}{ Scott, Paul } \\
\hline Smith, J.D. & (505) 844-0531 & jdsmitih@sandia.gov & SNL \\
\hline Sokol, John & (740) $897-4426$ & Ko8@bechteljacobs.org & ORNL \\
\hline Taylor, Victor & (513) 648-3121 & vic.taylor@,fernald.gov & DOE-Fernald (EUSC) \\
\hline Thiel, Liz & (208) 526-3684 & ethiel@inel.gov & INEEL \\
\hline Thompson, Gary & (303) 966-6419 & Gary.Thompson@,rfets.gov & (TAG) \\
\hline Thompson, Major & (803) 725-2507 & Major.Thompson@ssrs.gov & SRS \\
\hline Tseng, John & (301) 903-4482 & John.tseng@em.doe.gov & DOE-HQ \\
\hline Vieth, Don & (513) 583-0805 & DLVieth@email.msn.com & (TAG) \\
\hline Walton, Terry & (509) 372-4548 & Terry.Walton@pnl.gov & PNNL \\
\hline Wheatley, Philip & (208) 526-9348 & pdw@inel.gov & INEEL \\
\hline Wolf, Stanley & (301) 903-7962 & Stanley.wolf@em.doe.gov & DOE-HQ \\
\hline
\end{tabular}

